\title{
Institutional support for a program of activities within the pilot health project in the West Bank and Gaza
}

Health, Development, Information and Policy Institute

Follow this and additional works at: https://knowledgecommons.popcouncil.org/departments_sbsr-rh

Part of the Demography, Population, and Ecology Commons, International Public Health Commons, Maternal and Child Health Commons, and the Women's Health Commons How does access to this work benefit you? Let us know!

\section{Recommended Citation}

Health, Development, Information and Policy Institute. 2002. "Institutional support for a program of activities within the pilot health project in the West Bank and Gaza," FRONTIERS Final Report. Washington, DC: Population Council. 


\section{Institutional Support for a Program of Activities within the Pilot Health Project in the West Bank and Gaza}

December 2002

\section{Health, Development, Information and Policy Institute (HDIP)}

This study was funded by the U.S. AGENCY FOR INTNATIONAL DEVELOPMENT (USAID) under the terms of Cooperative Agreement Number HRN-A-00-98-00012-00 and the Population Council Subagreement number AI00.16A. The opinions expressed herein are those of the authors and do not necessarily reflect the views of USAID. 


\section{Background}

The United States Agency for International Development (USAID), in collaboration with the Population Council, the Palestinian Ministry of Health and seven non-governmental organizations (NGOs), designed and implemented a twenty-eight month long pilot project that was to have a significant impact on the health status of Palestinian women and their children in the West Bank and Gaza. The goal of this Pilot Health Project (PHP) was to upgrade antenatal and postpartum services in 27 primary health care clinics in three areas of the West Bank and Gaza. In addition, it was to collect data on the population and special topics, which would assist in developing better health strategies and improve the evaluation of the PHP.

This document contains the reports of three of these activities, and is organized into three separate but related sections. Specifically, it includes results from an award to the Health, Development, Information and Policy Institute (HDIP) on the following activities:

- Survey of clients and providers in the primary health care areas to measure key indicators for planning and evaluating the Pilot Health Project, "Pilot Health Project Baseline Survey Report, January 2001”.

- A study entitled, "Involving Men in their Wives' Postpartum Care in Palestine, December 2002."

- A study entitled, "Outreach Linkages with Public Hospitals to Promote Postpartum Care, October 2002."

Each section fully describes the role of the activity in the Pilot Health Project and the results obtained. As the HDIP was the responsible organization for each of these activities and all contributed to the planning process for the Pilot Health Project, they are combined in this report. Overall, there were seven intervention, technical assistance and evaluation projects in the West Bank and Gaza supported by the Frontiers in Reproductive Health Program from 2000 through 2002. These reports are available through the following website, www.usaid.gov/policy/cdie or through the Population Council's website, www.popcouncil.org. The attractive format of each section of this report was the responsibility of the HDIP and the Council's Regional Office in Cairo, Egypt. 

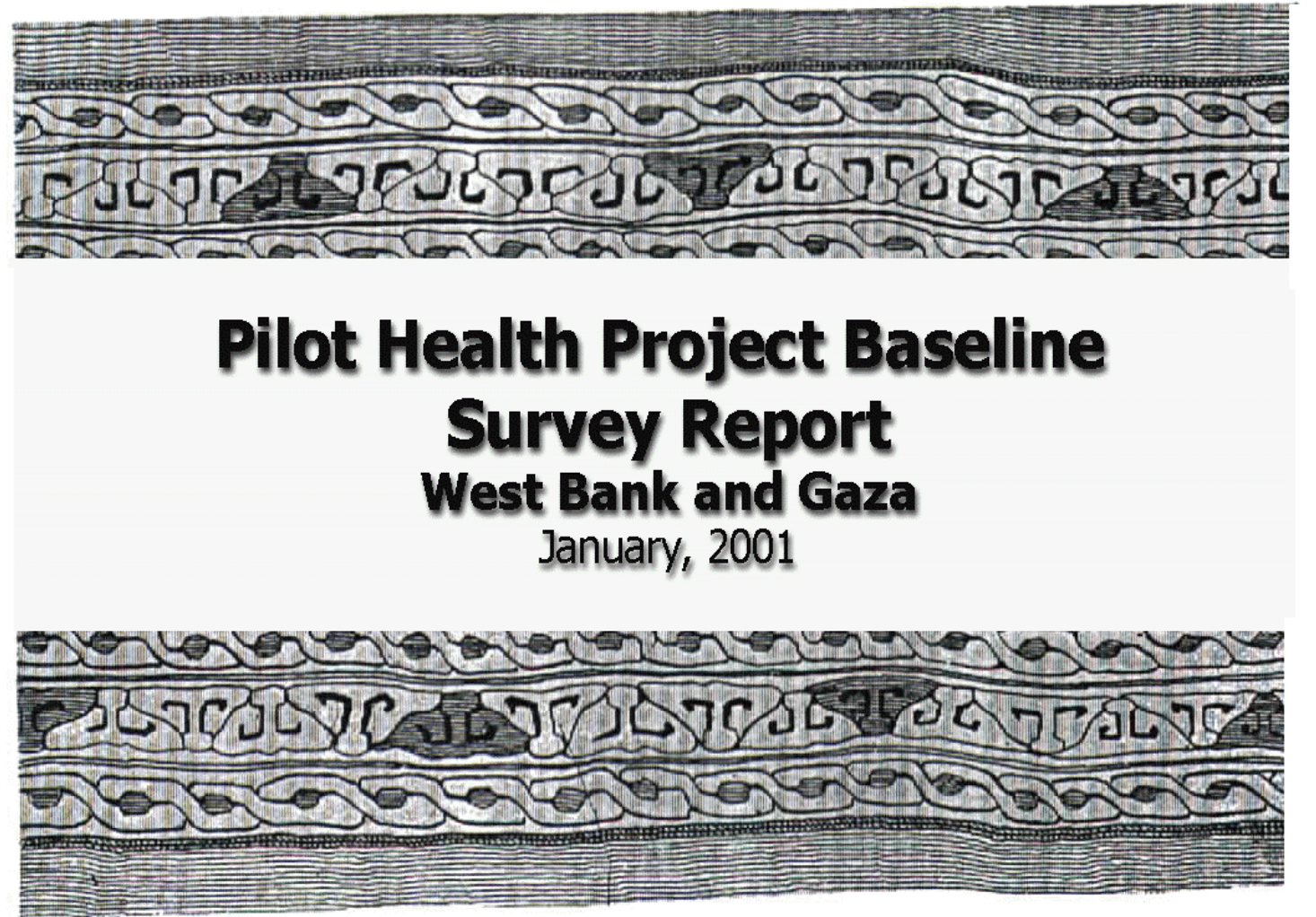

This study was funded by the U.S. AGENCY FOR INTERNATIONAL DEVELOPMENT (USAID) under the terms of Cooperative Agreement number HRN-A-00-98-00012-00 and Project number AI0016A. The opinions expressed herein are those of the author(s) and do not necessarily reflect the views of USAID. 


\section{ACKNOWLEDGMENTS}

Health, Development, Information And Policy Institute (HDIP) would like to thank the Population Council for their invaluable advice and technical support throughout the conduct of this study. Our gratitude and thanks is also extended to the management and staff of the Union of Palestinian Medical Relief Committees, Patient Friends Society, and the Union of Health Workers Committees and Birzeit University's Institute of Community and Public Health for their cooperation and assistance during the preparation and fieldwork phases of the study.

We would also like to acknowledge and thank the research team, including the field supervisors, data collectors and data entry clerks for their hard work for the successful completion of this study. Special thanks go to all the clients for their cooperation and participation in the study.

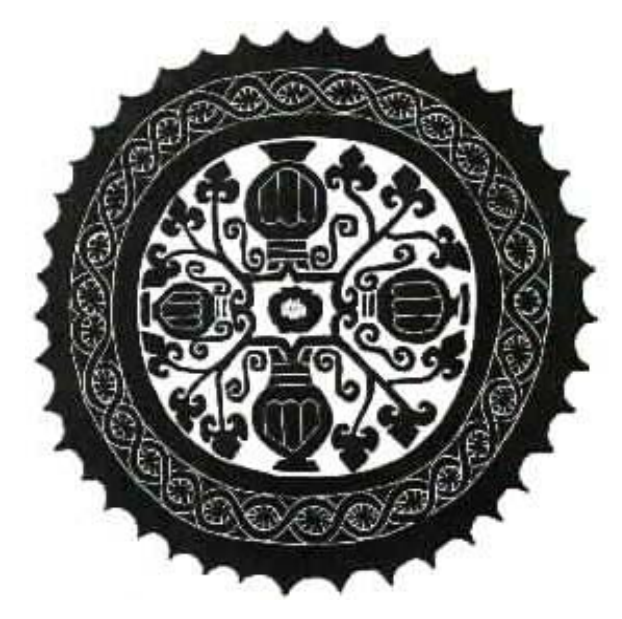




\section{CONTENTS}

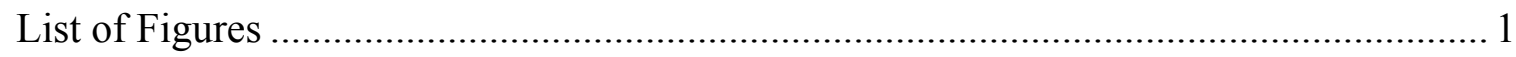

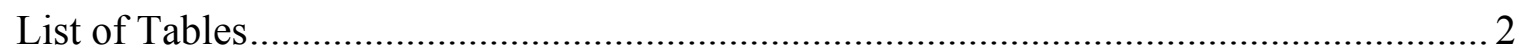

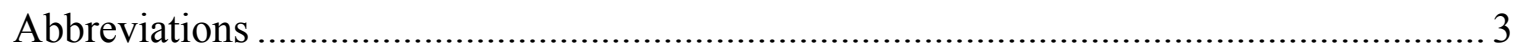

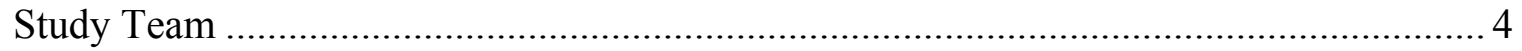

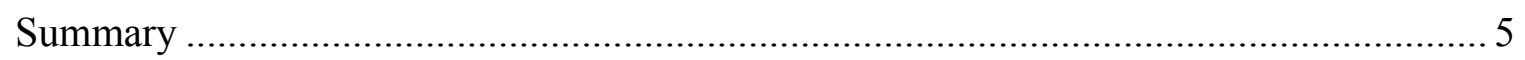

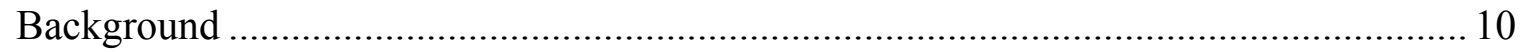

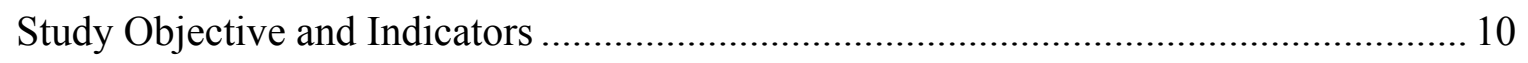

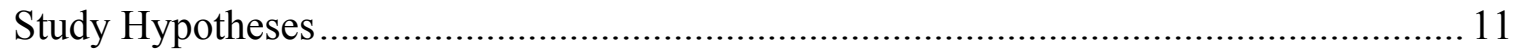

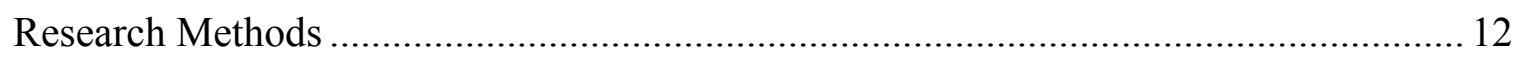

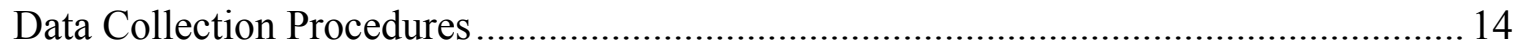

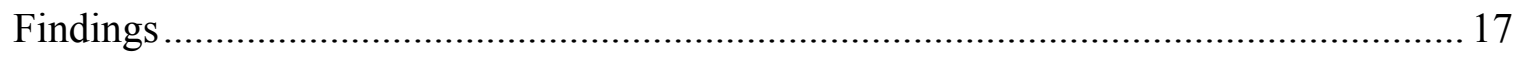

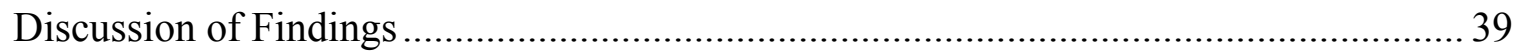

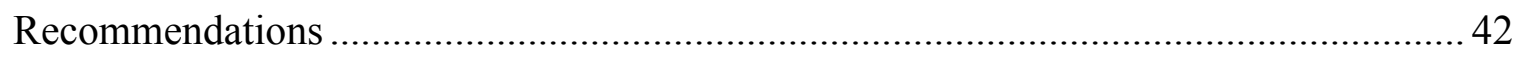

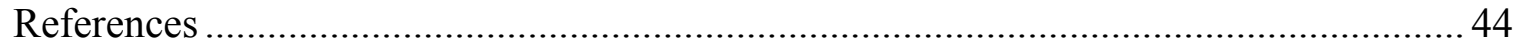




\section{LIST OF FIGURES}

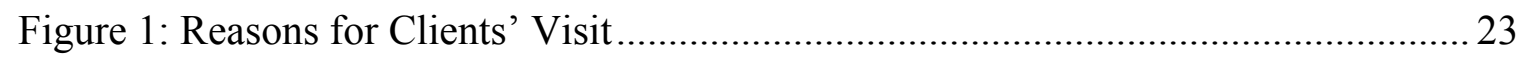

Figure 2: Antenatal Care Experience of Women Receiving Postpartum Care ................. 24

Figure 3: Postpartum Clients Checked at the Visited Clinic............................................ 25

Figure 4: Reasons of Visits of Postpartum Clients to PHP Clinics ................................ 27

Figure 5: Knowledge of Family Planning Methods ...................................................... 28

Figure 6: When Did You First Begin Using a Family Planning Method ......................... 29

Figure 7: Percent Distribution of Current Users of Contraceptives by Number of Living

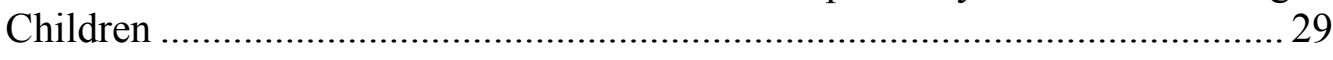

Figure 8: Knowledge and Practice of Breast self Examination among Antenatal Care and

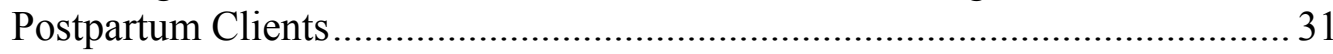

Figure 9: Pap smear Test for Antenatal and Postpartum Clients .................................... 31

Figure 10: Elements of Health Education Discussed during postpartum Home Visits .... 33

Figure 11: CHW/Nurse Advice about Postpartum Medical Check-up ............................. 33

Figure 12: Coverage of Information/ Counseling Received by Clients during ANC \& PP

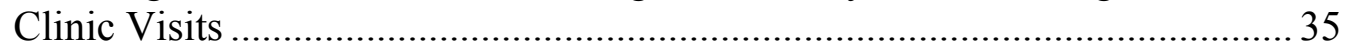

Figure 13: Follow-up Information Given to Antenatal Care Clients ............................... 35

Figure 14: Have You Ever Received any Contraceptives from this Clinic?..................... 36

Figure 15: Selected Indicators of Quality of Care.......................................................... 37

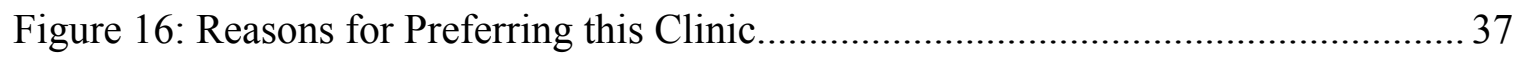




\section{LIST OF TABLES}

Table 1: Location, Affiliation and Staffing of the Pilot Health Project Clinics................ 13

Table 2: Sampling Results of Eligible MCH Clients by Clinic and Reason for Visit ...... 15

Table 3: Socioeconomic and Demographic Characteristics of Women and Husbands ... 17

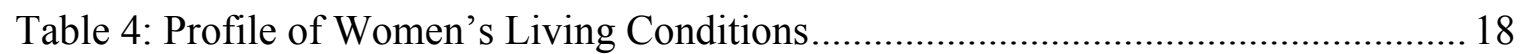

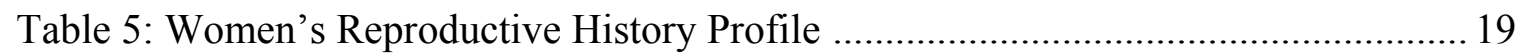

Table 6: Desire for Additional Children by Number of Living Children and Sons.......... 19

Table 7: Sex Preference for Next Child among Women and Husbands Who Want More

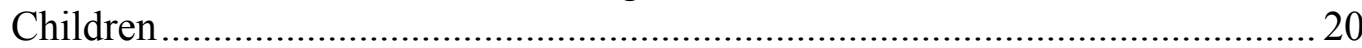

Table 8: Background Characteristics of Nurses and Community Health Workers........... 20

Table 9: Background Characteristics for Physicians ...................................................... 21

Table 10: Caseload by Reason for Visit during the 6 Months Preceding the Survey ...... 22

Table 11: Obstetrical Service Utilization of Postpartum Clients ....................................26

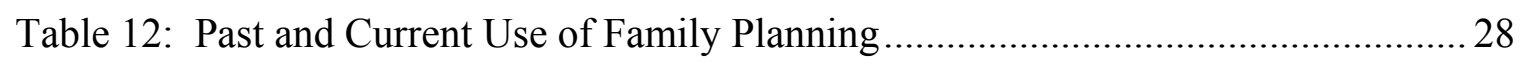

Table 13: Knowledge of ANC, Postpartum and Infant Health Warning Signs ............... 30

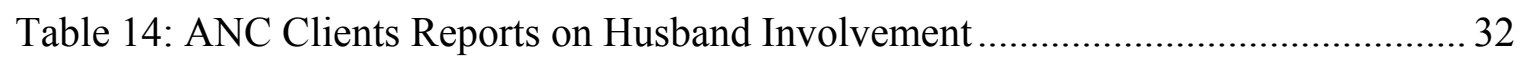

Table 15: Physician Technical Knowledge on ANC and Postpartum Care ....................... 34

Table 16: Selected Aspects of Accessibility to PHP Clinics ............................................ 38 

ABBREVIATIONS
ANC
Antenatal Care
$\mathrm{BCC}$
Behavior Change Communication
CARE
CARE International
CDPHC Center for Development in Primary Health Care
HDIP Health, Development, Information and Policy Institute
IEC Information, Education and Communication
IUD Intrauterine Device
LAM Lactation Amenorrhea Method
PCBS Palestinian Central Bureau of Statistics
PFS Patients Friends Society
PHP Pilot Health Project
PP Postpartum
PRC Planning and Research Center
$\mathrm{MCH} \quad$ Maternal and Child Health
MCH/FP Maternal and Child Health / Family Planning
MIS Management Information System
$\mathrm{MOH} \quad$ Ministry of Health
NGO Non-governmental organizations
SES Socio-economic status
UHWC Union of Health Work Committees
UNFPA United Nations Population Fund
UNRWA United Nations Relief Work Agency
UPMRC Union of Palestinian Medical Relief Committees
USAID United States Agency for International Development
WHO World Health Organization 


\section{STUDY TEAM}

Health, Development, Informational and Policy Institute (HDIP)

Team Leader/Study Coordinator

Field/Study Manager

Data Analyst

Field Supervisors

Data Collectors

Data processing

Consultant

Trainers

Translator

\section{Population Council's FRONTIERS Team}

Laila Nawar

Nancy Ali

Dale Huntington

Sahar Hegazi

Mahmoud Shaheen
Tamara Tamimi

Atef Shubaita

Dr. Lama Jamjoum

Samar al Khalili

Diana Abu Jebarra

Dr. Imad Gabreel

Abeer Daraghmeh

Kowthar Shehadeh Abu Hjair

Itimad Mohammad alQadi

Vivian Askandar

Lubna Diab Khalil Arrar

Nadia Ahmad

Jinan Barghouthi

Kowthar Abu Khalil

Nibal Awad

Dr. Khadija Jarrar

Hanan Halabi

Dr. Khadija Jarrar

Dr. Malek Quttaineh

WANA, Regional Advisor

Program Associate

Regional Director, ANE

Regional Communication Officer

PHP National Manager 


\section{SUMMARY}

The lack of care provided to women and newborns during the postpartum

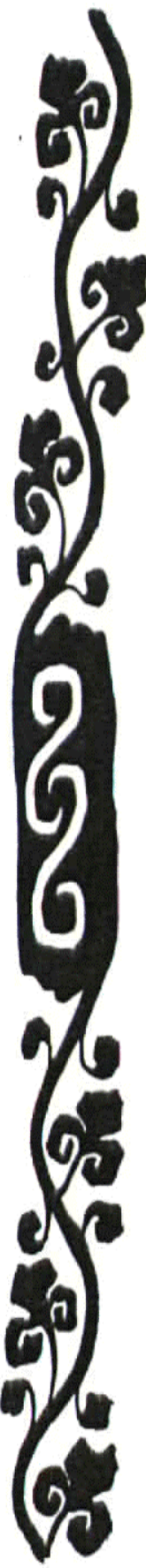
period is a serious gap in the primary health care system of the West Bank and Gaza. While a large percentage of women receive some prenatal care, very few return to health facilities for postpartum follow-up visits. To improve the health status of Palestinian women and their children in the West Bank and Gaza, the United States Agency for International Development (USAID), in collaboration with the Palestinian $\mathrm{MOH}$ and seven partners, ${ }^{1}$ designed and funded a twentyeight month long pilot activity that is expected to have significant impact on the health of women and children. The goal of this Pilot Health Project (PHP) is to upgrade antenatal and postpartum services in 27 primary health care clinics in three areas of the West Bank and Gaza. The project interventions include establishing a basic package of quality antenatal and postpartum care services aimed at improving the health-giving practices of providers and health-seeking behavior of families. The project will also provide accurate and reliable data on reproductive health, including maternal, child health and family planning at the primary health care level.

To determine the baseline measures of the Pilot Health Project's key outcome indicators among health care providers and clients, a single crosssectional survey (i.e., baseline survey) was undertaken. This report presents the results of this survey and a comprehensive assessment of the antenatal and postpartum care services, including family planning, that are currently provided at the project clinics. A post-intervention survey collecting similar data on key outcomes was conducted after the Pilot Health Project's interventions were established.

The study used multiple methods of data collection to obtain baseline quantitative estimates of key indicators. The following three research methods were employed: abstract of routinely collected service statistics; standardized interviews with health care providers; and standardized exit interviews with antenatal, postpartum and family planning clients.

\footnotetext{
${ }^{1}$ Partners include CARE International, the Population Council, the Patients Friends Society (PFS), the Union of Palestinian Medical Relief Committees (UPMRC), the Union of Health Work Committees (UHWC), the Health Development, Information and Policy Institute (HDIP) and the Center for Development in Primary Health Care (CDPHC).
} 
The study's sampling frame consists of 27 clinics that participate in the Pilot Health Project and are located in villages surrounding the Jenin area, Hebron and Gaza, and are managed by the three partner NGOs (UPMRC, PFS and UHWC). For the study, 9 physicians, 3 nurses and 42 community health workers who worked in the 27 Pilot Health Project clinics were interviewed. All antenatal, postpartum and family planning clients who visited the clinics during the data collection period were eligible for exit interviews. The study's total sample size was 792 respondents. Interviews with female clients (with their informed consent) were conducted in a private setting as they exited the clinic. Service statistics on caseloads by reason of visit were prepared for the months of November 1999 through May 2000 by the survey data collection teams using forms designed for this purpose. Data was collected at the Pilot Health Project clinic sites during the period May 30 to August 15, 2000.

Findings showed that almost half of the women who visited the clinics were 20 to 29 years old and the majority (96 percent) were housewives. More than one-third had completed at least nine years of schooling. Half of the women were married to men related to them. Husbands were on average older than their wives and had higher levels of education. Yet, more than one-third were unskilled laborers.

In general, Palestinian women have a relatively high fertility level. For all the women attending the Project's clinics the mean number of children born was 3.0, women closer to the end of the childbearing period (40 years or more) had on average more than seven children ever born to them. Wives reported that their husbands had higher fertility preferences than themselves. Only one half of women reported wanting more children as compared to about three-fourths of their husbands (as reported by women). Women also reported that their husbands indicated a higher preference for males compared to them.

The majority of women receive some antenatal care, yet only a few return to clinics for postpartum care and follow-up. On average women made about five antenatal visits to the clinics during their pregnancies and many of these women sought antenatal care as early as the first month of pregnancy. However, only 3.3 percent of women interviewed reported returning to the clinic for postpartum care. It is worth noting that the majority of postpartum women ( 85 percent of the 3.3 percent of women who returned for postpartum care) delivered their index babies at the hospital.

Most of the women who returned for postpartum visits made the index visit before day 40 after delivery ( $84 \%$ of the $3.3 \%$ of women who returned for postpartum care). However, when asked about the number of postpartum visits made to the clinic after index delivery, 
more than 70 percent of the 3.3 percent of women who returned for postpartum care reported visiting the clinic only once after the delivery.

Very few women reported receiving a home visit after the index delivery. Only onethird of the 3.3 percent of women who returned to the clinic for postpartum care reported receiving a home visit by a health provider after their delivery. Most of them received the home visit three to seven days after delivery. Community health workers conducted most of these home visits.

A good number of postpartum women accepted a family planning method during their clinic visit (about $41 \%$ of the 3.3 percent of women who returned for postpartum care). Most women went to clinics to receive a family planning method after four weeks of index delivery. However, some (18\% of the $3.3 \%$ of women who returned for postpartum care) went to clinics to receive a method early after the index delivery (before 30 days of index delivery).

Despite almost universal knowledge about family planning (99\%), only 58 percent of women who were interviewed had ever used a family planning method, and 14 percent are currently using a family planning method. On average, women began using family planning methods when they had about three living children, and not a single woman reported use of a contraceptive method to delay the first birth. The IUD is the most commonly used method by both ever and current users. It is also interesting to note that 14 percent of ever users depend on withdrawal.

Information/ counseling received by women regarding antenatal and postpartum care, including family planning was partial or weak. Approximately two-thirds of the antenatal care (ANC) (67.3 percent) and postpartum (69.2 percent) clients knew at least one or two warning signs, and all of the postpartum clients knew at least one or two infant health warning signs. Between one-half and two-thirds of the ANC clients reported receiving follow-up information about three to five items of ANC. However, about one-third reported receiving follow-up information on about one to two items and one-fifth reported receiving no information at all. Postpartum clients were more likely to have received follow-up information. At least twothirds had received postpartum consultation on three or more topics.

Although breast and cervical cancer screening services are not part of the routine services offered at the Pilot Health Project clinics, less than one-half of the physicians $(n=9)$ reported that they routinely counseled their clients on how to conduct self-breast examinations. Slightly more than one-third of pregnant and postpartum women interviewed reported receiving instructions or counseling on how to conduct a self-breast examination. 
Similarly, only about half of the physicians interviewed reported providing services for obtaining Pap smear tests at the Pilot Health Project clinics. When probed, only one-fifth of the physicians in the study reported obtaining Pap smear samples as part of their routine procedures. Very few women reported ever receiving a Pap smear test at the clinics they attended.

Women reported that husbands in general do play a role in antenatal and postpartum care, including family planning. Nearly all women reported that their husbands encouraged them to seek antenatal care services at Pilot Health Project's clinics. However, when asked, women reported that only about one-fourth of their husbands accompanied them to the clinics. The exit interviews also revealed that most women reported discussing family planning use with their husbands. Almost all women indicated that they communicated and agreed with their husbands about whether or not to use a family planning method.

The study results suggest that all categories of providers had inadequate technical knowledge and skills. Although close to three-fifths of community health workers $(n=42)$ reported having diplomas or receiving training, the overall level of education and training of all categories of staff were not consistent or standard. In fact, most physicians reported the need to receive more training in the area of woman's health. Reasons for preferring the clinics visited were also assessed. The most commonly cited reason (68 percent) was that the clinic was close to their homes. Many of the other reasons given by women for visiting the specific clinics reflect their satisfaction with the quality of care provided at those particular clinics.

Finally, the study findings reflect high levels of accessibility to PHP clinics. More than one-half of women reported that they only need up to ten minutes to get to the clinics. About three-fourths said that they just walk to clinics, and no transport is needed.

The following steps are recommended at both the policy and program levels to institutionalize quality antenatal and postpartum services:

- The adoption of recently developed national standard protocols and guidelines for antenatal and postpartum care, including family planning and breast and cervical cancer screening, for primary health care facilities/clinics is needed.

- Additional training for all categories of service providers on antenatal, postpartum and family planning services should be emphasized. Monitoring and supervision systems to ensure the sustainability of training activities should be an integral part of all training programs. 
- Referral mechanisms should be established between hospitals and primary health care facilities / clinics to ensure that women receive essential postpartum care.

- Medical schools and training programs need to increase the number of training hours on women's health.

- The public needs to learn more about the importance of antenatal and postpartum care, including family planning and breast and cervical cancer screening.

- Better outreach services are needed to track and reach women who have either stopped going for antenatal visits or do not intend to seek postpartum care.

- Quality assurance and good management need to be incorporated into the overall services provided at primary health care clinics.

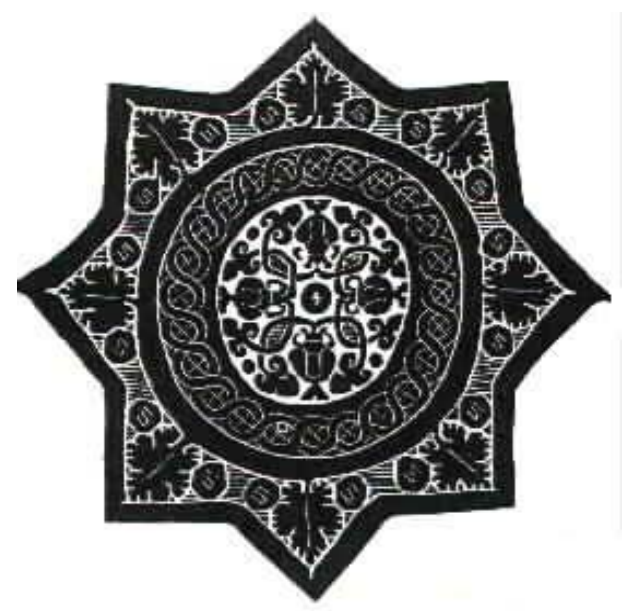




\section{BACKGROUND}

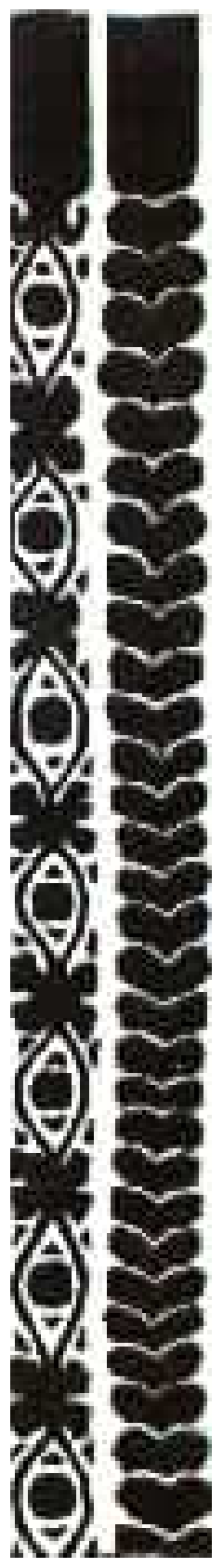

The lack of care provided to mothers and newborns during the prenatal period is an important health care problem in the West Bank and Gaza. Although a large proportion of mothers receive some prenatal care, only about 17 percent return for postpartum check-ups and few adopt family planning for spacing births during the postpartum period (Ismail and Shahin 1996). Fertility rates in the West Bank and Gaza are higher in comparison to other countries in the region of similar development status. Married women of reproductive age in Gaza have an average of 6.8 children, while those in the West Bank have 5.5 (PCBS, 2000). Cultural norms favor early marriage and a preference for sons, in addition to large family size. Since almost one half (47\%) of the West Bank and Gaza population is less than 15 years old, there will be substantial population momentum even if birth rates fall during the coming years ((PMOH, 1997, PCBS, 2000).

Although current levels of modern contraceptive use (estimated at 38.8\% in West Bank and 32.7\% in Gaza) are moderate, they tend to mask wide variations of use. For example, rates range from over $50 \%$ in parts of East Jerusalem to near zero in isolated areas of the West Bank. More importantly, they mask the fact that contraceptive use is very low among younger, low-parity women and that family planning is generally only acceptable after parity 4 for most families (PCBS, 2000).

The 28-month Pilot Health Project has been designed to improve the health status of Palestinian women and their children by upgrading antenatal and postpartum services in three areas of the West Bank and Gaza. The project interventions include a basic package of antenatal and postpartum care services aimed at improving the health-giving practices of providers and health-seeking behavior of families.

\section{STUDY OBJECTIVE AND INDICATORS}

The principal objective of this study is to determine baseline measures for the Pilot Health Project's key outcome indicators among health care providers and clients. These indicators are listed below:

1. Percentage of mothers and babies who make return visits to the clinics to receive postpartum care out of those who received antenatal care (according to "mothers only," "mothers and babies together," and "babies only"). 
2. Percentage of mothers who accept a family planning method out of those who made return visits to the clinic.

3. Percentage of low-parity women (1-2 living children) accepting a family planning method.

4. Increase in mothers' knowledge of antenatal and postpartum danger warning signs for themselves and their babies.

5. Increase in percentage of women seeking treatment in case of recognizing dangerwarning signs for themselves and their babies.

6. Increase in women's knowledge and practice of self-breast examinations and Pap smear tests.

7. Increased percentage of husbands and other males who are aware of the importance of at least a 36-month birth interval, prenatal and postpartum care, and family planning use.

8. Increased knowledge and skills of all categories of health care providers.

9. Improved follow-up information given to antenatal and postpartum women on antenatal and postpartum care, including nutrition, hygiene, breastfeeding and the need to use a family planning method.

A post-intervention survey collecting similar data on key outcomes will be conducted after the Pilot Health Project's interventions have been established. The impact of the project will be assessed by comparing changes between the two surveys on the key outcome indicators.

\section{STUDY HYPOTHESES}

Although this report is limited to a single cross-sectional survey (i.e., baseline survey), a repeat survey at the end of the Pilot Health Project will assess the impact of the Pilot Health Project on selected indicators. Therefore, the following hypotheses are relevant to the overall pre- and post-test study design.

1. Providing the basic model of services at the Pilot Health Project sites will increase the clinic caseload for antenatal and postpartum care, including family planning.

2. Health providers who receive training and offer services will demonstrate improved clinic practices and skills in antenatal and postpartum care, including family planning, and will have positive attitudes towards integrating and offering these services. 
3. Clients and their families will have greater knowledge, acceptance and improved practices related to antenatal and postpartum care, including optimal birth spacing and use of family planning methods.

\section{RESEARCH METHODS}

\section{Study Design}

The study used multiple methods of data collection to obtain baseline quantitative estimates of key indicators. The following three research methods were employed:

1. Abstract of routinely collected service statistics

2. Standardized interviews with health care providers

3. Standardized exit interviews with antenatal, postpartum and family planning clients

\section{Sampling Methods}

The study was conducted in each of the 27 clinics that participate in the Pilot Health Project (Table 1). These clinics are located in villages surrounding the Jenin area, Hebron and Gaza, and are managed by the three service delivery NGOs that form the partnership of the project along with CARE, HDIP, CDPHC, USAID and the MOH. Maternal and Child Health (MCH) services are provided at clinics only when physicians are available. At the PFS sites physicians are available only on a rotating basis, with some of the clinics being visited only once every two weeks. The staffing pattern and schedule of physician visits to these smaller and more isolated clinics is somewhat irregular, which caused complications in the sampling of cases (described below).

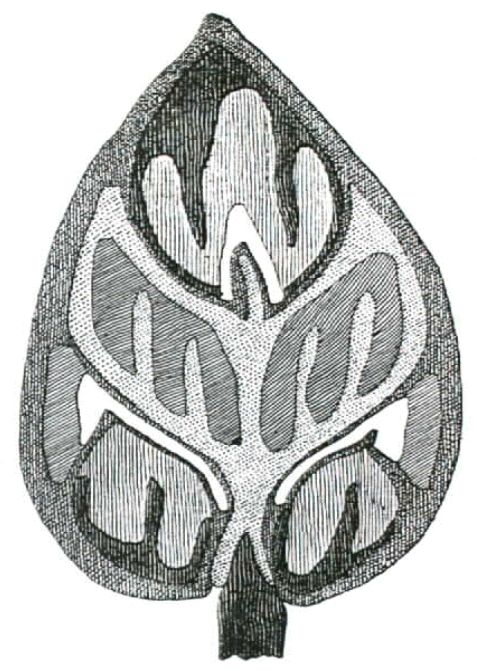


Table 1: Location, Affiliation and Staffing of the Pilot Health Project Clinics

\begin{tabular}{|l|l|l|l|l|}
\hline \multicolumn{1}{|c|}{ Village and Clinics } & \multicolumn{1}{|c|}{ District } & NGO & \multicolumn{1}{c|}{$\begin{array}{c}\text { Physicians* and } \\
\text { Community Health } \\
\text { Workers }\end{array}$} \\
\hline Qabatia & Jenin & PFS & & 1 \\
\hline Dier Abu -D'ief & Jenin & PFS & & 1 \\
\hline Rumaneh & Jenin & PFS & & 1 \\
\hline Kufdan & Jenin & PFS & & 1 \\
\hline Al- Almanieh & Jenin & PFS & & 1 \\
\hline Misielieh & Jenin & PFS & & 1 \\
\hline Araneh & Jenin & PFS & 1 & \\
\hline Zabdeh & Jenin & PFS & & \\
\hline Nazlet Al-Shiekh Hussain & Jenin & PFS & & 1 \\
\hline Al-Tarem & Jenin & PFS & & \\
\hline Al-Funfoukomieh & Jenin & PFS & 1 & 2 \\
\hline Mashro' Beit -Qad & Jenin & PFS & & 1 \\
\hline Ta'anak & Jenin & PFS & & 2 \\
\hline Sier & Jenin & PFS & & \\
\hline Al-Shuhada & Jenin & PFS & & 1 \\
\hline Sielet Alharthieh & Jenin & UPMRC & & 2 \\
\hline Miethaloon & Jenin & UPMRC & 1 & 3 \\
\hline Al-Zababdeh & Jenin & UPMRC & 1 & 1 \\
\hline Toubas & Jenin & UPMRC & & 2 \\
\hline Al-Nassarieh & Jenin & UPMRC & & 2 \\
\hline Ithna & Hebron & UPMRC & & 5 \\
\hline Ras El Joura & Hebron & UPMRC & 1 & 2 \\
\hline Biet- Hanoun/Alquds Clinic & Gaza & UHWC & 1 & 6 \\
\hline Jabalia Camp/Al-Assrieh Clinic & Gaza & UHWC & 2 & 5 \\
\hline $\begin{array}{l}\text { Al-Nusseirat Camp/ Alkhirieh } \\
\text { Clinic }\end{array}$ & Gaza & UHWC & & \\
\hline Rafah/Rafah Medical Center & Gaza & UHWC & 1 & 4 \\
\hline Al-Awda Hospital & Gaza & UHWC & & $\mathbf{4 5}$ \\
\hline Total & & & $\mathbf{9}$ & \\
\hline & & & \\
\hline
\end{tabular}

* The table provides information about the location where the interview was conducted. Physicians and nurses/health workers might rotate in more than one clinic.

\section{Sample Size}

The 9 physicians who worked in the 27 Pilot Health Project clinics were requested to consent to an interview. An additional 3 nurses and 42 community health workers were also interviewed. All antenatal, postpartum and family planning clients who visited the clinics during the data collection period were eligible cases for the baseline survey. Clients who were visiting the clinics for other reproductive or primary health care services were not included in the study. Originally, the study was designed to obtain a sample size of 43 exit interviews per clinic (total sample of 1000). However, several logistical impediments prevented this from being possible at all clinic sites. The two principal constraints are explained below. 
- Rotation of Physicians

Maternal and child health services are offered at the clinic sites only when physicians who are on rotating schedules are available at any given site. All three-service delivery NGOs have rotating schedules for their physicians. In some of the smaller PFS clinics physicians only visit once every two weeks. No MCH/FP services are provided if the physician is not present. Since interviews could only be conducted with women who had just completed either a physical exam or a counseling session with an $\mathrm{MCH}$ physician, data collection was limited to the days when a physician was attending each clinic.

\section{- Low Caseloads}

Even on days when a physician was on duty, certain clinics had extremely low caseloads (e.g., one or two eligible clients per MCH day). Given that data collectors were limited to interviewing only antenatal, postpartum or family planning clients, data collection at clinics with low caseloads and at clinics that opened once a week or once every two weeks severely limited the sample size obtained from those clinics and the overall study sample size.

As a result of the difficulties encountered with obtaining appropriate sample sizes from some clinics, the study over-sampled higher caseload clinics to obtain a sample of 792 (see Table 2). In addition, data collection procedures were extended for two weeks longer than originally planned.

\section{DATA COLLECTION PROCEDURES}

\section{Training}

Interviewers and field supervisors participated in an intensive training course held at HDIP from May 15 - 27, 2000. The training course began with a two-day review of concepts in reproductive health relevant to the Pilot Health Project. Training activities on day three included a general introduction to field surveys, the definition and characteristics of structured interviews, and a discussion of the steps that follow data collection (coding, data entry, cleaning). The client questionnaire developed for the study was also reviewed, as were issues of eligibility and informed consent procedures. Role-playing was a key component of the training. Participants spent three sessions with data collectors practicing interviewing and completing the questionnaire on hypothetical antenatal or postpartum cases. Pairs of field 
workers acted out an interview while the rest of the group responded with comments, questions and suggestions for improvement.

Table 2: Sampling Results of Eligible MCH Clients by Clinic and Reason of Visit to Clinic

\begin{tabular}{|c|c|c|c|c|c|}
\hline Study Site & Prenatal & Postpartum & $\begin{array}{c}\text { Family } \\
\text { Planning }\end{array}$ & $\begin{array}{c}\text { Postpartum } \\
\text { and Family } \\
\text { Planning }\end{array}$ & Total \\
\hline \multicolumn{6}{|l|}{ HEBRON } \\
\hline Ithna & 63 & & 2 & & 65 \\
\hline Hebron & 28 & 1 & 7 & & 36 \\
\hline \multicolumn{6}{|l|}{ GAZA } \\
\hline Bayt Hanoun-Alquds & 70 & 2 & 7 & & 79 \\
\hline Jabaliyya R.C (Al-'asrriyya) & 34 & 1 & 8 & & 43 \\
\hline $\begin{array}{l}\text { A-nussirat R.C (Al- } \\
\text { Khaiyriyya) }\end{array}$ & & & 2 & & 2 \\
\hline Rafah & 1 & 1 & 1 & & 3 \\
\hline Al-"Awwda Hospital & 43 & 2 & 4 & & 49 \\
\hline \multicolumn{6}{|l|}{ JENIN } \\
\hline Al-Nazleh & 6 & & & & 6 \\
\hline Beit Qada & 6 & & & & 6 \\
\hline Zabda & 9 & & & & 9 \\
\hline Al-Almaniyya & 11 & & 1 & & 12 \\
\hline Atirm & 2 & & 1 & & 3 \\
\hline Mislieh & 14 & 1 & 3 & & 18 \\
\hline Sier & 1 & & & & 1 \\
\hline Al-Fandqumiyya & 34 & 1 & 7 & 1 & 43 \\
\hline Kufr Dan & 34 & 1 & 8 & 3 & 46 \\
\hline Ta'nik & 7 & 1 & 1 & & 9 \\
\hline Al-Shuhda & 6 & & 1 & & 7 \\
\hline Arraneh & 9 & & 3 & & 12 \\
\hline Dayr Abu Da'if & 30 & & 5 & & 35 \\
\hline Rumaneh & 28 & & 5 & & 33 \\
\hline Qabatiya & 27 & 1 & 6 & 1 & 35 \\
\hline Maythalun & 65 & 2 & 11 & 2 & 80 \\
\hline Silat Al-Harthiyya & 49 & 1 & 2 & 1 & 53 \\
\hline Toubas & 30 & 1 & 14 & 1 & 46 \\
\hline Al-Azbabdeh & 34 & & 3 & 1 & 38 \\
\hline Anassariyya & 15 & 1 & 7 & & 23 \\
\hline Total & 656 & 17 & 109 & 10 & 792 \\
\hline
\end{tabular}

The sessions also included discussions on logistical issues and potential problems such as clinic caseloads, the ability to secure privacy for the interview, determining eligibility, obtaining informed consent and incomplete interviews. The last two sessions were dedicated to the special training of field supervisors. One day was spent reviewing the physician, nurse and community health worker questionnaires (one questionnaire for physicians and one for both nurses and community health workers) that were only to be administered by the supervisors. 


\section{Pilot Testing of the Study Instruments and Data Collection Procedures}

The client exit interview instrument was pre-tested in four different clinics that were not part of the Pilot Health Project (Biddo, Qalqilya, Tulkarem and Gaza). The objective of the pilot testing was to examine the results of the questionnaires (item wording, translation, and mechanics) and to give the field staff an opportunity to practice the data collection procedures in a

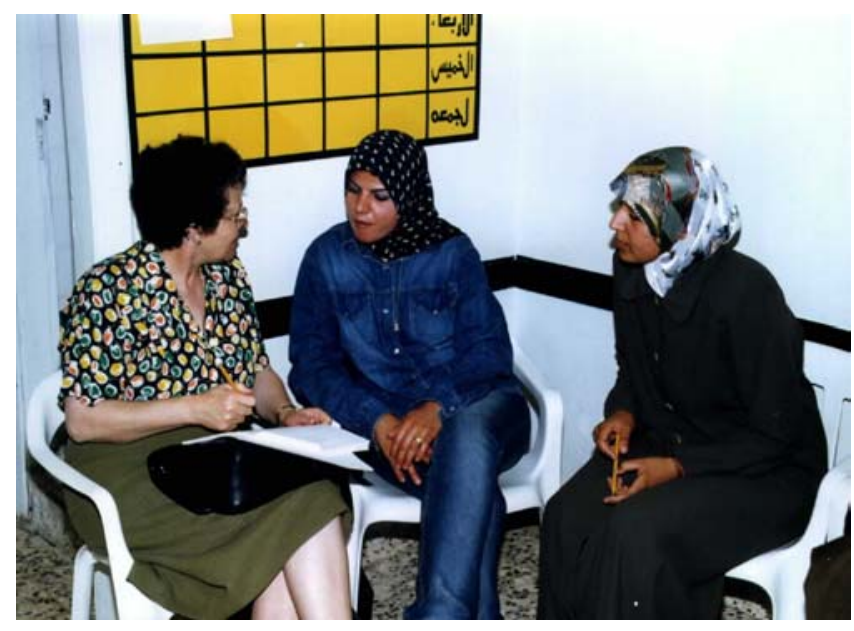
realistic setting.

\section{Field Work}

Data collection at the Pilot Health Project clinic sites was carried out during the period May 30 - August 15, 2000. Four teams each composed of two interviewers and one supervisor were sent to UPMRC, PFS and UHWC clinics whenever MCH doctors were available to provide antenatal, postpartum or family planning services. Exit interviews were conducted with all eligible and consenting clients who received those services at the 27 Pilot Health Project clinic sites. Interviews were conducted in a private setting with women as they were exiting from the clinic and after they had given their informed consent.

\section{Physician and Nurses/Community Health Workers Interviews}

Interviews using structured questionnaires were also conducted with $\mathrm{MCH}$ physicians, clinic nurses and community health workers who provide services at the Pilot Health Project clinics. Data collection supervisors, who all have extensive experience in the health field or in health research, conducted interviews with health care providers.

\section{Abstract of Clinic Caseload Information}

Service statistics on caseloads, by reason of visit, were summarized for the months of November 1999 through May 2000 by the survey data collection teams. It is important to note that routinely collected service statistics are not systematically recorded by the 27 clinics, and when statistical information was available, it was incomplete. The development of a comprehensive management information system by the Pilot Health Project will address this shortcoming, but not for the purposes of providing reliable and valid baseline statistics.

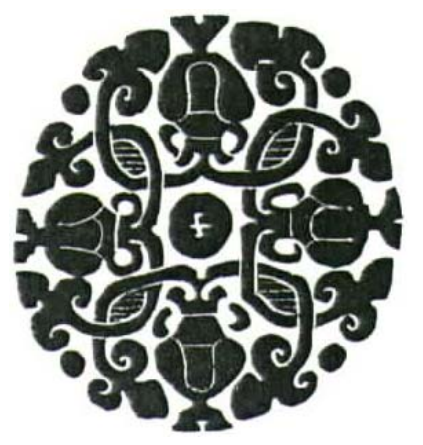




\section{FINDINGS}

\section{Selected Background}

\section{Characteristics of Clients}

Table 3 presents selected socio-economic and demographic characteristics of women and their husbands who participated in the study. The average age of women in the study sites is about 27 years and most are housewives (96 percent), with only about three percent working outside the home for payment. Husbands on average are older than their wives by five years (32 years old) and have relatively higher levels of education (11 versus 9.2 years of schooling). About two-fifths of husbands are unskilled laborers and most of the remaining (onefifth each) are either skilled laborers or hold white-collar jobs (employees).

As probable within the context of the Arab culture, marriage among relatives is common. Approximately one-half of the women (51 percent) are married to men related to them. Within this category, 53 percent are married to their first cousins (father's or mother's side), and 40
Table 3: Socio-economic and Demographic Characteristics of Women and Their Husbands

\begin{tabular}{|c|c|}
\hline Women Characteristics & Percent \\
\hline \multicolumn{2}{|l|}{ Age $(n=792)$} \\
\hline $15-19$ & 12.6 \\
\hline $20-24$ & 30.6 \\
\hline $25-29$ & 25.7 \\
\hline $30-34$ & 17.6 \\
\hline $35-39$ & 10.8 \\
\hline $40-44$ & 2.3 \\
\hline $45+$ & 0.3 \\
\hline Mean age & 26.5 \\
\hline \multicolumn{2}{|l|}{ Occupation $(n=791)$} \\
\hline Housewife & 96.0 \\
\hline Working & 3.3 \\
\hline Student & 0.6 \\
\hline \multicolumn{2}{|l|}{ Education $(n=791)$} \\
\hline None & 11.3 \\
\hline Primary (6 years) & 27 \\
\hline Preparatory ( 9 years $)$ & 35.5 \\
\hline Secondary (high school / 12 years) & 17.2 \\
\hline Technical $(<4$ years after high school $)$ & 6.9 \\
\hline University (4 years after high school) & 2.0 \\
\hline Post-graduate ( $>4$ years after high school) & 0.1 \\
\hline Mean years of schooling completed & 9.2 \\
\hline \multicolumn{2}{|l|}{ Husbands Characteristics } \\
\hline \multicolumn{2}{|l|}{ Age $(n=791)$} \\
\hline$<25$ & 13.8 \\
\hline $25-34$ & 55.7 \\
\hline $35+$ & 30.4 \\
\hline Mean Age & 31.7 \\
\hline \multicolumn{2}{|l|}{ Mean age difference between husband and wife / years } \\
\hline \multicolumn{2}{|l|}{ Occupation $(n=789)$} \\
\hline Unemployed & 2.5 \\
\hline Unskilled laborer & 38.8 \\
\hline Skilled laborer & 21.2 \\
\hline Agriculture & 4.4 \\
\hline Employee & 22.0 \\
\hline Business owner & 10.9 \\
\hline \multicolumn{2}{|l|}{ Education $(n=792)$} \\
\hline$<10$ years & 37.0 \\
\hline $10+$ & 63.0 \\
\hline Mean years of schooling & 11.0 \\
\hline \multicolumn{2}{|l|}{ Husbands' relationship } \\
\hline Husband related to wife $(n=792)$ & 50.8 \\
\hline Kind of relationship $(n=401)$ : & \\
\hline First cousin & 53.1 \\
\hline Second or higher order cousin & 39.4 \\
\hline From hamoula* & 6.2 \\
\hline Others & 1.2 \\
\hline Husband has other wives (\% yes) & 2.3 \\
\hline
\end{tabular}

Source: client exit interview

* It is a root by which families identify themselves. 
percent are married to a second or higher order cousin. Table 4 presents a profile of women's living conditions. On average, women in the study sample reported living in houses composed of about four rooms (other than the kitchen).

The average household size is 6.8 persons (including the woman herself). About two-thirds of women live in households with only their husbands and children, and the remaining one-third of women have, in most cases, in-laws living with them (usually their mother-in-law). The majority of women's families own a color TV and refrigerator (about 91 and 87 percent respectively), and to a lesser extent a manual washing machine (65 percent) and a telephone or cell phone (64 percent). About two-thirds (65 percent) of women's households are connected to piped water. A composite index for the socio-economic status of women's households was developed (see note at the bottom of Table 4). The average value for this indicator is 4.9 on a scale ranging from zero to eight, indicating a modestly strong possession of valuable assets in the women's households.

\section{A. Women's Reproductive Health Profile}

\section{Table 4: Profile of Women's Living} Conditions

\begin{tabular}{|l|l|}
\hline Characteristic (n=792) & Percent \\
\hline Average household size / persons & 6.8 \\
\hline Average number of rooms & 3.9 \\
\hline Crowdness (persons/room) & 2.0 \\
\hline People living in household & \\
\hline Husband and children only & 67.7 \\
Somebody else lives with family & \\
(n=256) & \\
Mother-in-law & 86.3 \\
Father-in-law & 58.6 \\
Husband's brothers or sisters & 70.0 \\
Wife's mother & 1.6 \\
\hline Household that own & \\
\hline Private car & 23.2 \\
Color TV & 90.9 \\
Refrigerator & 86.9 \\
Manual washing machine & 64.8 \\
Full automatic washing machine & 12.1 \\
Video & 15.3 \\
Satellite dish & 29.2 \\
Telephone or mobile phone & 64.0 \\
\hline Households connected to piped & \\
\hline water & 65.3 \\
\hline Socio-Economic Status (SES) & \\
\hline indicator* & 37.0 \\
Low (0-4) & 49.2 \\
Medium (5-6) & 13.8 \\
High (7-8) & 4.9 \\
Mean SES* & \\
\hline Source: client exit interview & \\
\hline
\end{tabular}

Source: client exit interview

*A composite indicator for socio-economic status of the household. It includes 8 variables with the value one for possession or zero for no possession: (1) private car, (2) color TV, (3) refrigerator, (4) manual washing machine, (5) satellite dish, (6) telephone or mobile phone, (7) whether or not the $\mathrm{HH}$ is connected to piped water (yes $=1 / \mathrm{no}=0$ ). The eighth variable is an indicator of crowdness (number of persons per room): if $\leq 2=1$ / if $>2=$ zero. The composite SES indicator has a value ranging between 0 and 8 .

The average age of marriage for women in this sample is approximately 19 years, with the first birth occurring within the first year of marriage (see Table 5). Women in the study have on average three children ever born to them. Women close to the end of childbearing period (40 years or more) report having an average of more than seven live births (7.2). For all women in the study the mean number of living children is 2.9. About one-third of women have one or two living children and about one-fourth have five living children or more. The incidences of stillbirths and/or miscarriages reported in this sample are very low. 


\section{B. Fertility Preference}

The study asked women about their and their husband's fertility preferences (see Table 6). Predictably, women state that their husbands have higher fertility preferences than they do. About three-fourths of the women report that their husbands want more children (74 percent) while only about one-half (53 percent) of the women want more children.

As expected, proportions of both women and their husbands who desire more children decrease with increasing numbers of living children and living sons, yet important differences in the fertility preferences of the couple remain in effect, even as family size grows.

In addition to the perceived higher preferences for more children among husbands compared to women, women also report that their husbands have a higher preference for sons (see Table 7).
Table 5: Women's Reproductive History Profile

\begin{tabular}{|c|c|}
\hline Characteristic & Percent \\
\hline $\begin{array}{l}\text { Mean age at first marriage (years) } \\
(\mathrm{n}=792)\end{array}$ & 18.5 \\
\hline $\begin{array}{l}\text { Mean age at first pregnancy (years) } \\
(\mathrm{n}=771)\end{array}$ & 19.3 \\
\hline $\begin{array}{l}\text { Mean number of children ever born } \\
\text { alive }(n=772)\end{array}$ & 3.0 \\
\hline $\begin{array}{l}\text { Mean number of children born alive } \\
\text { then died }(n=772)\end{array}$ & 0.1 \\
\hline $\begin{array}{l}\text { Living children }(\mathbf{n}=\mathbf{7 7 2}) \\
0 \\
1-2 \\
3-4 \\
5+\end{array}$ & $\begin{array}{l}17.0 \\
33.8 \\
24.1 \\
25.1\end{array}$ \\
\hline $\begin{array}{l}\text { Mean number of living children } \\
(\mathrm{n}=772) \\
\text { Boys } \\
\text { Girls }\end{array}$ & $\begin{array}{l}2.9 \\
1.4 \\
1.5\end{array}$ \\
\hline $\begin{array}{l}\text { Women aged } 40+\text { years }(\mathbf{n}=\mathbf{2 1}) \\
\text { Mean number of children ever born } \\
\text { alive } \\
\text { Mean number of living children }\end{array}$ & $\begin{array}{l}7.2 \\
6.9 \\
\end{array}$ \\
\hline $\begin{array}{l}\text { Mean number of previous stillbirths } \\
(\mathrm{n}=768)\end{array}$ & 0.005 \\
\hline $\begin{array}{l}\text { Mean number of previous } \\
\text { miscarriages }(n=769)\end{array}$ & 0.62 \\
\hline $\begin{array}{l}\text { Mean age of youngest child (years) } \\
(\mathrm{n}=642)\end{array}$ & 2.4 \\
\hline
\end{tabular}

Table 6: Desire for Additional Children by Number of Living Children and Sons

\begin{tabular}{|l|l|l|}
\hline & $\begin{array}{c}\text { Percent of women who } \\
\text { want more children } \\
(\mathbf{n}=\mathbf{6 5 7}) *\end{array}$ & $\begin{array}{c}\text { Percent of husbands } \\
\text { who want more } \\
\text { children** } \\
\text { (n=667) }\end{array}$ \\
\hline All Women/Husbands & 53 & 74 \\
\hline Number of living children & 76 & 85 \\
\hline 0 & 60 & 80 \\
$1-2$ & 42 & 67 \\
$3-4$ & 30 & 61 \\
$5+$ & & \\
\hline Number of living sons & 71 & 83 \\
\hline 0 & 52 & 73 \\
1 & 41 & 71 \\
2 & 24 & 57 \\
3 & 24 & 60 \\
$4+$ & & \\
\hline
\end{tabular}

Source: client exit interview

* Remaining percentage includes those who do not want more children or are not sure.

**As reported by wives. 
About 36 percent of husbands preferred their next child to be a son compared to 28 percent of their wives. This pattern is consistently valid for each sex composition of living children.

Table 7: Sex Preference for Next Child among Women and Husbands Who Want More Children

\begin{tabular}{|l|l|l|l|l|l|l|}
\hline & \multicolumn{3}{|c|}{ Women (n=424) } & \multicolumn{3}{c|}{ Husbands (n=513) } \\
\hline & Boy & Girl & Up to God & Boy & Girl & Up to God \\
\hline Total & $\mathbf{2 7 . 5}$ & $\mathbf{1 0 . 6}$ & $\mathbf{6 1 . 9}$ & $\mathbf{3 5 . 7}$ & $\mathbf{6 . 9}$ & $\mathbf{5 7 . 3}$ \\
Sex composition of living children & & & & & & \\
No boys & 35.8 & 6.7 & 57.5 & 36.2 & 8.6 & 55.2 \\
No girls & 16.3 & 20.5 & 63.2 & 22.9 & 14.6 & 62.4 \\
Boys $>$ girls & 7.0 & 26.1 & 67.0 & 27.9 & 10.4 & 61.7 \\
Boys = girls & 21.3 & 8.5 & 70.1 & 22.7 & 9.4 & 68.0 \\
Boys $<$ girls & 49.7 & 0.7 & 49.7 & 55.1 & 1.7 & 43.3 \\
\hline
\end{tabular}

Source: client exit interview

\section{Selected Background Characteristics of Service Providers}

\section{A. Nurses / Community Health Workers}

Nine physicians, 3 nurses and 42 community health workers provide services at the Pilot Health Project clinics. Table 8 reviews some of the background characteristics of these staff. The majority of nurses and community health workers fall within the age group of 30 to 39 years, with a mean age of 34.8 years. Close to three-fifths of these providers had diplomas, which varied by NGO (all of the nurses have diplomas). The community health workers with PFS are more likely to have diplomas certifying that they had received two years of training from CDPHC. Community health workers with UHWC do not have diplomas, but do possess certificates from a 4-6 month training course in community health. It is important to note that about two-fifths of community health workers did not have any type of educational degree.

On average the nurses and Table 8: Selected Background Characteristics of 3 Nurses and 42 Community Health Workers

\begin{tabular}{|l|l|}
\hline \multicolumn{1}{|c|}{ Characteristic $(\mathbf{n}=\mathbf{4 5})$} & Percent \\
\hline Age & \\
300 & 17.8 \\
$30-39$ & 60.0 \\
$40+$ & 22.2 \\
Mean age & 34.8 \\
\hline Education (highest degree attained) & \\
None & 37.8 \\
Tawjihi & 4.4 \\
Diploma* & 57.8 \\
\hline Years working at this clinic (completed years) & \\
\hline $0-2$ & 29.0 \\
$3-5$ & 40.0 \\
$6+$ & 31.0 \\
Mean years working at the clinic & 5.0 \\
\hline Number of working days per week & \\
\hline 3 & 31.3 \\
4 & 2.2 \\
6 & 66.7 \\
\hline Source: Nurse / CHW intviews
\end{tabular}

Source: Nurse / CHW interviews

*Includes degrees in nursing, teaching, PHC, community health development, health work, health education, nursing assistant, medical secretary and community health.

community health workers have worked for five years at the clinic where they were 
interviewed. Depending on the type of NGO where they work, the majority of nurses and community health workers work six days a week (67 percent).

\section{B. Physicians}

Nine physicians work at Pilot

Health Project clinics. As

described previously, some of

these physicians are part of a

mobile unit that circulates

between villages to provide

$\mathrm{MCH} / \mathrm{FP}$ services, sometimes

visiting several clinics on the

same day. Table 9 reviews some

of the background

characteristics of the physicians.

Physicians are on average

slightly younger than the nurses

and community health workers

(mean age 32.1 years), and they

joined their respective NGOs

more recently than the nurses

and community health workers

(3.5 versus 5.0 years of service).

Most of the physicians are

general practitioners and report
Table 9: Selected Background Characteristics for Physicians

\begin{tabular}{|c|c|}
\hline Characteristic $(n=9)$ & Percent \\
\hline $\begin{array}{l}\text { Age } \\
<35 \text { years } \\
35 \text { years and above } \\
\text { Mean age }\end{array}$ & $\begin{array}{c}67 \\
33 \\
32.1\end{array}$ \\
\hline $\begin{array}{l}\text { Specialization } \\
\text { General practitioner/ Women's health specialist } \\
\text { Resident }\end{array}$ & $\begin{array}{l}78 \\
22\end{array}$ \\
\hline Got any degrees following university degree? No & 100 \\
\hline $\begin{array}{l}\text { Received any training in aspects of women's } \\
\text { health? (yes) }\end{array}$ & 89 \\
\hline $\begin{array}{l}\text { How long have you been working for this NGO? } \\
<3 \text { years } \\
\text { 3-4 years } \\
5+\text { years } \\
\text { Mean number of years working at this NGO }\end{array}$ & $\begin{array}{l}45 \\
22 \\
33 \\
3.5\end{array}$ \\
\hline $\begin{array}{l}\text { How long have you been working at this clinic? } \\
<1 \text { year } \\
\geq 1 \text { year } \\
\text { Mean number of years working at this clinic }\end{array}$ & $\begin{array}{l}67 \\
33 \\
1.3\end{array}$ \\
\hline $\begin{array}{l}\text { Work in other places in addition to this clinic } \\
\text { (yes) (Hospital, Primary Health Care clinic) }\end{array}$ & 44 \\
\hline $\begin{array}{l}\text { Do you think you need to receive training on } \\
\text { certain aspects/topics in women's health? Yes }\end{array}$ & 89 \\
\hline $\begin{array}{l}\text { Proposed Topics (multiple answers) } \\
\text { Family planning } \\
\text { Menopause } \\
\text { Pap smear } \\
\text { Women's health } \\
\text { Infertility } \\
\text { Pregnancy and labor } \\
\text { Ultrasound } \\
\text { Breast cancer } \\
\text { Postpartum care } \\
\text { Mammography }\end{array}$ & $\begin{array}{l}33 \\
33 \\
22 \\
33 \\
22 \\
22 \\
22 \\
11 \\
11 \\
11\end{array}$ \\
\hline
\end{tabular}

Source: physicians' interviews

previous training on women's health, yet the large majority stated a desire for additional professional support to develop their skills on women's health care.

\section{Service Statistics}

The study's attempt to abstract routinely collected service statistics by reason for visit during the six months preceding the baseline survey yielded mixed results that are of generally poor quality (e.g., incomplete and unreliable). This is presented in Table 10 and is intended to present a highly cautionary impression of the semi-annual caseload in the Pilot Health Project clinics. 
Table 10: Caseload by Reason for Visit during the Six Months Preceding

the Baseline Survey (11/99 - 4/00)

\begin{tabular}{|c|c|c|c|c|c|c|c|c|c|}
\hline Site & Gynecology & $\begin{array}{l}\text { Pap } \\
\text { smear }\end{array}$ & PP clinic & $\begin{array}{l}\text { PP home } \\
\text { visits }\end{array}$ & ANC clinic & $\begin{array}{l}\text { ANC home } \\
\text { visits }\end{array}$ & \begin{tabular}{|c|} 
ANC \\
and PP \\
home \\
visits
\end{tabular} & OB/GYN & FP \\
\hline \multicolumn{10}{|l|}{ UPMRC } \\
\hline Hebron & 27 & 1 & 0 & 27 & 69 & 13 & & & 34 \\
\hline Ithna & 30 & 0 & 0 & 110 & 290 & 82 & & & 221 \\
\hline Toubas & 31 & 1 & 4 & 11 & 113 & 21 & & & 128 \\
\hline Maythalun & 57 & 26 & 5 & 41 & 747 & 21 & & & 217 \\
\hline Nassariyeh & 21 & 0 & 0 & 14 & 65 & 30 & & & 29 \\
\hline Silet il Harthiyeh & 20 & 9 & 8 & 37 & 196 & 18 & & & 58 \\
\hline Zababdeh & 23 & 1 & 0 & 14 & 225 & 6 & & & 76 \\
\hline \begin{tabular}{|l|} 
Subtotal \\
\end{tabular} & 209 & 38 & 17 & 254 & 1,705 & 191 & & & 763 \\
\hline \multicolumn{10}{|l|}{ PFS } \\
\hline Qabatia & & & & & 407 & & 86 & & 1,245 \\
\hline Mashrou Beit Q. & & & & & 27 & & 41 & & 190 \\
\hline $\begin{array}{l}\text { Nazleh Sheikh } \\
\text { Zeid }\end{array}$ & & & & & 36 & & 83 & & 168 \\
\hline Zabdeh & & & & & 45 & & 98 & & 66 \\
\hline Funduqumia & & & & & 150 & & 119 & & 327 \\
\hline Sier & & & & & 21 & & 80 & & 12 \\
\hline \begin{tabular}{|l|} 
Misilyeh \\
\end{tabular} & & & & & 133 & & 183 & & 211 \\
\hline Al Tarem & & & & & 13 & & 55 & & 56 \\
\hline Al Almaniyeh & & & & & 79 & & 133 & & 122 \\
\hline Rumaneh & & & & & 167 & & 198 & & 346 \\
\hline Dier Abu Dief & & & & & 353 & & 91 & & 505 \\
\hline Araneh & & & & & 82 & & 79 & & 182 \\
\hline Al Shuhada & & & & & 50 & & 79 & & 67 \\
\hline Kufr Dan & & & & & 179 & & 90 & & 109 \\
\hline Ta' anik & & & & & 55 & & 35 & & 69 \\
\hline \begin{tabular}{|l} 
Subtotal \\
\end{tabular} & & & & & 1,797 & & 1,450 & & 3,675 \\
\hline \multicolumn{10}{|l|}{ UHWC } \\
\hline Nusseirat & & & & & & & & 249 & 6 \\
\hline \multicolumn{10}{|l|}{ Rafah } \\
\hline Jabalia & & & & & & & & 870 & \\
\hline \multicolumn{10}{|l|}{\begin{tabular}{|l|} 
Beit Hanoon \\
\end{tabular}} \\
\hline \multicolumn{10}{|l|}{ Al Awda Hosp. } \\
\hline Subtotal & & & & & & & & 1,119 & 6 \\
\hline TOTAL & 209 & 38 & 17 & 254 & 3,502 & 191 & 1,450 & 1,119 & 4,444 \\
\hline
\end{tabular}

Source: Abstracted figures from service statistics of the participating NGOs; for UPMRC the data from $2 ? 00$ are missing. 
These statistics suggest that postpartum services in the clinic are mostly non-existent, yet the outreach activities of the community health workers during the postpartum period seemingly do take place. By comparison, ANC services appear to be better established. These findings also corroborate well with data from previous surveys and studies regarding this topic. A study completed by the Planning and Research Center (PRC) in 1996 reported that 80 percent of women delivering in hospitals received no postnatal examination or family planning advice (Ismail and Shahin 1996). According to the 1998 PCBS health survey, only 20 percent of Palestinian women reported receiving postpartum care.

Finally, although some NGOs and UNWRA provide home visits if clinic schedules permit, only a small percentage of women and newborns are actually visited by a trained provider (UNFPA 2000). Additional insights on antenatal and postpartum care will be provided in the subsequent sections of this report.

Women's visits to PHP clinics by reasons of visit

The large majority of visits to the

Figure 1: Reasons for Clients' Visit

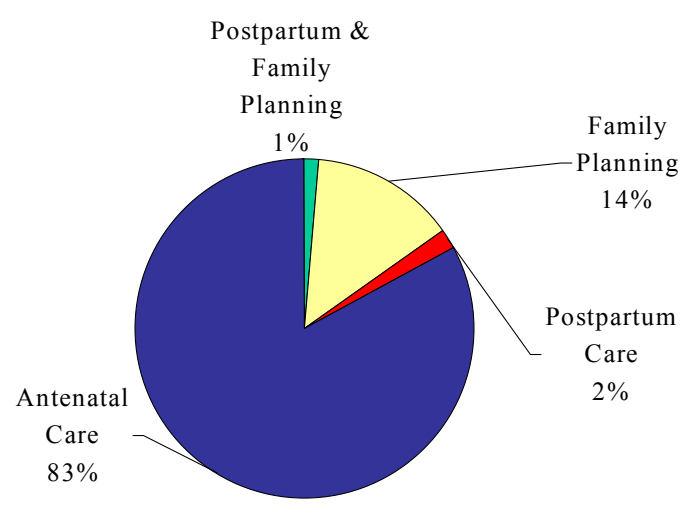

Source: Client exit interview, $(\mathrm{n}=792)$ study's clinics were for antenatal care services ( 83 percent). The second most common reason for visiting the clinic was for family planning services (14 percent). A small proportion of women reported postpartum care as the reason for the visit (about 3 percent) (see Figure 1). 


\section{Baseline Levels of Eight Key Outcome Indicators for the}

\section{Pilot Health Project}

This section of the report presents the principal findings for the baseline levels of the eight key outcome indicators measured in this study.

\section{Indicator 1: Percentage of mothers and babies who make return visits to the clinics to receive postpartum care out of those who received antenatal care (according to "mothers only," "mothers and babies together" and "babies only").}

Ideally, baseline data on this indicator would be obtained from the management information systems of the Pilot Health Project service delivery NGOs. However, the existing health information systems of the Pilot Health Project service delivery NGOs were shown to have many gaps and weaknesses (HDIP 1999). The HDIP assessment of the existing information systems found that the manual aggregation of data produced substantial error and only allowed for the aggregation of a limited number of variables. It was also determined that the Pilot Health Project service delivery NGOs did not have standard filing systems, and some of the clinics assessed did not keep records pertaining to women's health together in one file. Furthermore, discrepancies were identified in the classification of postpartum care services and differences in case definitions. These deficiencies and others will be rectified through the planned creation of a unified management information system. However, this does not assist in the analysis of baseline data for this key outcome indicator. The only available data of acceptable quality come from the client exit interviews, as shown in Figure 2.

Figure 2 presents information on the antenatal care experience of

Figure 2: Antenatal Care Experience of Women Receiving Postpartum Care

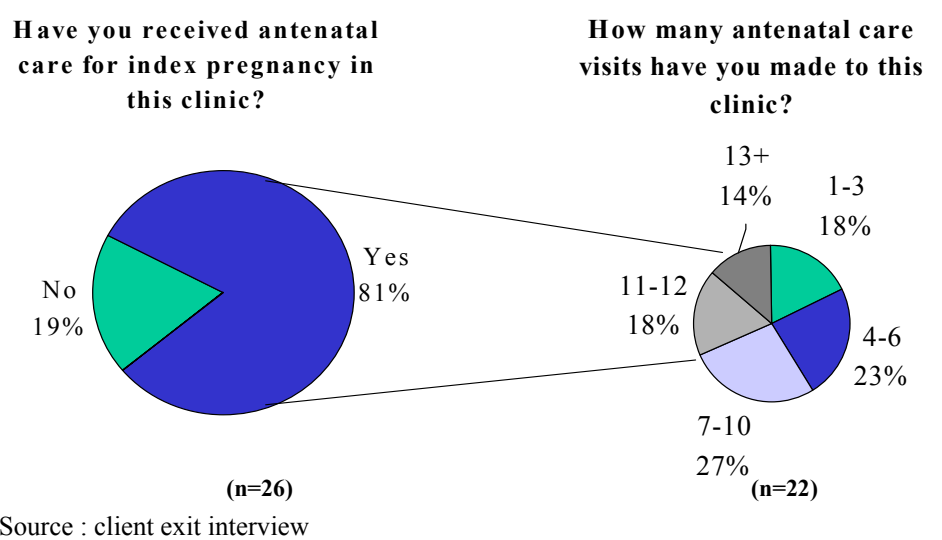

Source : client exit interview postpartum women who came to Pilot Health Project clinics to receive postpartum care. These data should not mask the fact that very few women visit Pilot Health Project clinics to receive 
postpartum care as indicated earlier in Figure 1 (approximately 3.4 percent of the women interviewed gave as their primary reason of visit "postpartum" or "postpartum and family planning"). Of the women who were seeking postpartum care, the large majority had received antenatal care services at the same pilot health project clinic (about 81 percent). About 23 percent of these women made up to six antenatal visits during their pregnancy while others made seven visits or more. The WHO standards for $\mathrm{MCH} / \mathrm{FP}$ services recommend a minimum of four antenatal visits during pregnancy. These findings confirm the results of other studies conducted in the West Bank and Gaza reporting on the quantity of antenatal visits in West Bank and Gaza primary health care clinics. According to an HDIP household study conducted in the West Bank and Gaza, women have an average of 7.5 antenatal visits per pregnancy (Lennok and Shubita 1998). The Ministry of Health in Gaza reported an average of six antenatal visits per pregnancy (Gaza Health Services Center 1996, cited in UNFPA, 2000).

Additional insights of postpartum visits to Pilot Health Project clinics are provided in Figure 3. Approximately one-half of the 27 postpartum clients stated that they visited the clinics to receive postpartum care for themselves, and an additional 33 percent indicated they sought services for themselves and their infants. Reported reasons for seeking postpartum care visits included: postpartum check-up, seeking medical care for a health problem, seeking advice/counseling on family planning methods, or to receive

Figure 3: Postpartum Clients Checked at the Visited Clinic

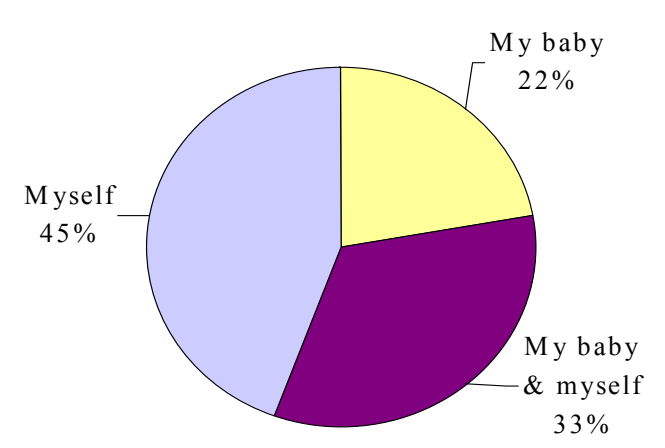

Who Received the Service Today?

Source: Client exit interview $(\mathrm{n}=27)$ a family planning method. Women sought postpartum care visits for their babies for wellbaby check-ups, medical consultations because the baby was sick, immunizations, and advice for care for the baby (not shown in Figure 3).

Despite the finding that only a small number of postpartum women were interviewed in the baseline survey ( $n=27$, or 3.4 percent of the entire sample), their background and obstetric care history constitute important descriptive information for the baseline indicators of the Pilot Health Project. 
Table 11 shows that the majority of the postpartum clients delivered their babies at a hospital (85 percent). Most of the women were discharged shortly after delivery (about 30 percent were discharged after 1-4 hours and about 35 percent after 5-12 hours). Approximately one-half (56 percent) of the postpartum clients were first seen by a health care provider within ten days of delivery. Most of these women received the first postpartum service from the same clinic where they were interviewed, but about one-fifth (19 percent) went to a private physician or hospital and about one-sixth (15 percent) went to UNRWA or MOH health facilities for the first postpartum check-up visit. Only one-third of postpartum clients reported receiving a home visit by a health provider after their index delivery (Table 11), usually within three to seven days after index delivery (45 percent). A community health worker most frequently did the home visit. However, it is interesting to note that some postpartum women did report receiving a home visit by a physician. This could be due to the fact
Table 11: Obstetrical Service Utilization of Postpartum Clients

- Where did you deliver index baby? $(\mathrm{n}=27)$

Hospital

At home

$85 \%$

Health clinic

$11 \%$

- How long have you stay at hospital after index delivery? $(n=23)$

1-4 hours

5-12 hours

$13+$ hours

- When were you first seen by a health provider after index delivery? $(n=27)$

1-4 days

5-10 days

11-29 days

$30+$

- Where were you first seen by a health provider after index delivery? $(n=26)$

At this clinic

Private physician/hospital

UNRWA/MOH

Home visit

- Were you visited at home by a health provider after index delivery? $(n=27)$ Yes

No

- After how many days since delivery were you visited at home? $(\mathrm{n}=9)$

1-2 days

$3-7$

$8+$

- $\quad$ Visited by whom? $(\mathrm{n}=9)$

CHW

Nurse

Physician $33 \%$

- How many times did you visit the clinic after the index delivery? $(\mathrm{n}=27)$

1 visit

2 visits 3 visits

- Age of the newborn in days at the time of the index postpartum visit $(\%)(n=27)$

$<15$ days

15-29 days

30-39 days

40 days

$41+$ days

Source: Client exit interviews

that community health workers may have identified a health problem for the woman or her newborn and referred her to a physician who was willing to make a house call. (Though not shown in a figure or table, community health workers reported this situation during interviews with them.) Activities conducted during home visits included examination of the baby's 
umbilical cord, measuring the baby's temperature and his/her length and head circumference. Mothers received an abdominal exam, a breast exam and some health education messages about breastfeeding.

Finally, it is important to note that when asked about the number of postpartum visits made to the clinic after index delivery, over 70 percent of women reported visiting the clinic only once after delivery. Table 11 shows that some postpartum women made return visits to the clinic during the first two weeks after delivery ( 22 percent). In general, about 84 percent of women made the index visit (at time of interview) before day 40 after delivery. The findings in Table 11 should not mask the overall very low rate of postpartum clinic attendance at the baseline of the Pilot Health Project; 27 women out of 792 were visiting the clinic for postpartum services.

\section{Indicator 2: Percentage of mothers who accept a family planning method out of those who made return visits to the clinic.}

Among the 27 postpartum clients, a little less than one-half (41 percent) stated the reason for the visit was for family planning (Figure 4). Almost one-fifth of these family planning seekers returned to the clinic within the first month postpartum. However, the large majority (81 percent) returned to clinics to receive a family planning method between 30-40 days after delivery.

\section{Figure 4: Reasons of Visits of Postpartum Clients to PHP Clinics}

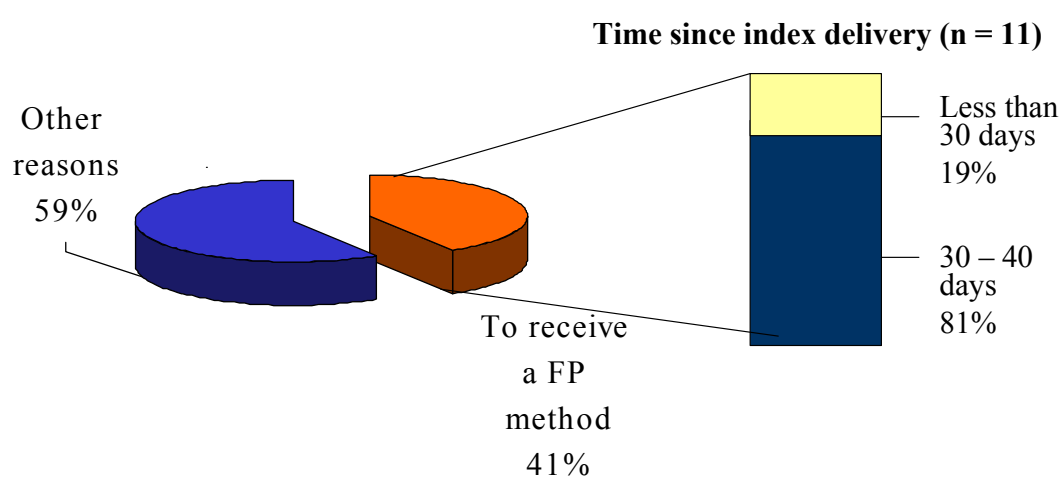

Source : client exit interview $(n=27)$ 
The baseline study examined clients' knowledge about family planning methods (Figure 5). Overall, knowledge about at least one family planning method was universal: 99 percent of the 792 women reported knowing at least one family planning method. Slightly more than one-half of the women knew about four or five family planning methods. The IUD and the oral contraceptives are the most widely known methods (98 and 95 percent, respectively), with about one-half of the women reporting some knowledge of injectables and condoms (52 percent and 45 percent respectively). Only 14 percent of women reported knowledge of prolonged breastfeeding (the LAM approach) as a method of contraception.

Table 12 provides additional insights on ever use of family planning methods.

Overall, approximately 58 percent of the women in the study reported ever using a family planning method. The IUD is clearly the most popular method among women interviewed (ever used by about

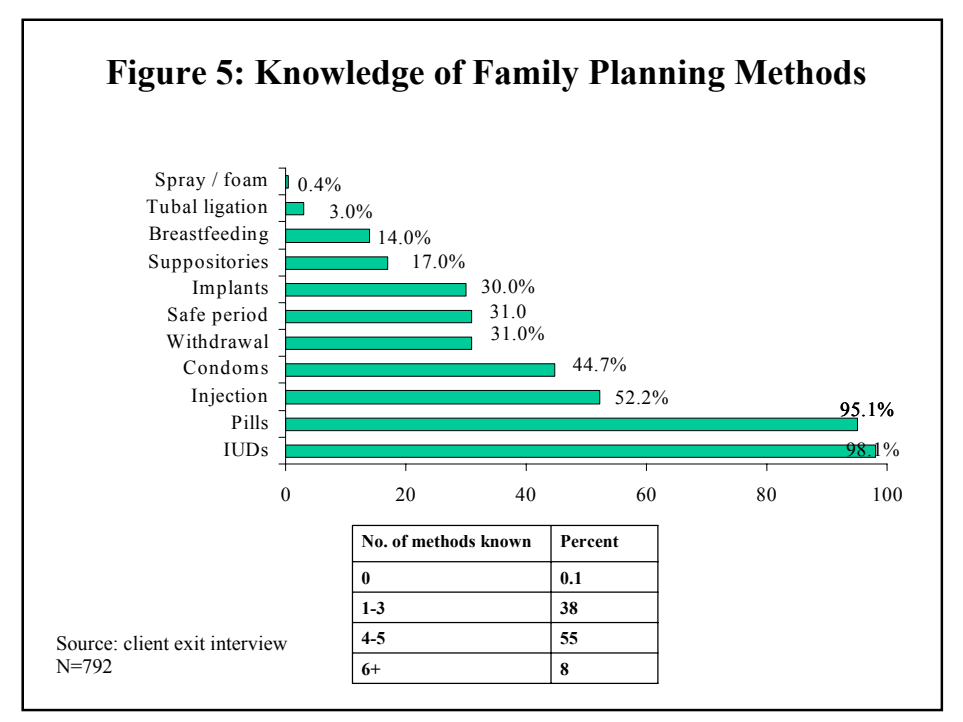

Table 12: Past and Current Use of Family Planning

\begin{tabular}{|l|l|}
\hline \multicolumn{1}{|c|}{ Aspect of Use } & Percent \\
\hline Ever used any method $(\mathbf{n}=\mathbf{7 8 9})$ & 57.7 \\
\hline Ever used a modern method $(\mathbf{n}=\mathbf{4 0 9})$ & 51.8 \\
\hline Methods ever used (n=455) & \\
IUD & 66.6 \\
Pills & 42.4 \\
Condoms & 17.4 \\
Injection & 6.4 \\
Implant & 0.2 \\
Suppositories & 3.1 \\
Withdrawal & 13.8 \\
Breastfeeding & 3.3 \\
Safe period & 11.2 \\
\hline Currently using any method (n=792) & 14.4 \\
\hline Currently using a modern method $(\mathbf{n}=\mathbf{7 9 2})$ & 13.9 \\
\hline Methods currently used $(\mathbf{n}=\mathbf{1 1 4})$ & \\
IUDs & 74.1 \\
Injection & 11.6 \\
Pills & 10.7 \\
Condoms & 1.8 \\
Other & 0.9 \\
\hline Mean number of children at first use $(\mathbf{n}=\mathbf{4 2 6})$ & 2.9 \\
\hline Mean age at first use (years) $(\mathbf{n}=\mathbf{4 5 5})$ & 24.0 \\
\hline
\end{tabular}
67 percent) followed by the pill (ever used by about 42 percent). On average, women began using family planning methods when they had about three living children. Their average age at first use was 24 years. About 14.4 percent are current users of family planning methods with almost three-quarters of the current users reporting use of the IUD (74 percent) (Table $12)$. 


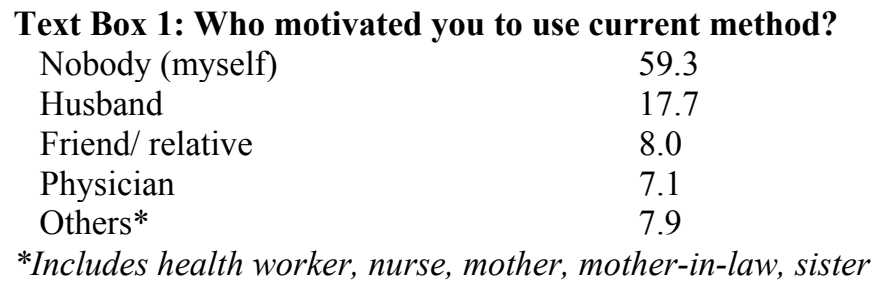

However, substantially fewer women are currently using the pill (only about 11 percent) and the condom (only about 2 percent of couples). Injectables are

currently used by about 12 percent of women. Women in most cases chose the method they were using on their own (60 percent of cases). About one out of six (18 percent) women in the study reported that their husbands had a say in the choice of family planning method used (see Text Box 1). Only a few cases indicated that health providers advised or motivated them to choose the family planning method that they were currently using.

\section{Indicator 3: Percentage of low- parity women (1-2 living children) accepting a family planning method.}

Women who had ever used a contraceptive method were asked to give their parity at the time of first use. Approximately, one-half of these women (47 percent) stated a

Figure 6: When Did You First Begin Using a Family Planning Method?

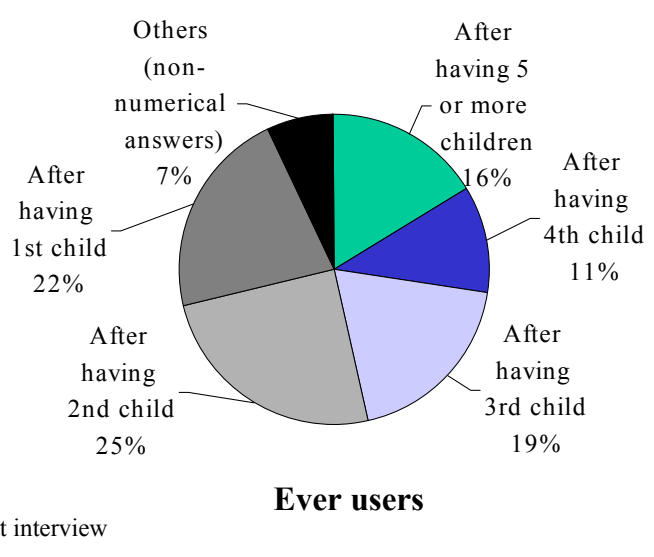

parity of 1-2 children. No one claimed to have used a contraceptive to delay the first birth (Figure 6). Among women who are currently using a modern family planning method, only about onesixth are low-parity women, and no one is using a method to delay the first birth (Figure 7).

Figure 7: Percent Distribution of Current Users of Contraceptives by Number of Living Children

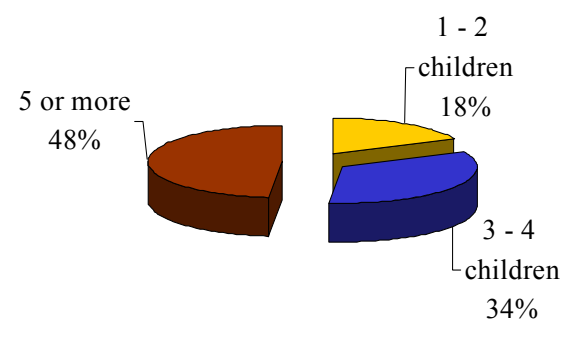

Source : Client exit interview $(\mathrm{n}=103)$ 


\section{Indicator 4: Increase in mother's knowledge of antenatal and postpartum danger warning signs for themselves and their babies.}

The study asked a series of questions on knowledge about specific maternal warning signs that a woman may experience during pregnancy (12 items), during the postpartum period (6 items) and infant health warning signs during the first three months of life (8 items). The results of these factual knowledge questions are summarized in (Table 13). These findings indicate high levels of baseline knowledge on ANC, postpartum and infant health warning signs.

Approximately two-thirds of the ANC (67.3 percent) and postpartum (69.2 percent) clients knew at least one or two signs, and all of the postpartum clients knew at least one or two infant health warning signs. It is noted that these results are more indicative of awareness rather than comprehensive technical knowledge. However, it is also noted that one-third of both ANC and postpartum clients did not receive any warning signs.

Table 13: Knowledge of ANC, Postpartum and Infant Health Warning Signs

\begin{tabular}{|c|c|c|c|}
\hline Number of Signs & $\begin{array}{c}\text { Percentage of ANC Clients } \\
\text { Who Know of ANC Warning } \\
\text { Signs (n=655) }\end{array}$ & $\begin{array}{c}\text { Percentage of Postpartum } \\
\text { Clients Who Know of } \\
\text { Postpartum Warning signs } \\
(\mathbf{n}=\mathbf{2 7})\end{array}$ & $\begin{array}{c}\text { Percentage of Postpartum } \\
\text { Clients Who Know of Infants } \\
\text { Warning Signs (n=27) }\end{array}$ \\
\hline 0 & 32.7 & 30.8 & 0 \\
\hline $1-2$ & 15.5 & 42.3 & 33.3 \\
\hline
\end{tabular}

\section{Indicator 5: Increase in women's knowledge and practice of self-breast examinations} and Pap smear tests.

Breast cancer has been suggested as being among the most frequently diagnosed cancers among Palestinian women (UNFPA 2000). Although accurate data on incidence of different types of cancer are not available, a study in 1994 found that 28.5 percent of reported female cancer cases were due to breast cancer (Abdeen and Barghouti 1994, cited in UNFPA 2000). In response to concerns about breast and cervical cancers, the Palestinian National Strategic Health Plan (1999-2003) emphasizes the need to increase by 25 percent the number of primary health care centers that provide screening services for cervical and breast cancers and sexually transmitted diseases. The Pilot Health Project's fifth outcome indicator directly supports this policy of improving access to breast and cervical cancer services.

The majority of physicians ( 89 percent) interviewed during the baseline survey reported having received training on how to counsel clients to conduct self-breast examinations prior to the Pilot Health Project. However, only about one-half of the 
physicians in the study (4 out of 9) reported that they routinely counseled their clients on how to conduct self-breast examinations.

This indication of infrequent education on breast self-examination is confirmed in the women's interviews that indicate about one-third of the ANC and postpartum clients (36 percent, $n=680$ ) were told how to conduct a self-breast examination (Figure 8).

When asked where they received this information, about one-fifth (21 percent) reported receiving the information at the same health facility where they were interviewed and slightly less than one-third (31 percent) reported receiving the information at another health facility. Other women

Figure 8: Knowledge and Practice of Self-Breast Examination among Antenatal care and Postpartum Clients

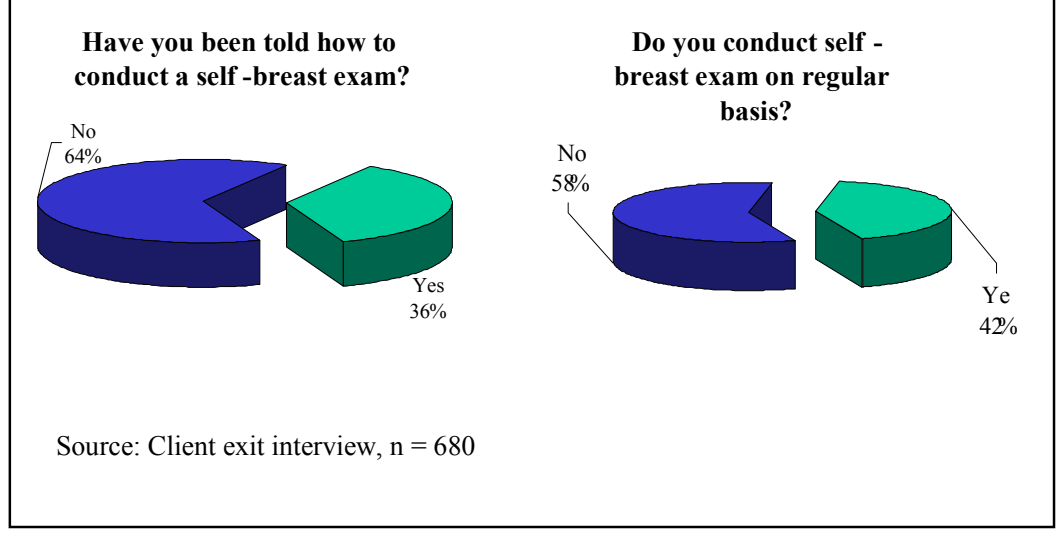
reported receiving the information through friends or mass media. Despite receiving information on how to conduct self-breast examinations for early detection of breast cancer, only two-fifths (42 percent) of the ANC and postpartum clients report conducting self-breast exams on a regular basis (Figure 8).

The Pilot Health Project will also address improvements in the detection and treatment of cervical cancer. The baseline measures of this study indicate that about one-half ( 56 percent) of the nine physicians working in the Pilot Health Project clinics report that the clinics provide the PAP smear test (not shown). The results in Figure 9 reveal that only about 11 percent of the indicated ANC and postpartum clients have ever had a PAP smear test.
Figure 9: Pap smear Test for Antenatal and Postpartum Clients (35 years old and

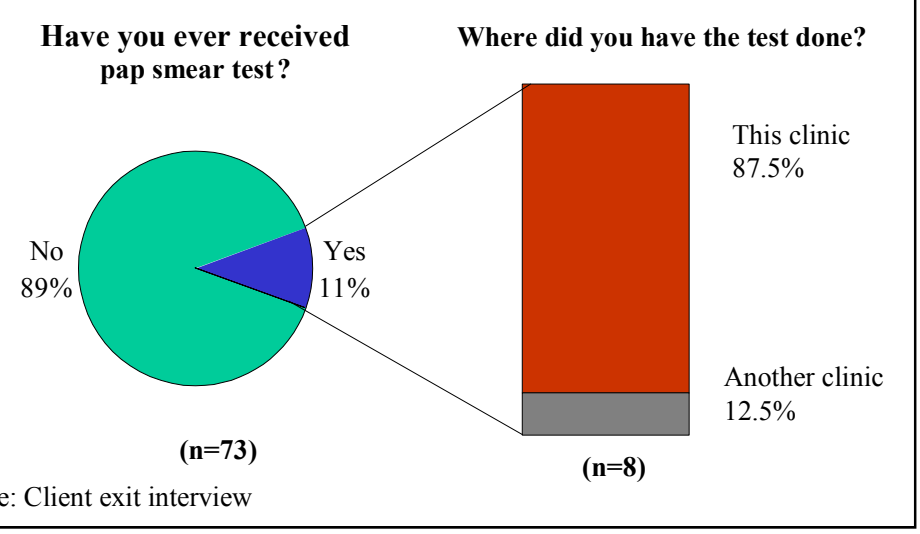




\section{Indicator 6: Increased percentage of husbands and other males who are aware of the importance of at least 36 months birth interval, antenatal and postpartum care and family planning use}

Almost all of the antenatal clients (98 percent) reported that their husbands encouraged them to seek

antenatal care

Table 14: ANC Clients Reports on Husband Involvement

services at

Pilot Health

Project clinics

and an almost

equal

proportion $(96$

percent)

reported that

their husbands

think that

Husband's involvement in the following issues

Antenatal Care $(\mathbf{n}=\mathbf{6 5 5})$

Husband thinks antenatal care is important for woman's health

Husband encourages woman to go to antenatal clinic

Woman discusses with husband antenatal visit results

Husband goes with woman to antenatal visits (yes and sometimes)

Husband accompanied women today to the clinic

Birth Spacing*

Proportion who prefer to wait 36 months between births

Husbands $(\mathrm{n}=348)$

ANC clients $(n=318)$

Mean number of years desired before having next child

Husbands

ANC clients

Family Planning

Discuss use of family planning with husband? (yes) $(\mathrm{n}=789)$

Agree with husband about whether or nor to use FP? (yes) $(n=725)$

*Among those who want more children

antenatal care

Source: client exit interview

is important for their wives' health. Also, most of the ANC clients ( 96 percent) say that they discuss the outcome of their antenatal visits with their husbands (see Table 14). These baseline indicators of husband awareness of ANC services are very high. Husband's involvement (e.g., accompanying his wife to the clinic for ANC services) is less frequent. Though most husbands encouraged their wives to seek antenatal care, only about one-fourth of them accompanied their wives to the clinics. Furthermore, when asked if husbands accompanied them that day to the clinic, only 5.6 percent answered "yes."

Women seeking antenatal care who wanted more children were asked how long they preferred to wait after delivery of the index pregnancy until the next birth. They were also asked about their husbands' preferences for birth spacing (in cases where husbands indicated they wanted more children). Almost one-half of the ANC clients (55 percent) stated a preference to wait 36 months before the next pregnancy and an equal proportion (52 percent) thought their husbands preferred to wait 36 months as well (Table 14).

The exit interviews with ANC clients also showed that most husbands and wives communicate with each other about family planning use (as reported by women). Almost all of the ANC clients (94 percent) reported that they agreed with their husbands about whether or not to use a family planning method. However, data on communication between husbands 
and wives regarding use of family planning could mask the dynamics of the negotiation process between husbands and wives, including wives' negotiation power.

\section{Indicator 7: Increased Knowledge and Skills of Health Care Providers, Community Health Workers and Nurses}

Home visits by community health workers are one of the principal activities of the Pilot Health Project.

Figure 10 reviews the components of health education during these home visits as reported by the paramedical staff.

Breastfeeding, well baby care, the need to use a family planning method and proper nutrition are most frequently

Figure 10: Elements of Health Education Discussed during Postpartum Home Visits

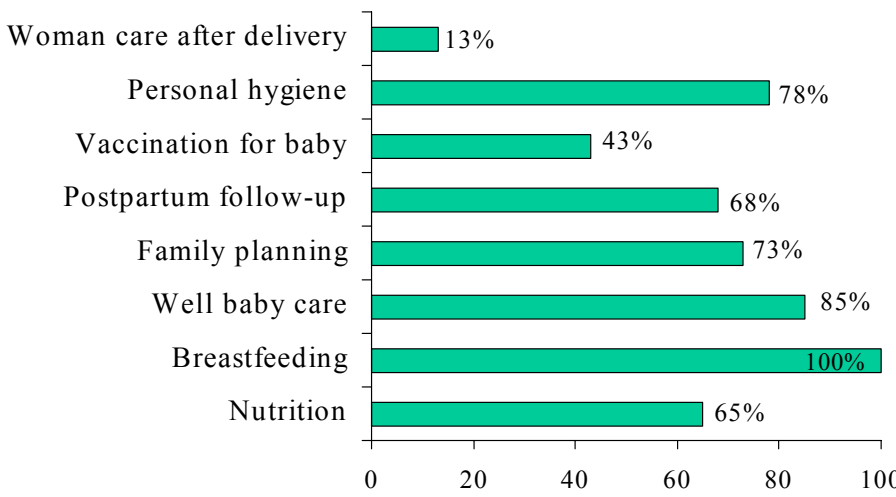

Source: Community health worker and nurse interview $\mathrm{N}=40$

mentioned during the home visit sessions. In addition to health education, community health workers also conduct some elements of medical examination (breast, abdomen, and perineum) and measure vital signs, though less often undertaken.

Figure 11 indicates that the majority of the community health workers and nurses encourage women to return within one month of delivery to the clinic for a postpartum maternal check-up (76 percent) and for an infant health checkup (84 percent).

\section{Figure 11: CHW/Nurse Advice about Postpartum Medical Check-up}
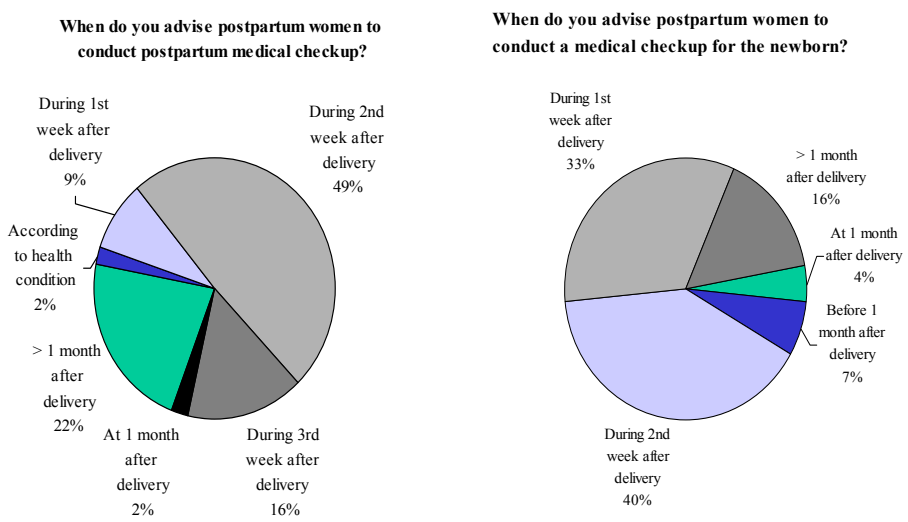
Table 15 summarizes physician technical knowledge on ANC and postpartum care. The baseline level of knowledge about warning signs for the antenatal period is high. All physicians were able to report at least five elements out of twelve. Elements of warning signs of postpartum period and warning signs for newborns are relatively less frequently mentioned, though still high. The majority of physicians ( 89 percent) were able to report at least 5 items out of 16 items of obstetric history that they should ask women. Finally, there was

disagreement among physicians about the minimum number of antenatal care visits that a pregnant woman should receive (Table 15). It may be noted here that antenatal women reported making on average 5.4 antenatal visits for the index pregnancy, and about 70 percent of them started to make these visits as early as during the first two months of index pregnancy (not shown in a table).

\section{Indicator 8: Improved follow-up information given to antenatal and postpartum women on ANC and postpartum care including nutrition, hygiene, breastfeeding and the need to use family planning.}

During their exit interviews, women who received antenatal or postpartum care were asked about the information they received from health providers on specific antenatal care topics. Figure 12 summarizes women's reports on antenatal and postpartum follow-up information items that they received. Among antenatal women, about 18 percent reported not receiving any information. However, about 29 percent received one or two information items and about two-fifths received information on at least five items (out of 12 items). 
Pregnant women were more likely to receive information on adequate nutrition, tetanus toxoid immunization and breastfeeding and less likely to receive information on breast hygiene, newborn care and the need for a family planning method following the index pregnancy (not shown in the figure).

Most postpartum women reported receiving information on a few postpartum care items during their postpartum visits. About one-

Figure 12: Coverage of Information/Counseling Received by Clients during ANC \& PP Clinic Visits

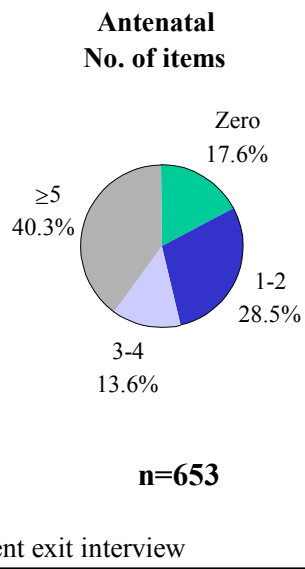

Postpartum
No. of items

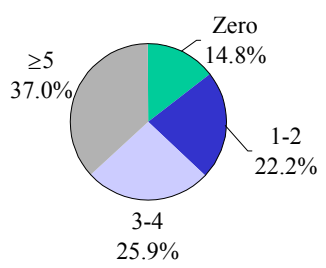

$\mathbf{n}=\mathbf{2 7}$ About one-fourth reported receiving information on three or four items and close to two-fifths received information on at least five items (out of nine items). Postpartum women were more likely to receive information on breastfeeding, newborn care including vaccination schedule, and family planning. They were, however, less likely to receive information on postpartum exercise, personal hygiene and proper nutrition (not shown in a figure).

Only about two-fifths of the women who received antenatal care were told what to do if they experienced any warning signs for the index pregnancy (see Figure 13). Between 73 and 97 percent of women, however, were told about their due dates for delivery, the routine antenatal schedule, the schedule of their next visit and the outcome of their visits the day they were exit interviewed. When asked if they had ever received any contraceptives from the clinic where they had been interviewed, about 40 percent of women who ever used

\section{Figure 13: Follow up Information Given to Antenatal Care Clients}

Did the physician tell about?

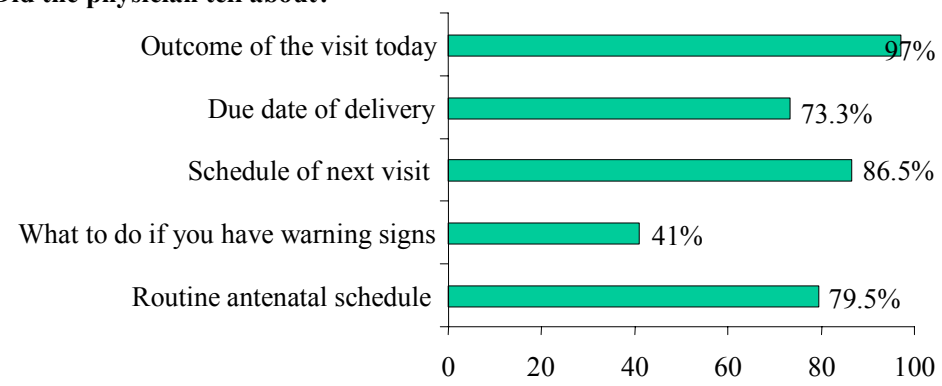

Source: client exit interview $\mathrm{N}=655$ contraceptives said "yes" (see Figure 14).

These women were asked about the type of information they received at the time they received the method. About two-thirds of women reported receiving basic information on the 
method they received. This included information on how the method works to protect against pregnancy, how to use the method, method effectiveness, its advantages and side effects, and what to do if complications occurred from using the method.

Despite the above findings, there is still room for improvement in the process of information giving related to family planning. Women need to receive more information about the different types of family planning methods that are available and family planning consultations need to be provided to all women attending

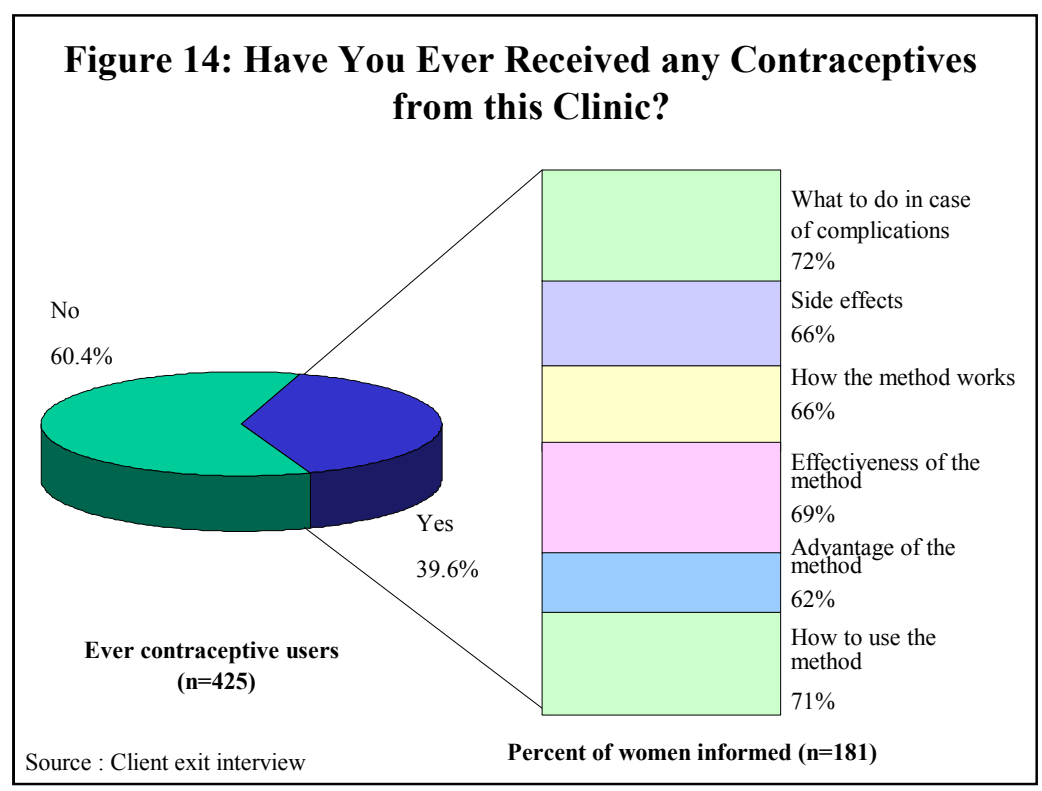
Pilot Health Project clinics, especially since about one-third of women reported not receiving any family planning information.

\section{Additional Information on Services Offered at Pilot Health Project Clinics}

In addition to collecting data that measure the baseline level of the Pilot Health Project's outcome indicators, this study also provides insights into the quality and accessibility of $\mathrm{MCH}$ care services. This section discusses some of those findings.

\section{Quality of Care}

The results presented in Figure 15 indicate that the large majority of the women who seek health care services at the Pilot Health Project clinics perceive the physical environment to be of good quality

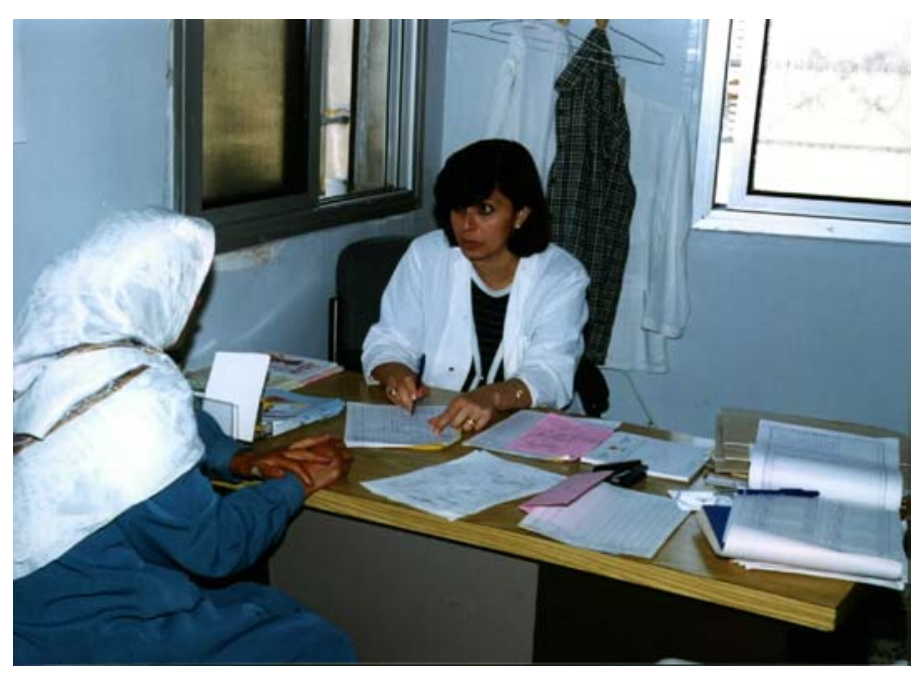
and the clinic staff to be courteous and respectful. They appreciated the privacy they received during examinations, the time they were given to ask providers questions, and the warm welcome they received when they first entered the clinics (reported by 93 to 98 percent of women). Also, the majority of women reported that they were seated in the waiting area and 
that they felt comfortable during the time they waited (96 and 84 percent, respectively). These findings were also reflected in the assessment of standards of care of Pilot Health Project clinics that was done in 1999 (Younis and Hassanien 1999). However, it is worth noting that some women did have negative impressions about the space of the clinic. In responding to a question "was the clinic spacious", only 68 percent responded positively.

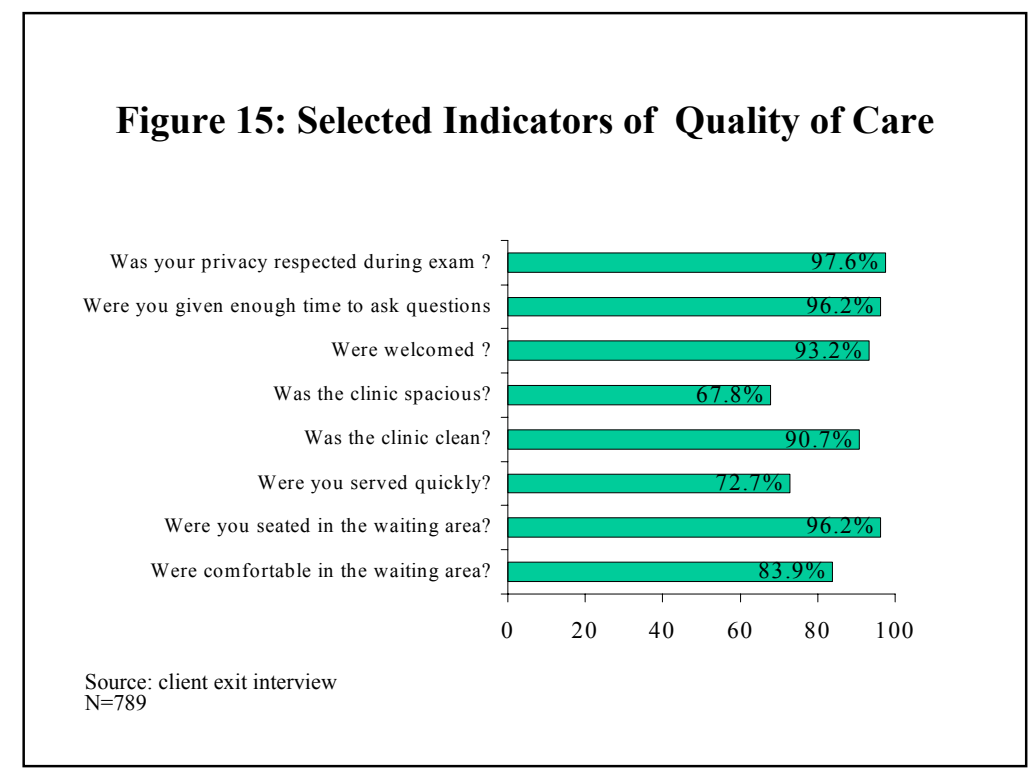

Women were also asked about reasons for preferring the clinics they visit (see Figure 16). The most commonly cited reason (68 percent) was that the clinic was close to their homes. Many of the other reasons given by women for visiting the specific clinics reflect their satisfaction with the quality of care provided at those particular clinics. These reasons include trust of the physician (about 26 percent), better quality of care than other clinics (28 percent), availability of laboratory (21 percent) and availability of physician (21 percent). It is important to note that 25 percent of women reported lower cost of the services as a reason for visiting some of the clinics. Also, about 16 percent of women reported having no other options, and the clinics visited were

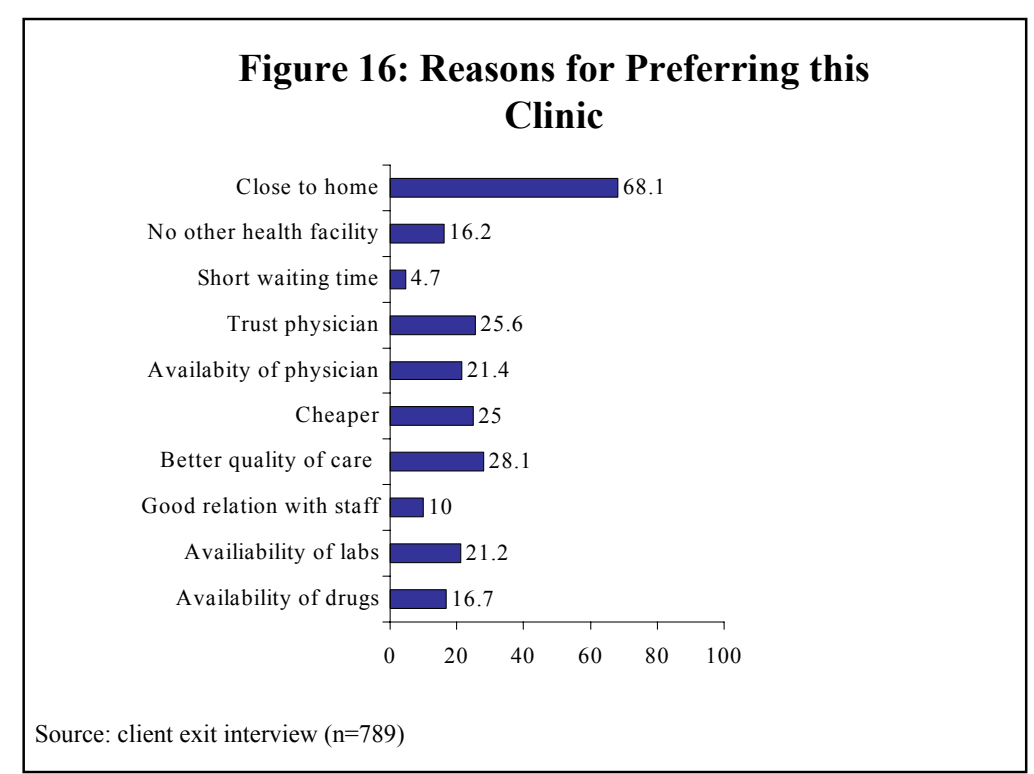
the only ones available to them. 
Accessibility of Health Care Services

The data in Table 16 clearly show easy accessibility to the health facilities. More than one-half of women reported that they only needed up to ten minutes to get to the clinics. About 40 percent reported that it takes between ten and thirty minutes to get to the clinic. In addition about three-fourths of women reported that they didn't need transportation to get to the clinics, and most of them walked. Twenty percent of women did, however, report going to clinics by taxi.

When asked who accompanied them to

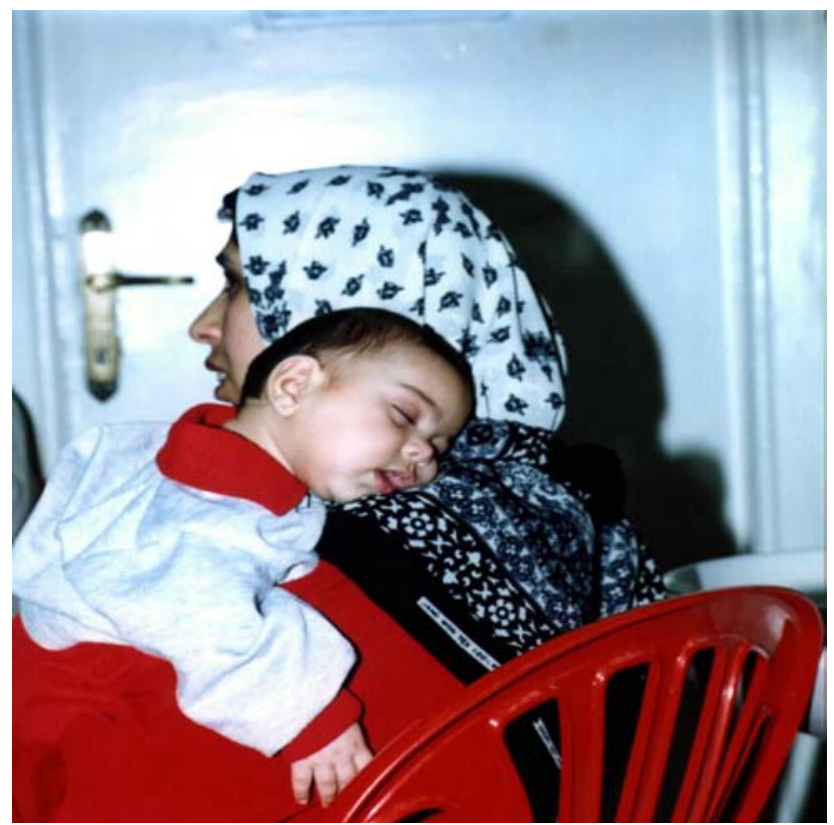
the clinics, about one-half of women reported that they went by themselves, 20 percent reported being accompanied by in-laws, and about 16 percent reported being accompanied by their relatives. Approximately one-half of women reported that they have been visiting the clinics during the last 20 months. The remaining women reported visiting the clinics during the past 21-51 months or more.

Table 16: Selected Aspects of Accessibility to PHP Clinics

\begin{tabular}{|l|c|}
\hline Indicator & Percent \\
\hline Time needed to get to the clinic (minutes) & \\
(n=788) & \\
$1-5$ & 24.4 \\
$6-10$ & 29.7 \\
$11-29$ & 40.4 \\
$30+$ & 15.5 \\
\hline Transport used (n=789) & \\
No transport / walking & 73.1 \\
Taxi & 20.0 \\
Private car & 6.6 \\
Public bus & 1.6 \\
Other & 0.6 \\
\hline Who accompanied you to the clinic today? & \\
(n=789) & \\
Nobody / came alone & 52.2 \\
Husband's relatives & 19.5 \\
Woman's relatives & 15.8 \\
Son / daughter & 6.2 \\
Husband & 5.6 \\
Neighbor & 1.5 \\
\hline Since when do you visit this clinic (months)? & \\
(n=788) & 6.5 \\
First time / less than one month & 20.7 \\
1-6 months & 18.8 \\
7-20 months & 30.5 \\
21-50 months & 23.5 \\
\hline 51+ months & \\
\hline
\end{tabular}




\section{DISCUSSION OF FINDINGS}

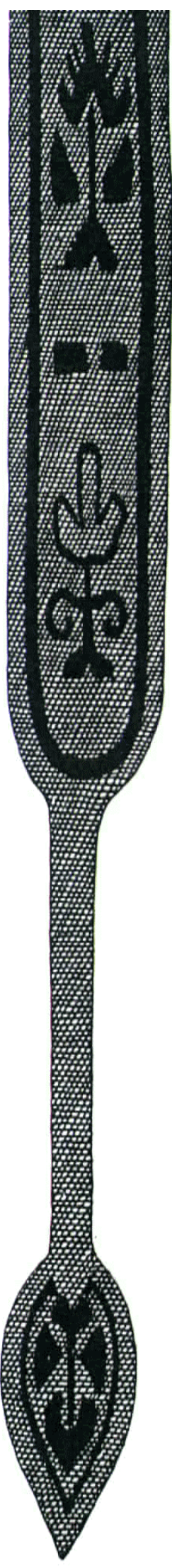

This study presents important data on the baseline levels of the Pilot Health Project outcome indicators. It provides a comprehensive assessment of the antenatal and postpartum care services, including family planning that are currently provided at project clinics. Key points that emerged from the analysis are listed below:

In general, Palestinian women have a relatively high fertility level. For all women attending the project's clinics, the mean number of children ever born was 3.0. Women close to the end of childbearing period (40 years or more) had on average more than seven children ever born to them. Wives reported that their husbands in general had higher fertility preferences than themselves; only one-half of women reported wanting more children as compared to about three-fourths of their husbands. Women also reported that their husbands indicated a higher preference for male children compared to them.

The majority of women receive some antenatal care, yet only a very small number return to clinics for postpartum care and follow-up. On average women made about five antenatal visits to the clinics during their pregnancies and many of these women sought antenatal care as early as the first month of pregnancy. However, only 3.3 percent of women interviewed $(n=792)$ reported returning to the clinic for postpartum care.

Women who returned for postpartum visits made the index visit before day 40 after delivery (84 percent of postpartum women). When asked about the number of postpartum visits made to the clinic after index delivery, more than 70 percent of the 3.3 percent of women who returned for postpartum care reported visiting the clinic only once after the delivery.

Very few women reported receiving a home visit after the index delivery. Only one-third of the 3.3 percent of women who returned to the clinic for postpartum care reported receiving a home visit by a health provider after their delivery. Most of them received the home visit three to seven days after delivery. In general, community health workers conducted most postpartum home visits.

A good number of postpartum women accepted a family planning method during their clinic visit (about 41 percent of the 3.3 percent of women who returned for postpartum care). Most women went to clinics to receive a family planning method after four weeks of index delivery. However, some women (18 percent of the 
3.3 percent of women who returned for postpartum care) went to clinics to receive a family planning method early after the index delivery (before 30 days of index delivery).

Despite almost universal knowledge about family planning (99 percent), only 58 percent of women who were interviewed ever used a family planning method. The IUD was the most popular method among women interviewed (ever used by about 67 percent) followed by the pill (ever used by about 42 percent). Very few women reported ever using a condom. On average, women began using family planning methods when they had about three living children and not a single woman reported use of a contraceptive method to delay the first birth.

The number of living children plays a large role in deciding when women will first begin to use contraception. Almost half of all contraceptive ever users interviewed initiated family planning use after having several children.

Information/counseling received by women regarding antenatal and postpartum care, including family planning, was partial or weak. Although most women were given some information about some aspects of antenatal and postpartum care, many did not receive important information that they should receive during pregnancy or the postpartum period. The findings indicated that women received incomplete information about warning/danger signs during pregnancy and/or the postpartum period. About one-third of both pregnant and postpartum women were not told about or had no knowledge about any of the warning signs that could occur during pregnancy or after delivery. Also, women reported receiving incomplete information on health problems among young infants (less than three months) that require immediate attention and/or treatment at a healthy facility (about one-third of women knew about only one or two of these potential health problems).

Breast and cervical cancer screening services are not part of the routine services offered at the Pilot Health Project clinics. Less than one half of the physicians $(n=9)$ reported that they routinely counseled their clients on how to conduct self-breast examinations. Slightly more than one-third of pregnant and postpartum women interviewed reported receiving instructions or counseling on how to conduct a self-breast examination. Many women reported receiving this information from other health facilities, through friends or mass media. Similarly, only about half of the physicians interviewed reported providing services for obtaining Pap smear tests at the Pilot Health Project clinics. When probed, only one-fifth of the physicians in the study reported obtaining Pap smear samples as part of their routine procedures. Only a few women reported ever receiving a Pap smear test at the clinics they attended. 
Women reported that husbands in general do play a role in antenatal and postpartum care, including family planning. Nearly all women reported that their husbands encouraged them to seek antenatal care services at Pilot Health Project clinics. However, when asked, women reported that only about one-fourth of their husbands accompanied them to the clinics. The exit interviews also revealed that most women state they discuss family planning use with their husbands. Almost all women reported that they agreed with their husbands about whether or not to use a family planning method.

The study results suggest that all categories of providers had inadequate technical knowledge and skills. Although close to three-fifths of community health workers $(\mathrm{n}=42)$ reported having diplomas or receiving training, the overall level of education and/or training of this category of staff was not consistent or standard. In fact, two-fifths of community health workers did not have any type of educational degree. Most physicians reported receiving training on women's health. However, when asked, the majority of them felt that they still needed additional training on some aspects of women's health. 


\section{RECOMMENDATIONS}

- Urgent adoption of recently developed national standard protocols and

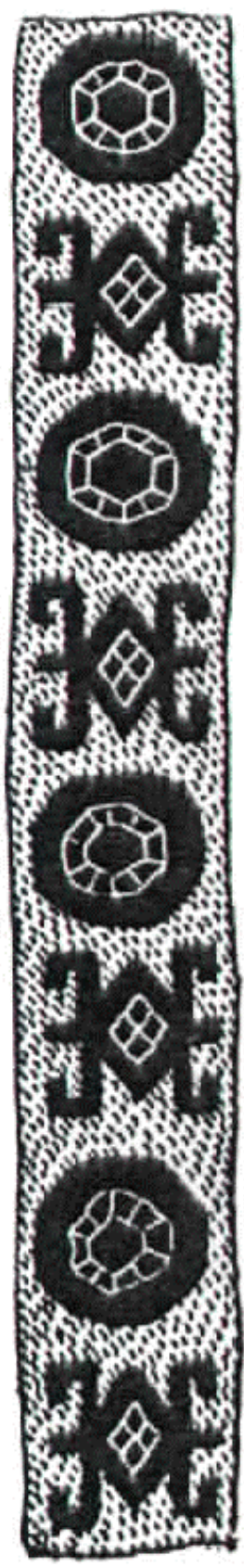
guidelines for antenatal and postpartum care, including family planning and breast and cervical cancer screening, for primary health care facilities/clinics are needed. The adoption of recently developed national standard protocols and guidelines for the above-mentioned services in addition to competencybased training for all categories of health providers (including training on the newly developed protocols and guidelines) will result in significant improvement in the quality of services provided at primary health care facilities/clinics.

- Additional training and supervision for service providers on antenatal, postpartum and family planning services needs to be emphasized.

Competency-based training should be provided to all categories of service providers at primary health care clinics to improve their technical knowledge and skills in maternal and child health care skills, according to the WHO standards. Training programs should be designed to improve essential obstetric care, including antenatal and postpartum care, infection prevention practices, counseling, interpersonal communication, family planning, breast and cervical cancer screening, and information education and counseling (IEC). Improvement of management skills among all staff should also be emphasized. Monitoring and supervision systems to ensure the sustainability of training activities should be an integral part of all training programs.

- Referral mechanisms should be established between hospitals and primary health care facilities to ensure that women receive essential postpartum care. Linkages should be made between hospitals and primary health care clinics so that women who recently delivered are not lost to follow-up and receive the essential postpartum care needed for themselves and for their babies.

- Medical schools and training programs need to increase the number of training hours on women's health. The importance of providing quality care, particularly in the areas of antenatal and postpartum care and family planning services needs to be highlighted. Good communication and counseling skills for these services needs to be emphasized.

- The public needs to know more about the importance of antenatal and postpartum care, including family planning and breast and cervical cancer screening. Health education messages should be addressed to women and their families (especially their husbands), 
stressing the importance of these services and encouraging them to go to the clinics, particularly for postpartum care and follow-up.

- Better outreach services are needed to track and reach women who have either stopped going for antenatal visits or do not intend to seek postpartum care. Encouraging women to return to clinics for follow-up care needs to be emphasized by all Pilot Health Project clinic staff.

- Quality assurance and good management need to be incorporated into the overall services provided at primary health care clinics. Specialized training to help develop competent clinic managers is essential. In addition, training programs for physicians and nurses/community health workers to improve their management and supervision skills should be considered. These programs will help providers solve problems and effectively manage the daily work at the clinics and will improve record keeping systems. The collection of accurate and comprehensive service statistics from primary health care clinics can be further improved through the development of a unified and competent management information system, which is already in progress.

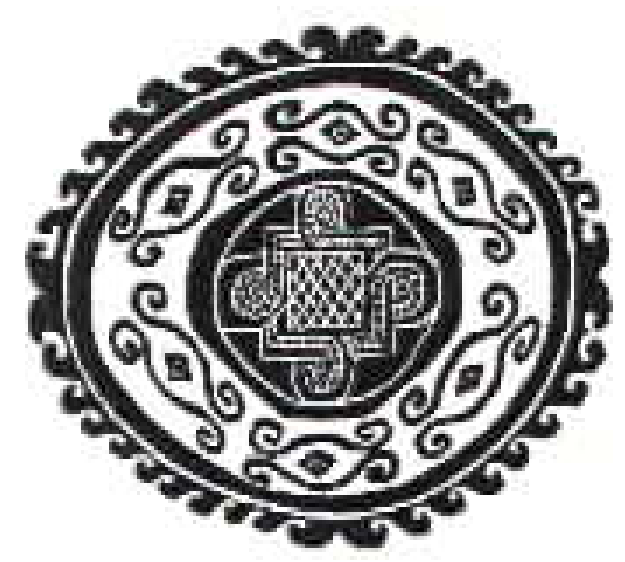




\section{REFERENCES}

Abdeen, Z. and F. Barghouthi. 1994. Palestinian Cancer Statistics: Seventeen Years of Cancer Incidence, 1967-1992. Arab College of Medical Professions, Al Quds University: Ramallah, Palestine.

Health Development Information and Policy Institute. 1999. Management Information System Assessment. Ramallah, Palestine.

Ismail, N. and M. Shahin. 1996. Family Planning and Women's Reproductive Health Survey in the West Bank. Planning and Research Center: Ramallah, Palestine.

Lennock, J and A. Shubita. 1998. Health Insurance and Health Service Utilization in the West Bank and Gaza Strip. The Health, Development, Information and Policy Institute (HDIP): Ramallah, Palestine.

National Strategic Health Plan, Palestine, 1999-2003.

Palestinian Central Bureau of Statistics. 1997. The Demographic Survey in the West Bank and Gaza Strip: Final Report. Ramallah, Palestine.

Palestinian Central Bureau of Statistics. 1998. Women and Men in Palestine: Trends and Statistics. Ramallah, Palestine.

Palestinian Central Bureau of Statistics, 2000. Health Survey 2000 - Main Findings. Ramallah, Palestine.

Palestinian Ministry of Health, 1997. Annual Report 1997. Gaza/Nablus, Palestine.

UNFPA. 2000. The Occupied Palestinian Territory: Country Population Assessment. Ramallah, Palestine.

Younis, N. and N. Hassanien. 1999. Consultancy Report: Assessment of Standards of Health Care Services: Pilot Health Project. Cairo. 


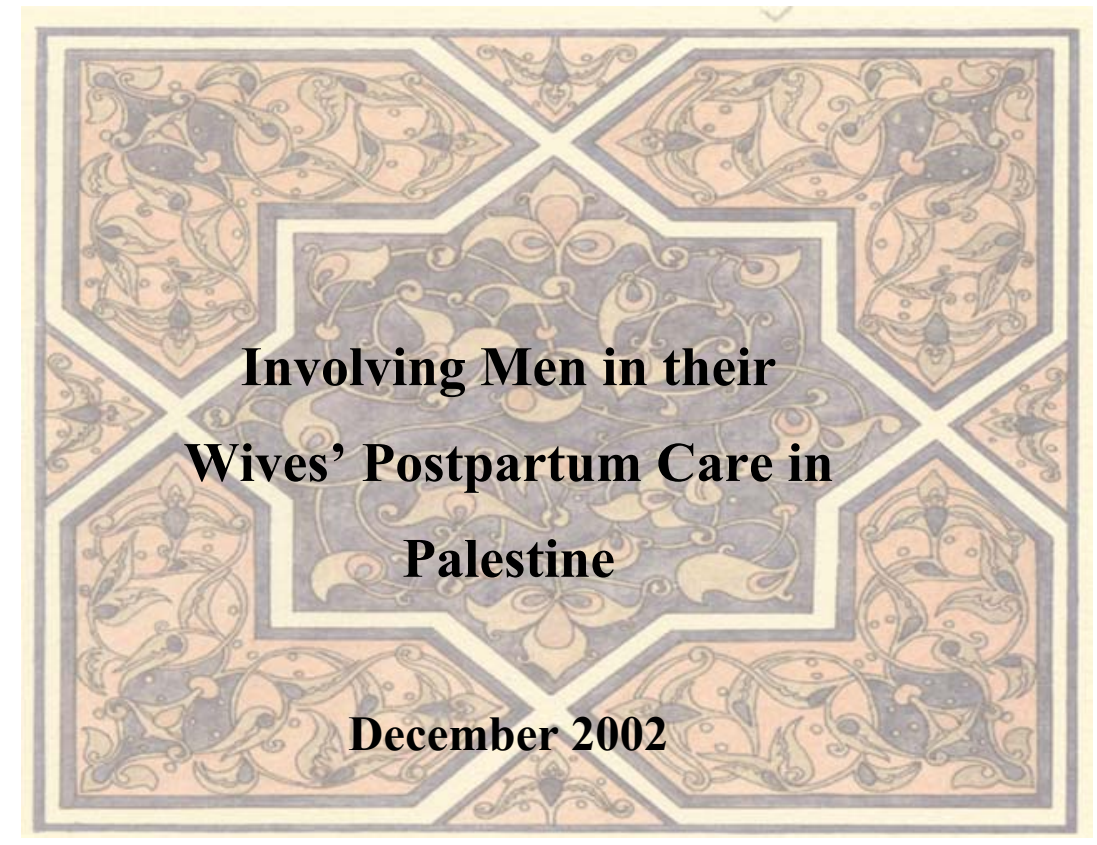

Health, Development, Information and Policy Institute (HDIP) in collaboration with

The Population Council's

Frontiers in Reproductive Health Program

This study was funded by the U.S. AGENCY FOR INTERNATIONAL DEVELOPMENT (USAID) under the terms of Cooperative Agreement number HRN-A-00-98-00012-00 and Project number AI00.16A. The opinions expressed herein are those of the authors and do not necessarily reflect the views of USAID. 


\section{Health, Development, Information and Policy Institute (HDIP)}

Principal Investigator

Research Supervisor

Team Leader

Research Assistant

Field Researchers

Assistant Data Processor

Trainers
Mustafa Barghouti

Lama Jamjoum

Sama Farhan

Jareer Kassis

Rustum Khalaileh

Hamedah Dhedel

Kawthar Abu Hjer

Mufeed Jalghoum

Hadeel Farhan

Khadija Jarrar

Varseen 'Aghabikian Shaheen

Hayan Idrisi

\section{Frontiers in Reproductive Health Program}

Study Monitors

Laila Nawar

Nancy Ali

Dale Huntington

Mahmoud Shaheen

Editor of Final Report

Design and Dissemination

Design and Dissemination Support Geetha Vaithyanathan

Administrative Support
Nahla Abdel-Tawab

Sohini Roychowdhury

Gihan Hosny

Magda Fayek
WANA Regional Advisor

Program Associate

ANE Regional Director

PHP National Manager

FRONTIERS' Consultant

Regional Communication

Officer

Administrative Assistant

Administrative Assistant

Program Administrator 


\section{CONTENTS}

Executive

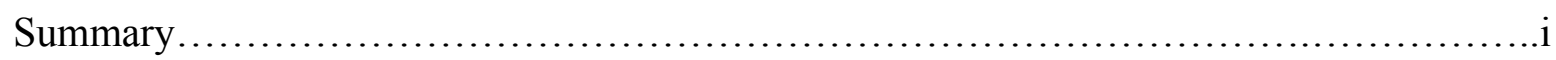

Background.............................................................

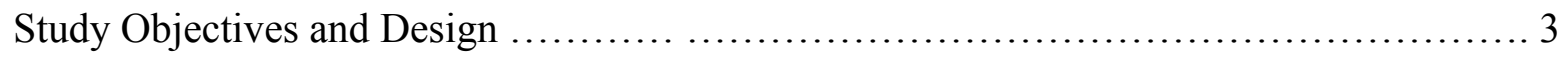

Research questions

Study design and data collection

Obstacles faced in data collection

Findings .8

Respondents' characteristics

Respondents' definition of reproductive health

Men's knowledge and attitudes towards selected aspects of reproductive health

Men's involvement in the reproductive health of their wives

Factors that inhibit/enhance men's involvement

Men's information needs

Suggestions for increasing men's involvement in the health of their spouses

Conclusions and programmatic implications .26

References. .28 


\section{ACKNOWLEDGMENTS}

Health, Development, Information and Policy Institute (HDIP) would like to thank the Population Council's Frontiers in Reproductive Health Program for the technical support provided throughout the conduct of this study. Special thanks are also extended to the management and staff of the Union of Palestinian Medical Relief Committees and Patient Friends Society for their support and cooperation during the conduct of the study.

The hard work and diligence of the research team, and their perseverance in overcoming hardships during data collection are deeply acknowledged. This study would not have been completed without the cooperation and candidness of the interviewed men, women, and health providers who sincerely shared their feelings and insights with the research team. 


\section{EXECUTIVE SUMMARY}

One of the most pressing health issues in Palestine is the low utilization of postpartum services as well as low levels of adoption of family planning methods for birth spacing. Greater male involvement in matters related to reproductive health has been shown in other countries to enhance service utilization as well as the use of contraception. In this pilot study, the state of men's awareness and involvement in women and men's reproductive health care was evaluated in Jenin and Hebron (two areas of the West Bank). The specific objectives of the study were: (a) to identify culturally sensitive mechanisms for approaching husbands and/or influential males in order to increase their knowledge and perceptions about the health care needs of both women and newborns during the antenatal and postpartum period, including family planning, (b) to identify specific program interventions that encourage husbands and influential males to support antenatal and postpartum health care needs for women and newborns, including family planning, and (c) to identify appropriate programmatic interventions that increase male knowledge about STIs and HIV/AIDS prevention practices, including dual protection.

In-depth interviews were conducted with 30 male respondents married to women of reproductive age and six female health care providers (physicians and nurses) from both regions living in the communities served by the USAID-supported Pilot Health Project (PHP). Moreover, focus group discussions were held with women visiting PHP clinics ( $n=4$ groups), men ( $n=2$ groups) and community health workers ( $\mathrm{n}=2$ groups). These interviews and discussions examined the concept of male involvement from the perspectives of men, women and health providers and served to identify culturally appropriate mechanisms for increasing men's participation in matters related to the health of their spouses. Moreover, the interviews assessed the role of social norms as well as other factors that may hinder men's involvement.

The results indicated that men are indirectly involved in several aspects of their spouses' health. Men's participation tends to be limited to the period of pregnancy where a man may 
encourage his wife to visit the clinic for prenatal care, insure that she eats nutritious food and buy all the medications and vitamins that she needs. Men tend not to help with housework during their wives' convalescence but make sure that other women in the family provide such support. The husband and wife make decisions regarding birth spacing jointly, but the use of family planning methods remains the responsibility of the woman.

Men seldom accompany their wives to public clinics but may accompany them to a private clinic, especially when the doctor is male. Reasons given by men for not accompanying their wives include clinic hours conflicting with their work schedules, the "female-dominated" atmosphere at the clinics, and the lack of male providers. The study findings showed that social norms in the Palestinian society do not encourage men's participation in what is considered to be women's health issues. However, a substantial proportion of participants, especially the younger ones indicated that such norms do not keep them from helping their wives.

The study identified several gaps in men's knowledge and/or behavior in relation to reproductive health. First, many of the interviewed men believe that STIs only exist in Western societies and that they are mostly diseases of women. Moreover, men need to learn more about the emotional changes that women experience during pregnancy and after delivery, and to provide more emotional support to their wife during those periods. In addition, women in the study expressed a desire that their husbands better appreciate the advantages of birth spacing.

Changes at the clinic level have been suggested by participants to enhance male involvement in the health of their spouses. The most frequently expressed suggestions included: (a) having an evening shift at the clinics so that husbands could join their wives at the clinic; (b) hiring male health providers to make it easier for men to ask any sensitive questions that they might have; and (c) allowing

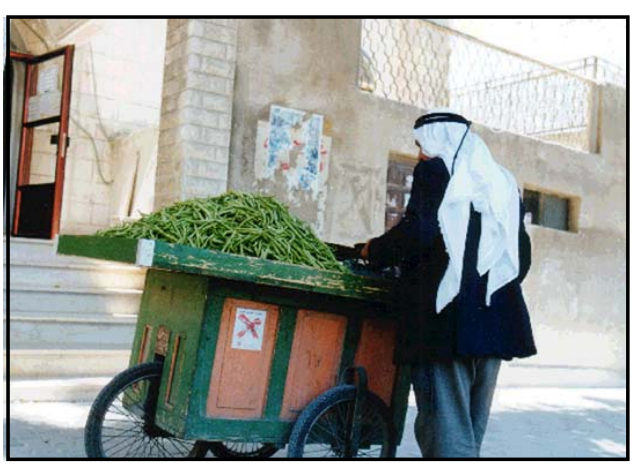
men to be present with their wives and if possible, arranging separate waiting areas for men. 
To increase men's knowledge about reproductive health matters participants suggested a number of mechanisms. One suggestion was to distribute health brochures for couples to read together. Another mechanism was to hold gender-specific seminars at the clinics or other public places. Sending a male health educator to discuss reproductive health matters with men at their homes, however, was not acceptable to most informants.

Incorporating reproductive health information into the school curricula of students at the intermediate and the secondary levels is considered by most participants as both acceptable and potentially effective, on the condition that the information is presented appropriately. Another strategy that was considered acceptable was broadcasting reproductive health information on television so couples can watch together. Preferred formats were soap operas, plays or panel discussions. Participants, however, suggested that such programs be aired late at night so as not to be watched by children and that the material be presented in an appropriate manner.

The above suggestions have important programmatic implications for Palestinian policy makers in the fields of reproductive health, education and mass media. However, caution should be exercised in implementing policies to increase male involvement in matters related to the health of their spouses so as not to infringe on women's autonomy or privacy rights. Women should always have complete and voluntary choice as to when and how to involve their husbands. 


\section{BACKGROUND}

The lack of adequate care for mothers and newborns during the postpartum period is one of the most pressing health care problems in the West Bank and Gaza today. Although most mothers receive some prenatal care, only about 17 percent return for postpartum checkups and few adopt family planning during the postpartum period for spacing births (Ismail and Shahin, 1996). Fertility rates in the West Bank and Gaza are higher in comparison to other countries in the region of similar development status. Married women in Gaza have an average of 6.8 children, while those in the West Bank have 5.5 (PCBS, 2000). Cultural norms favor early marriage and a preference for sons in addition to large family size. Since $46.9 \%$ of the West Bank and Gaza population is less than 15 years old, there will be substantial population momentum, even if birth rates fall during the coming years (PCBS, 2000)

Although current levels of modern contraceptive use are moderate (e.g., 38.8\% in the West Bank and $32.7 \%$ in Gaza), they tend to mask wide variations of use: from over $50 \%$ in parts of East Jerusalem to near zero in isolated areas of the West Bank. More importantly, they mask the fact that contraceptive use is very low among younger, low-parity women and that family planning is generally only acceptable after several births for most families (PCBS, 2000).

In response to the above problems a 28 month Pilot Health Project (PHP) was designed to improve the health status of Palestinian women and children through upgrading antenatal and postpartum services in three areas of the West Bank and Gaza. The interventions of the PHP include a basic package of antenatal and postpartum care services as well as operations research studies aimed at improving the health-giving practices of providers and health-seeking behavior of families. This report describes the objectives, methodology and findings of one operations research study, which has been designed to examine cultural and social beliefs among Palestinian men and women with regard to male involvement in reproductive health of their spouses, particularly with regard to antenatal and postpartum care. 


\section{STUDY OBJECTIVES}

The ultimate objective of this study is to reduce maternal and infant mortality in the West Bank and Gaza through increased involvement and participation of men in reproductive health care practices, particularly antenatal and postpartum care and family planning use.

The study addressed the following short-term objectives:

- To identify culturally-sensitive mechanisms for approaching husbands and/or influential males in order to increase their knowledge and perceptions about the health care needs of both women and newborns during the antenatal and postpartum care period, including family planning.

- To identify practical programmatic interventions that encourage husbands and influential males to support antenatal and postpartum health care needs for women and newborn, including family planning.

- To identify appropriate programmatic interventions that increase male knowledge about STIs and HIV/AIDS prevention practices including dual protection.

\section{Research questions}

The study investigates the following research questions.

1. Are women who receive antenatal services and follow-up postpartum visits interested in special counseling/health education to their husbands (or other male family member) concerning aspects of health care for themselves and their babies, including the need for birth spacing?

2. Are the husbands or other male family members of women who receive antenatal and postpartum care in the NGO clinics willing to receive a home visit by a trained educator to learn about the health care needs of their wives and infants? What are the socio-demographic characteristics educators should have to be acceptable to women and men?

3. What are the informational needs of men regarding maternal and infant health care needs, including family planning, STI, and HIV/AIDS risk reduction. 


\section{Study design and data collection}

This exploratory study investigates the feasibility and acceptability of conducting community outreach activities oriented towards men in the West Bank and Gaza sites of the Pilot Health Project. The study used two qualitative research methods: in-depth interviews and focus group discussions (FGDs) with men (key informants), women who attend antenatal or postpartum services, and service providers (physicians, nurses and community health workers) who are employed in a PHP participating clinic. The number of focus group discussions and in-depth interviews that were conducted with each of the above study groups is shown below.

The study was carried out in the communities of two PHP clinic sites in Hebron, Idna and Ras Al Jourah clinics and eight PHP clinic sites in Jenin. To maximize the amount of new information that was collected by this study and to avoid selection bias, PHP clinic sites in Jenin that were selected for this study were different from those included in the community outreach project for men that CARE International has developed. An assessment was done for clinics to identify those with adequate caseloads for inclusion in the present study.

Data was collected between October and December 2001. Male participants in FGDs and in-depth interviews were purposively selected according to the following criteria: (1) that they have spouses of reproductive age; and (2) they represent different age groups as well as different educational and socio-economic backgrounds. Potential male informants for the study included key members from the community e.g. religious leaders (sheikhs), mayors (mokhtars), school headmasters, political leaders as well as laymen. The help of clinic staff members was sought for identifying potential male respondents. All interviews with men (FGDs and in-depth interviews) were conducted by male interviewers/facilitators while those with women were conducted by female interviewers/facilitators. All interviews were taperecorded after the consent of the respondent had been obtained.

\section{In-depth interviews}

Four skilled social researchers conducted in-depth interviews with clinic staff $(n=6)$ and men in the communities $(n=30)$. Interviews with clinic staff were conducted the clinic, while those with men were conducted at their homes or at public settings such as community 
centers, clubs or informal workplaces. All

interviews were done in

private. Respondents'

informed consent was

sought before conducting

the interviews.
Number of FGDs / In-depth Interviews Conducted

With Each Study Group

\begin{tabular}{|l|c|c|}
\hline Study Group & $\begin{array}{c}\text { \# of In-depth } \\
\text { Interviews }\end{array}$ & $\begin{array}{c}\text { \# of Focus Group } \\
\text { Discussions }\end{array}$ \\
\hline Physicians and Nurses & 6 & - \\
\hline Community Health Workers & - & 2 \\
\hline Women attending PHP services & - & 4 \\
\hline
\end{tabular}

\section{Focus group discussions}

FGDs with men, women and community health workers had from 5 to 10 participants each. Participants in each group were matched on socio-demographic and economic characteristics, while participants in FGDs had different socio-economic and demographic characteristics to insure wider representation of opinions. FGDs with men and women were done separately. Women who were eligible for participation in FGDs were those of reproductive age, while the men were those who were married to women of reproductive age.

Women were recruited for the FGDs during the course of their visit to the clinic. When not enough women were recruited for a focus group discussion on one day, the women were asked to return to the clinic on the following day and were reimbursed for transportation costs. Four FGDs were conducted with women and two with men (one in Jenin and one in Hebron).

As there are relatively few Community Health Workers assigned to each of the PHP clinics (sometimes only one or two), this study grouped all of the Community Health Workers from each of the catchment's areas, Hebron and Jenin, together for one FGD in each site. Informed consent was sought from women, men and community health workers before participation in the focus group discussions.

The guides for the focus group discussions and in-depth interviews were structured around the following domains of inquiry:

- Perceptions of male involvement and acceptability of male involvement to men, women and health providers; 
- Social and clinic factors that facilitate or hinder male participation in postpartum health care and in providing support to mother and child during the postpartum period;

- Informational needs of husbands or male family members with regard to antenatal and postpartum care, family planning and STIs;

- Possible mechanisms for conveying information to husbands about the health of their wives (e.g. brochures, outreach workers, mass media, others); and,

- Health providers' willingness and readiness to provide joint counseling services or lectures for husbands and wives.

\section{Obstacles faced during data collection}

The study encountered several obstacles that constrained its efficient operations and that influenced the quality and substance of the discussions. These are listed here.

a) Political situation: The blockade that was imposed by the Israeli army on the West Bank resulted in a substantial delay in data collection. Fieldworkers were often harassed at military checkpoints and, in one case, a fieldworker was trapped for two weeks in one of the study villages after a siege was imposed on that village.

Participants in that village were initially critical of the study saying that this was not the right time to discuss health and reproduction when the village was under siege.

b) Topic sensitivity: Reproductive health and sex-related topics in general are considered to be sensitive topics in the conservative Palestinian culture. At the beginning of most interviews, fieldworkers sensed a general feeling of discomfort on the part of respondents. Although this discomfort usually dissipated as the interview progressed, there were a few occasions where the interviewee's discomfort continued throughout the interview. Furthermore, there were instances where the interviewees refused to be tape-recorded or where respondents failed to show up at the agreed-upon site for focus group discussions.

c) Privacy of interviews: Most interviews were conducted in interviewees' homes or local clinics where absolute privacy could not always be insured. Interruptions by family members were common which often distracted interviewees. Also, 
occasionally interviewees could not understand or misinterpreted some of the questions.

d) Delays in obtaining supervisors' approvals: In some clinics, approval of senior staff was needed before interviews could be conducted with clinic staff. On some occasions, there were delays in obtaining such approvals, although no interview was prohibited by supervisors. 


\section{FINDINGS}

\section{Respondents' characteristics}

The male participants in the in-depth interviews and focus group discussions were on average 36 years old (range 21 to 51 years), had on average 3.4 children, and education that ranged from 1 to 16 years of schooling. Women who participated in FGDs were on average 32 years old (range 22 to 45 years) with an education ranging from 0 to 16 years of schooling. All providers who were interviewed were female (4 physicians and 2 nurses). The highly educated respondents were grouped together, or interviewed separately, so that the composition of study's focus groups was homogeneous.

\section{Respondents' definition of reproductive health}

Men's definition of reproductive health revolved around the well being of the mother and infant during pregnancy. Several respondents also mentioned birth spacing and family planning as components of reproductive health. The majority of interviewed men and women limited their definition of reproductive health to the ability to reproduce and to the care of the woman during pregnancy and delivery. Other aspects of reproductive health, such as sexual health or RTIs, were rarely mentioned. Moreover, very few respondents mentioned men in their definition of reproductive health but when asked specifically if reproductive health involves men, the majority agreed that it does.

"Reproductive health means that a woman needs to be in good health and able to conceive, deliver and breastfeed her baby so he would get all his needs ... as breastfeeding a baby long enough would reflect on his health in the future and also on the health of the mother" (In-depth interview with a male respondent from Jenin)

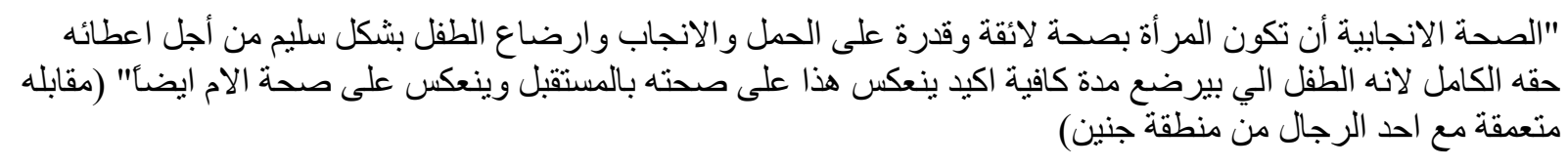


Female health service providers defined reproductive health as inclusive of all the stages of a woman's life and not just pregnancy and childbirth. All that pertains to the lives of men and women, including sexual health, family planning, and healthy pregnancy and proper childcare were referred to as being encompassed by reproductive health.

\section{Men's knowledge and attitudes towards selected aspects of reproductive health}

Aspects of reproductive health knowledge that are described in this section are: health needs of their wives during pregnancy and delivery, available RH services for women, birth spacing and family planning methods, and STIs.

In general, men were knowledgeable of their wives' needs, especially those related to pregnancy. Many cited psychological needs such as moral support, encouragement, and understanding. Others mentioned material needs, such as proper nutrition, reducing demands on her and paying the fees for her clinical visits. One respondent mentioned the importance of abstaining from sex during pregnancy, as it might be painful for the wife and/or risky for the baby. Several respondents also mentioned the importance of continued care for the wife after childbirth.

"To give her emotional and physical support and helping her at home, to be proactive at home so your son or daughter would learn from you and you become a role model for them ..." (In-depth interview with a male respondent from Hebron)

$$
\begin{aligned}
& \text { "الدعم المعنوي و المادي ومساعدتها في البيت، ان يكون ايجابياً في البيت حتى ابنك او ابنتك يتعلمو ا منك وتصبح قدوة }
\end{aligned}
$$

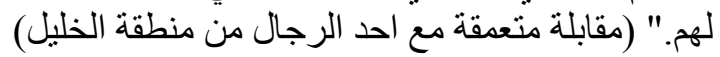

When asked about their knowledge of reproductive health-related services provided to their wives at the local clinics, almost all male participants listed only services provided to their wives during pregnancy, such as weight and blood pressure measurements, blood and urine tests, fetal examination, and health education on care for the woman and the baby. A few men, however, complained about the fact that in some clinics the doctor is available only once a week or that the doctors in those clinics were general practitioners.

"She goes to a specialist (female) regularly for blood and urine tests, to take her blood pressure or (treat) any complications, she also does investigations on sexual aspects and how they affect her general condition ..." (In-depth interview with a male respondent from Hebron)

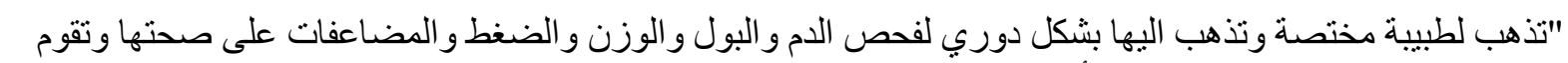

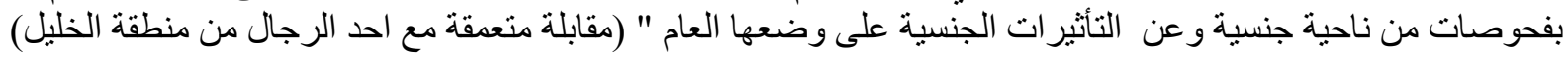


"The doctor comes to the clinic once a week or once every two weeks... the worker at the clinic is not qualified to see the case, she neither gives injections nor medication ..." (FGD with men from Jenin)

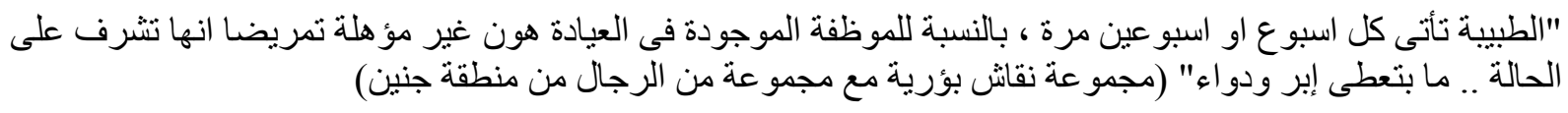

Regarding awareness of family planning methods, men commonly mentioned several family planning methods, such as the IUD, oral pills, injectables and rhythm, while barrier methods were least likely to be mentioned. Initially only few respondents mentioned breastfeeding as a family planning method, but when specifically asked about it the majority said that it is not a reliable method. Attitudes about condoms were negative, with several men associating their use with extramarital sexual relations.

"The available methods are the IUD, the condom for men and there is also the withdrawal method ... the most common is the IUD but it causes problems for some, while for others it does not ... there are also oral pills, but if the woman wants to get pregnant after the pills she faces some problems with her hormones ..." (In-depth interview with a male respondent from Hebron)

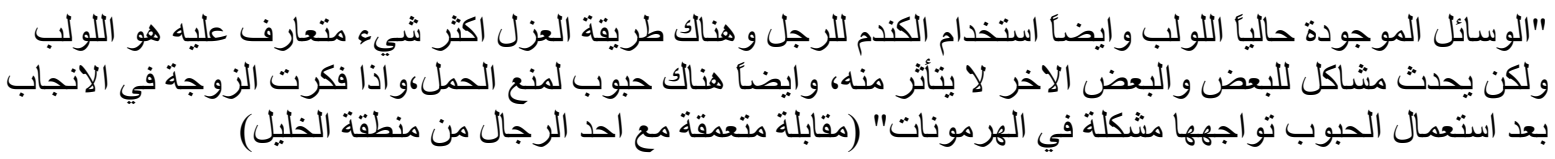

Most of the interviewed men were in favor of birth spacing for the benefit of the mother and child. Men distinguished between birth spacing and limiting the number of children. Birth spacing, according to the male participants, is endorsed by Islam, which recommends that the newborn be breastfed for two years. Birth limiting, on the other hand, is seen as an interference with God's will and hence is not viewed positively by male respondents.

According to participants, birth spacing provides the mother with physical and mental comfort and gives the woman's body a chance to regain its nutrients, shape and vitality. For the child, birth spacing allows the child a longer duration of breastfeeding, better health and more care and love from their parents. Also, birth spacing provides economic relief for the parents. There was some disagreement among participants, however, regarding the most suitable birth interval. While most of them believed that a 2-3 year interval was suitable, some 
of them were concerned that long birth intervals might have negative effects on the mother or the child.

"Planning of births that is to say every 2 to 3 years but not limiting, is good so the baby is breastfed long enough ..." (In-depth interview with a male participant from Hebron)

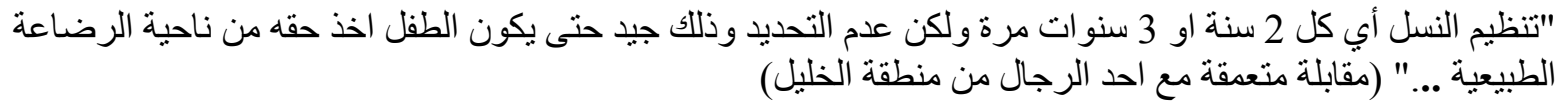

Men's knowledge of sexually transmitted infections was deficient as most respondents mentioned HIV/AIDS, while a few mentioned syphilis and gonorrhea. The most common cause of sexually transmitted infections, according to respondents, was extramarital sex. Other causes mentioned included transfusion of contaminated blood and use of contaminated razor blades for shaving. Other modes of transmission mentioned were lack of personal cleanliness, saliva, air, and unhygienic lifestyles. Interestingly, several male respondents indicated that STIs do not exist in Moslem societies because men do not engage in extramarital sexual relations.

Modes of preventing the transmission of STIs that were mentioned by respondents included use of condoms as well as "legitimate" sex (within the context of marriage), personal cleanliness especially during pregnancy, abstinence from sex when the wife has an infection, routine medical checkups, premarital medical tests and the use of condoms.

"Sexually transmitted diseases are transmitted through sex and other deviant behaviors that exist in the West, but among Moslems such diseases are rare..." (In-depth interview with a male respondent from Jenin)

"من خلال الجنس والانحر افات الموجودة في الغرب ، عند المسلمين حالات نادرة" (مقابلة متعمقة مع احد الرجال من

There is a general impression among men and women that women are more responsible for transmitting STIs than men. Some women respondents complained about being blamed for transmitting such infections to their husbands. It was also mentioned that if a woman were infected, her husband would insist she seeks treatment first. He would only seek treatment if her infection becomes worse or if her condition does not respond to treatment.

"Sometimes a woman would have recurrent RTIs, but when we tell her that perhaps your husband is the source of the infection and we give her a prescription for her husband, she would refuse to let us write his name on the prescription and would say no my husband is not sick..." (In-depth interview with a nurse) 


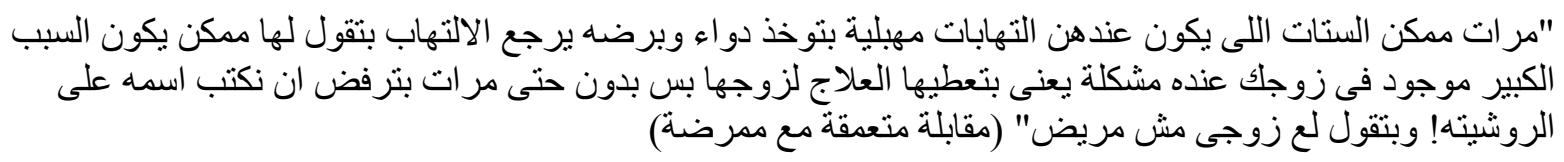

\section{Men's involvement in the reproductive health of their wives}

Most of the men considered their decisions regarding birth spacing to be a form of involvement, and viewed their encouragement of their wives to visit clinics for checkups during pregnancy or asking the wife about the advice that was given to her during the visit as evidence of their participation. A few men indicated that allowing their wives to visit the clinics or providing them with cash needed for such visits is a way of participating. Men, however, were less likely to mention providing support to their wives at times other than pregnancy and childbirth.

"To focus on her nutrition; spacing between pregnancies leads to better health for the woman..." (FGD with men from Jenin)

$$
\text { "التركيز على تغذيتها ، التقليل من الحمل يؤدى الى صحة جيدة للزوجة" (مجمو عة نقاش بؤرية مع مجمو عة رجال من }
$$

More direct forms of male participation, such as helping with housework or looking after the children, were less frequently mentioned by participants. Several men indicated that they would help in lifting heavy objects for their wife or take care not to put many demands on her when she is sick or pregnant. Help with housework and childcare was often provided by other women in the family.

"Regarding housework, she has people to help her like her sister and her daughter and I help her as much as I can ..." (FGD with men from Hebron)

$$
\text { "فى امور البيت لها من يساعدها من اختها او بنتها وانا قدر الامكان اقوم بمساعدنها" (مجموعة نقاش بؤرية مع مجموعة }
$$

The women as well as health providers also confirmed these patterns of male participation. Most of the women stated that their husbands participate during pregnancy by taking extra care in providing comfort for the wife and by encouraging her to do regular checkups. Several women also stated that their husbands participate in decisions related to 
family planning and allow them to space pregnancies. The responsibility for family planning, however, rests almost entirely with the women as most men refuse to use condoms.

"When I am feeling tired and the stove goes out of gas, he would tell me don't cook until I come home and change the gas container for you. He won't let me (do it) when I am pregnant ..." (FGD with women from Jenin)

$$
\begin{aligned}
& \text { " مثلا لما اكون تعبانة وتخلص جرة الغاز بقول لي مطبخيش الا لما اجي و اقيمها هو بحد ذاته بخلنيش لع طول ما انا حامل } \\
& \text { بخلنبش." (مجمو عة نقاش بؤرية مع مجمو عة سيدات من منطقة جنين الغنين }
\end{aligned}
$$

"When I first inserted an IUD and I had problems, he refused to wear (a condom) but then he got convinced and put on a condom because this IUD affected my health ... the husband should participate with his wife ..." (FGD with women from Jenin)

$$
\begin{aligned}
& \text { " ليّا حطيت لولب وصار عندي مشاكل رفض انه يحط (و اقى) بعدين خلص اقتنع وحط هو و اقي لانه هذا اللولب اثر على ئى }
\end{aligned}
$$

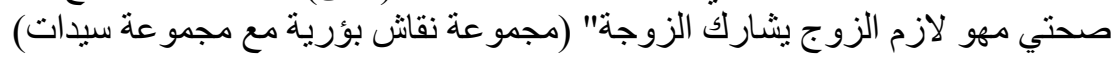

"Whatever we ask women to do (check-ups, investigations, others), the women do them very easily ... had those women not been supported by their husbands they would not have been able to do them, especially that more than half of those women are financially dependent on their husbands ..." (In-depth interview with a female physician)

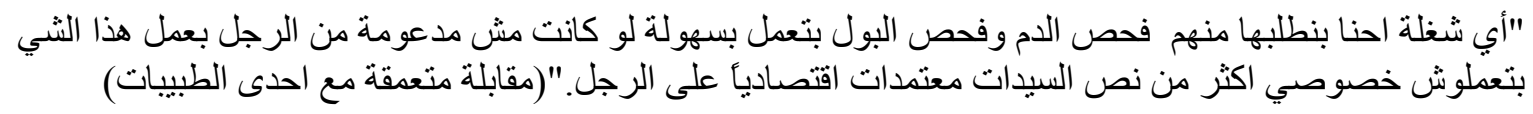

Men seldom accompany wives to health clinics. Women tend to go alone or with another female family member, such as mother or sister-in-law. Many men do not see a need to accompany their wives to the clinic, unless if she is going to see a male physician. Others indicated that they would only go with their wives to a private clinic, where they do not have to wait too long and where there is less crowding. Health providers mentioned that men occasionally accompany their wife to clinics during pregnancy, only to find out the sex of the baby.

"A man who tells you that he goes with his wife each time that she goes to the clinic would be lying to you ... the maternity clinic that we have here has female staff ... if she was going to a male doctor, I would go with her but if they are all women from our village why should the husband go?" (FGD with men from Hebron)

$$
\begin{aligned}
& \text { "اذا و احد بيقول للك انا اذهب مع زوجتى باستمر ار يكون كذاب فيه عندنا عيادة للامومة و مفتوحة وفيها بنات ، ممكن لو لو }
\end{aligned}
$$

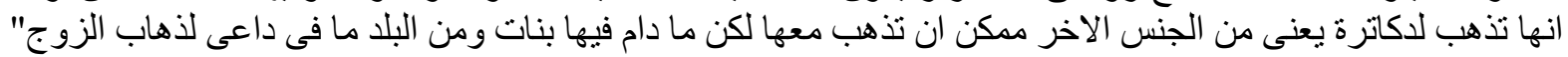

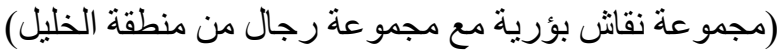

Many respondents referred to a trend towards increased male involvement among the younger generation of Palestinian men. Several providers stated that they have noticed an increase in male involvement in the last five years due to better education and increased awareness. In the interviews, younger men were more likely to express interest and 
willingness for greater involvement in reproductive health matters compared to older men. Some of the older men do not see a need to participate in such matters, especially if their wives have stopped having children.

"This generation is more aware; they do not have one child right after the other ... before they get married they agree on the number of children that they like to have ... the man now uses family planning ... before family planning methods did not exist ..." (FGD with women from Jenin)

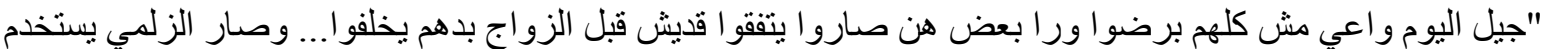

$$
\begin{aligned}
& \text { وسائل تنظيم الاسرة ويعرفو أزمان ، مكنش فيه وسائل تنظيم" (مجمو عة نقاش بؤرية الزواجية مع سيدات من منطقة جنين) }
\end{aligned}
$$

"I am 51 and my kids have grown up; the youngest is now ten; so I do not have the motivation to learn, participate or understand about those issues ..." (In-depth interview with a male participant from Jenin)

$$
\begin{aligned}
& \text { "عمرى } 51 \text { سنة اطفالى كبار اصغر واحد عمره عشر سنوات شايف ما عندى حافز انى اعرف او اثـارك او افهم" (مقابلة } \\
& \text { متعقة مع احد الرجال من منطقة جنين) }
\end{aligned}
$$

\section{Factors that inhibit/facilitate men's involvement in their wife's health}

\section{Social norms}

According to the participants, Palestinian culture views women's health, pregnancy, and childbirth as "women only" issues. Traditionally, society has had a negative image of men who get too involved in women's affairs. A man who accompanies his wife to the clinic or who helps her with housework may be labeled as "woman-controlled". Interestingly, more men in the Hebron area than in the Jenin area mentioned that their social upbringing restricts involvement in matters related to their wife's health. In fact, several men stated that, while such norms exist, they don't prevent them from being involved in their wife's health. A few respondents also mentioned that due to the present political and economic conditions in Palestinian society, men are more preoccupied with political issues and with securing a daily living for their families than with topics such as involvement in the health of their spouses.

"Our upbringing plays a role in preventing participation ... no one draws our attention to such issues, especially our parents ..." (In-depth interview with a male participant from Hebron)

$$
\text { " احد الرجقال التربية لها دور في المنع من المشاركة.... لا احد يلفت نظرنا لهذا الموضوع وخصوصاً اهلنا" (مقابلة متعمقة مع }
$$


"In my neighborhood, people knew that I was helping my wife and they used to see us clean the house and wash clothes together... I never cared about what people would say ..." (In-depth interview with a male participant from Jenin)

$$
\begin{aligned}
& \text { "وكانوا عندنا بالحارة يعلمون انى اشطف مع زوجتى و اعمل معها ويرون ذللك عندما اكنس.. و اغسل و انشرمعا دون ان } \\
& \text { اهتم لأحد" (مقابلة متعمقة مع احد الرجال من منطقة جنين) }
\end{aligned}
$$

Religion is seen as a factor that promotes male involvement in reproductive health in contrast to local cultural norms that inhibit male involvement. The majority of interviewed men and women viewed Islam to be in favor of male responsibility and involvement in matters related to promoting the health of their wife and children. Some participants quoted sayings of the Prophet in which he urges men to look after their families, while others mentioned that there is nothing wrong with helping one's wife since the Prophet himself reportedly helped his wives with housework.

"The right thing for a man to do is to look after his family (wife and kids) as the Prophet said: A noble man is one who is kind to them (his wives), while a cruel man is one who humiliates them ..." (In-depth interview with a male respondent from Hebron)

$$
\begin{aligned}
& \text { "و الأنسان افضل شىع له ان يهتم بأهله (زوجته و او لاده) ويقول عليه السلام (ما اكرمهن الا كريم ، وما اذلهن الالئيم" } \\
& \text { (مقابلة متعقة مع احد الرجال من منطقة الخليل) }
\end{aligned}
$$

Education was believed to be associated with increased male involvement. While people with more education would consider male participation a positive thing, less educated people would consider male participation in matters related to reproductive health unusual.

"People differ on that matter, the more aware would view it positively while those with limited awareness or education, let's say, would be surprised to see a man who is knowledgeable of all the details on reproductive health. They would consider it strange, even uneducated women would think it is strange ..." (In-depth interview with a male participant from Jenin)

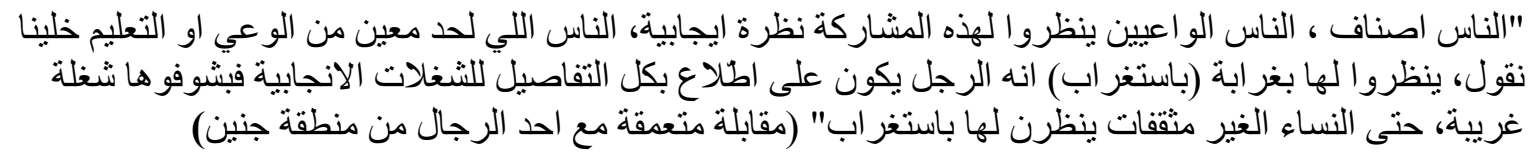

\section{Clinic-related factors}

There were several clinic-related factors, which according to respondents hinder men's participation in reproductive health. Most of the men interviewed complained that the hours of operation at the clinics $(9: 00-2: 00 \mathrm{pm})$ were incompatible with their work schedules, 
which usually extend until 4:00 or 5:00 pm. Others complained that the clinics were too small and were often crowded with women, with no separate sections for men in the waiting area. Moreover, several respondents mentioned that some clinics do not allow men to be present with their wives, a point that was confirmed by health providers.

"I return home from work at 7:00 p.m., so there is no way for me to go except on holidays..." (In-depth interview with a male participant from Jenin)

" ارجع الى البيت الساعة 7 (مساء) فلا يوجد أب مجال الا في العطل الرسمية." (مقابلة متعقة مع احد الرجال من منطقة

"The atmosphere at the clinic is female dominated and the medical staff is only qualified to provide services for women; they would even look with astonishment at a man who is accompanying his wife to the clinic ..." (In-depth interview with a male respondent from Hebron)

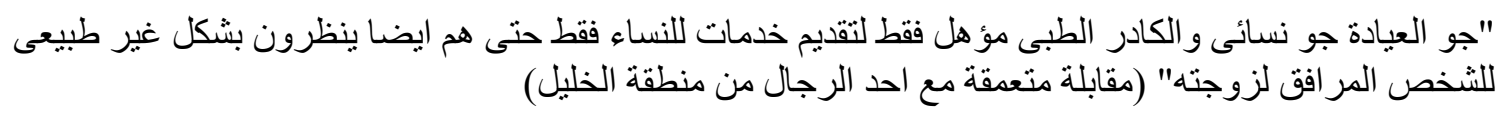

It was also mentioned that clinics do not have services for promoting male

involvement, e.g. joint sessions for husbands and wives or lectures that would address men's reproductive health issues. Some men stated that the personnel at the clinics are not qualified to deliver reproductive health information to men, or that the staff are all female which makes it embarrassing for men to ask questions.

"Health education services and reproductive health services but they are very limited and only for women ... it is important that men and women go to the clinic together because there is a lot that we do not know ..." (In-depth interview with a male participant from Hebron)

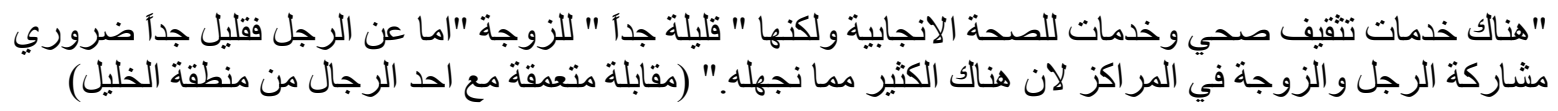

Health care providers admitted that at present, the opportunities for combined men and women health care activities or services were limited. Although most of the health care providers stated that their clinics had qualified personnel, they mentioned unsuitable hours of clinic operation, discomfort or shyness in dealing with husbands, and that the cultural norms do not permit such interactions between female health providers and husbands as reasons for not providing joint services for men and women. 
"It would be very difficult for me to explain to a man if he has a health problem, or for a doctor or a health worker to bring the men and women together in one lecture... this is unacceptable in our villages ..." (In-depth interview with a female physician)

$$
\begin{aligned}
& \text { "من الصعب جذا ان اشرح للرجل اذا كان يعانى من مشكلة وان تقوم الطبيبة او العاملة الصحية بجمع الرجال وال والنساء } \\
& \text { وتحكى لهم وتقدم خدمات مشتركة فهو غير مقبول فى قرانا" (مقابلة متعمقة مع احدى الطبيبات) }
\end{aligned}
$$

\section{Men's information needs}

When asked about their informational needs a few men stated at the outset that they had all the information they needed and were not in need of any more information. However, when pressed with specific issues such as the benefits of birth spacing or breastfeeding, they stated that they would benefit from more information and education. Topics which men said they needed more information on were: physical and emotional care of the mother and the newborn, characteristics of a normal pregnancy, physical and emotional changes in the woman's body during and after pregnancy, optimal frequency of breastfeeding, the most suitable birth intervals, advantages and disadvantages of different family planning methods.

"How intercourse during pregnancy affects the woman psychologically and how it affects you ... also before delivery what are the factors that affect the baby's health and intelligence ..." (In-depth interview with a male respondent from Jenin)

$$
\begin{aligned}
& \text { " الجماع خلال الحمل شو بيأثر نفسياً على المر أة وممكن انت شخصياً و قبل الو لادة ما هي الاشياء التي تؤثر بصحة } \\
& \text { الطفل بالذكاء و العقلية؟" (مقابلة متعقة مع احد الرجاء الرجال من منطقة جنين) }
\end{aligned}
$$

Women voiced somewhat similar topics, which they wished that their husbands would learn about. First, women wanted their husbands to appreciate the physical and emotional changes that women go through during pregnancy and after delivery, and requested that husbands provide them with more emotional support and put less demands on them during that period. They also wished that their husbands' support would extend beyond the period of pregnancy and that they share some of the childcare responsibilities.

"When I first got married he had no idea about the psychological changes a woman goes through during pregnancy ... and I was not aware of what happening with me either ... I was very tense I did not want to have sex with him, and this caused many problems between us ..." (FGD with women from Hebron)

$$
\begin{aligned}
& \text { "أنا فى البداية اول ما زوجت ، ما كانش عنده اى فكره عن مسألة التغيرات النفسية، يعنى منوقع انه يتغير شكل المر أة أنيا }
\end{aligned}
$$

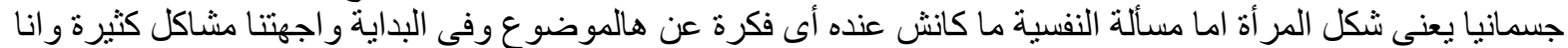

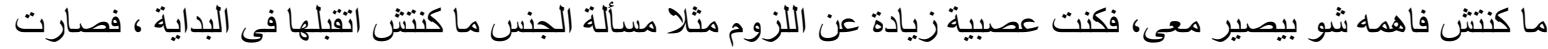

$$
\begin{aligned}
& \text { مشاكل كثيرة" (مجمو عة نقاش بؤرية مع مجمو عة من السيدات من منطقة الخليل) }
\end{aligned}
$$


"They do not appreciate ... when the children start crying and screaming, I tell him if you want to have children you must share the responsibility ..." (FGD with women from Jenin).

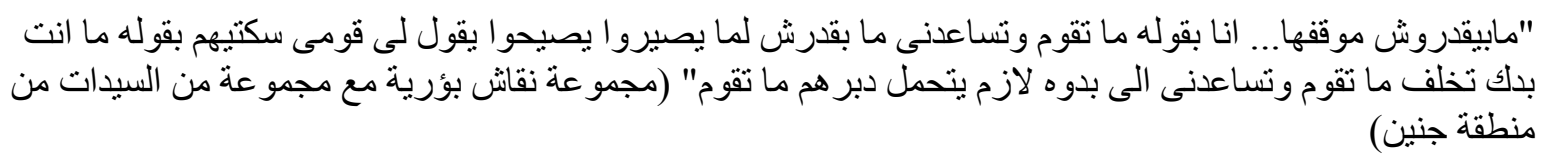

Another area highlighted by women is their need for their husband's support with family planning. Despite the highly positive attitudes towards birth spacing that were expressed by men, many women complained that their husbands still want them to have one pregnancy after the other. Women said they need rest between pregnancies, and that they would like their husbands to realize the advantages of breastfeeding and not be concerned about the woman's breast losing shape due to breastfeeding. Some women also wished that their husbands would participate more actively in family planning by using condoms.

"I wish my husband would understand that I need to have some spacing between pregnancies, because I want my body to recover ... I want to regain my health, because as you know when a woman has a child every year her body loses many things, blood, calcium and others ..." (FGD with women from Hebron)

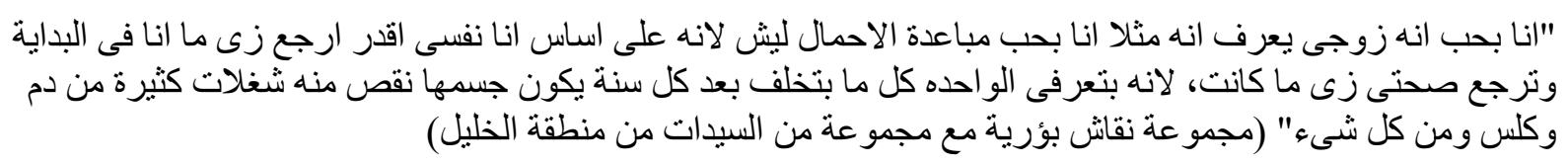

Women were divided regarding their attitudes about being accompanied by their husbands' to the clinic. Women from Jenin mostly preferred to visit the clinics alone, whereas those in Hebron preferred that their husbands accompany them. Some health workers recounted incidents where a husband's presence at the clinic was awkward for the wives themselves or for other women, e.g. a man refusing to have his wife undergo a vaginal exam or other women feeling uncomfortable at the presence of a man at the clinic.

"I prefer to go alone, that way I am free; if someone goes with me I won't be at ease, especially when it comes to personal matters ..." (FGD with women from Jenin)

"لع انا لوحدى بوخذ حريتى اكثر لانه الو احد يتقيد لما يكون حدا معهد وخاصة فى الامور الثخصية" (مجموعة نقاش بؤرية مع مجمو عة من السيدات من منطقة جنين)

"For me I like my husband to go with me wherever I go, to the doctor's or otherwise ..." (FGD with women from Hebron) 


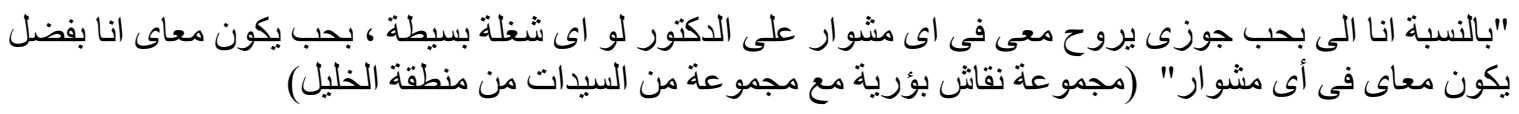

Health providers agreed with the women on their information needs. Health providers particularly emphasized the need for educating men on the psychological changes that women go through during pregnancy and after childbirth, family planning methods and sexually transmitted diseases.

"Awareness of the psychological changes is very limited ... sometimes the woman would experience postpartum depression when she would refuse to eat, breastfeed the baby and even hate the baby ... many of the

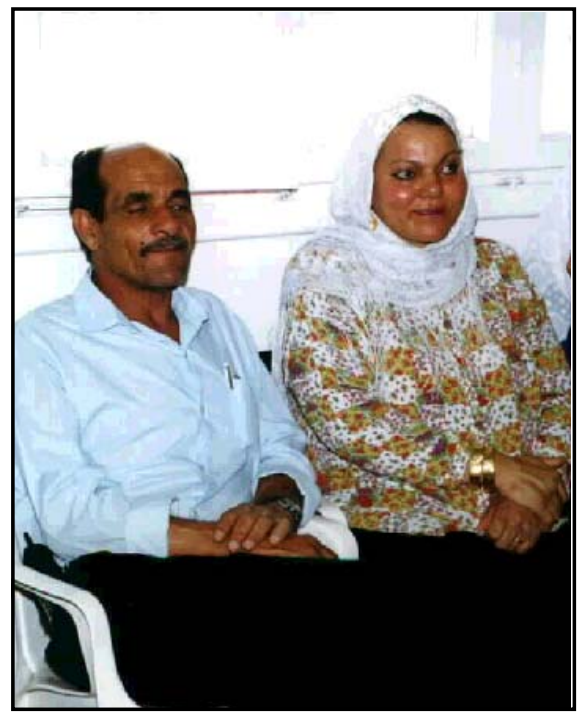
husbands are not aware of this problem ..." (In-depth interview with a female physician)

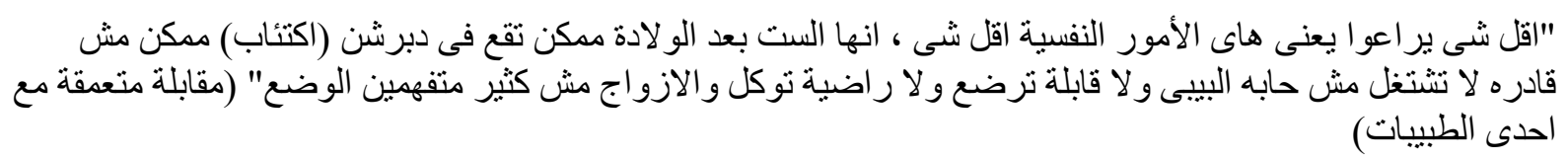

\section{Suggestions for increasing men's involvement in the health of their spouses}

\section{Changes in clinic operations}

Male respondents suggested the following changes in the clinics to increase male involvement: increasing the number of clinics so men do not have to wait too long when they come with their wives; having evening hours at current clinics so men can go with their wives after work; and increasing space in clinics to allow for the presence of men. Some men also suggested hiring male doctors and nurses so men won't feel embarrassed to ask them questions about sensitive matters. Some participants also suggested introducing an appointment system to reduce waiting times and encourage men to accompany their wives.

"Building larger clinics and hiring staff who is qualified to give seminars ... also having an evening shift in addition to the morning one ..." (In-depth interview with a male participant from Hebron)

$$
\begin{aligned}
& \text { "توسيع العيادات واحضار كادر مؤهل لاعطاء دور ات للناس ايضأ عمل فترة مسائية بالاضافة للفترة } \\
& \text { الصباحية" (مقابله متعقة مع احد الرجال مئل من منطقة الخليل) }
\end{aligned}
$$




\section{Lectures}

Most of the men indicated a preference for having separate lectures for men and women. Only a few stated that they would be willing to receive such education with their wives if the content and nature of participants permit. For notification about up-coming lectures, most male respondents indicated a preference for being contacted directly in person or by telephone two to three days before the lecture. A few respondents preferred to be contacted through their local clinics or their wives.

"If it were at home, I would receive this information with my wife but if it is at a health center and includes other men, I prefer to go alone... I do not prefer to take my wife to joint lectures with men ..." (In-depth interview with a male respondent from Hebron)

"اذا فى البيت افضلها مع زوجتى ، لكن اذا فى مر اكز وتخص الرجال افضل اخذها معهم (بدون الزوجة) ، اذا كانت

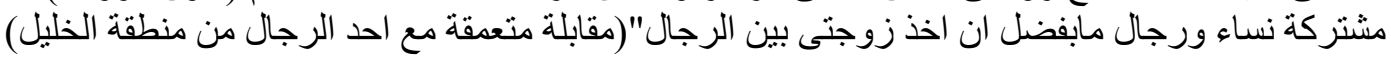

Health workers were reserved about giving those joint lectures, indicating that any joint education should be done outside of regular office hours or in a separate room. While almost all interviewed health providers claimed that they were qualified to give joint services, very few of them said they would be willing to do so. Several providers indicated that the men would not accept to be given such information by a female health provider, while others admitted that they themselves would feel uncomfortable discussing such issues with men. Some providers indicated that they are willing to give joint counseling to a husband and wife together, but not to a group of men and women together or to men alone.

"It would be difficult for me to convey the exact information, at the beginning it would be embarrassing but then I might get used to it ..." (FGD with female health workers from Hebron)

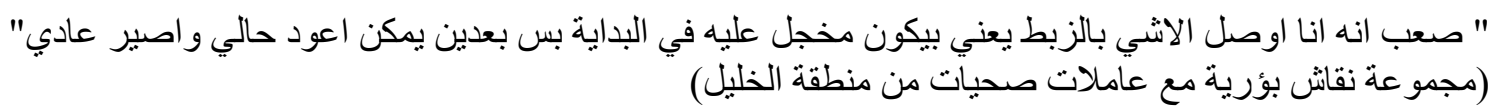

\section{Reaching men through their spouses}

Participants were asked about the acceptability and feasibility of reaching men through their spouses. Several of the men indicated that their wives can help them become more involved in matters related to their health by conveying all the necessary information to 
them. Thus increasing the woman's knowledge would eventually reflect on her husband. However, some participants expressed concerns that the wife may not be able to convey the information accurately to her husband or that some husbands may not accept information given to them by their wives.

"The more you give the wife information on the concept of reproductive health, her health and that of her baby after delivery, during childhood and adolescence, this would reflect positively on her husband ..." (In-depth interview with a male respondent from Jenin)

"كلما زادت معلومات الزوجة حول مفهوم الصحة الانجابية ومفهوم صحتها وصحة جنانينها وما بعد الجنين فترة النفاس و الاطفال و المر اهقة ينعكس بالايجاب على زوجة الزولها (مقابلة متعمقة مع احد الرجال من منطقة جنين)

"This would depend on the woman's level of education, if the woman is not well educated her understanding of health issues would be limited ..." (In-depth interview with a male respondent from Jenin)

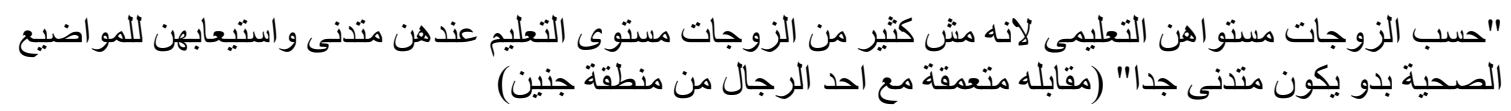

\section{Brochures}

Most of the men indicated that receiving brochures about reproductive health matters would be very useful. The women were also in favor of their husbands receiving such brochures, since they regard today's generation as educated and capable of reading and understanding such information. They would benefit from experts' opinions. Female health workers also saw a benefit to this since it would enable men to find answers to questions, which they would be shy to ask otherwise. A few health providers however, voiced concern that some men may not be interested in reading brochures. It was suggested that the titles of such publications be eye catching to raise the curiosity and interest of men.

"Sending men brochures would be very helpful because men sometimes do not like to be confronted with their problems or information needs so when they read about them they would respond better ..." (In-depth interview with a female physician)

$$
\begin{aligned}
& \text { "كثير كثير ... مجدى لانهم مرات كثير ميحبوش يو اجههم بالشغلة الناقصة عندهم او المشكلة اللى عندهم لما يقر أو ها او }
\end{aligned}
$$

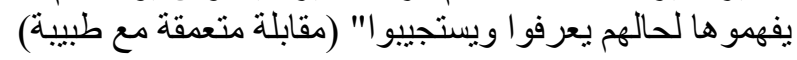

\section{School health education}

When asked about the feasibility of teaching reproductive health topics in schools, the majority of respondents supported including reproductive health awareness as part of the 
school curriculum. The two conditions mentioned by respondents were that this material be taught in the preparatory and secondary grades so that students would be old enough to absorb the material and that the subject matter is presented in a culturally appropriate manner.

Several respondents regarded school as an ideal venue for teaching youth about these topics, especially when they do not obtain advice or correct information from their parents. Very few respondents expressed concerns that including such topics in the school curriculum may be inappropriate at such an early age.

"It is very important at the intermediate level because we have early marriage and I think the boys and girls should be aware of such matters ... I think talking about it would be good ..." (In-depth the interview with a male respondent from Hebron)

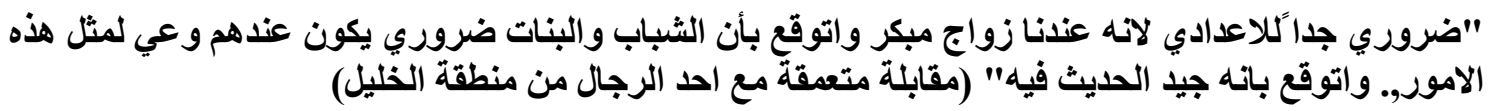

"This won't work because school children are at the stage of adolescence, this would be more suitable for a husband and wife but not for students ... this would corrupt society" (In-depth interview with a male respondent from Hebron)

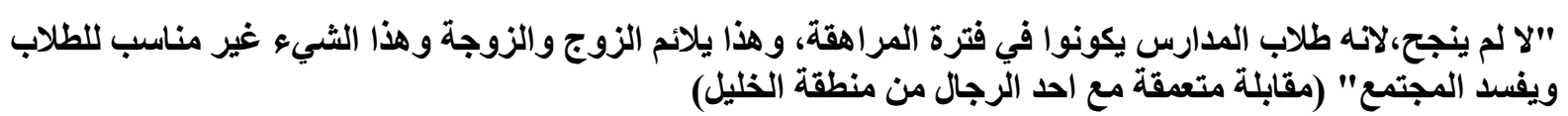

\section{Education at mosques}

A minority of respondents supported the idea of providing reproductive health education in local mosques arguing that the mosque is a credible source of information for many people and thus messages given through the mosque would be well received.

"I think mosques are quite popular in local communities, since people are more likely to accept what the Sheikh says ..." (In-depth interview with a male participant from Hebron)

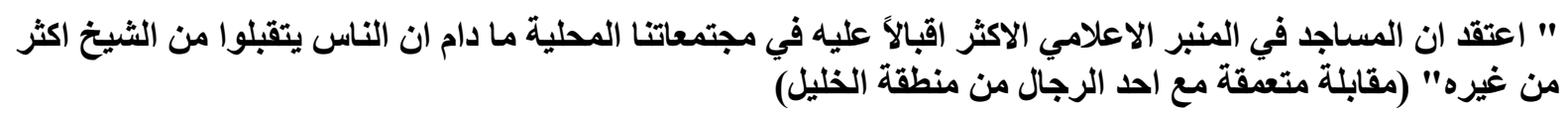

However, other participants stated that health providers are better qualified than religious leaders for discussing such topics as pregnancy, childbirth, sexual problems, and family planning methods. Some participants however, mentioned that the mosque can play a role in informing men about their religious duties towards their wives and children and encouraging them to get more involved. Also, through the mosque men can be informed about upcoming lectures, which then can be held elsewhere. 
"If a Sheikh gives a lecture at the mosque this would only solve part of the problem because he would only deal with the religious perspective and won't cover other aspects of the topic ..." (In-depth interview with a male respondent from Hebron)

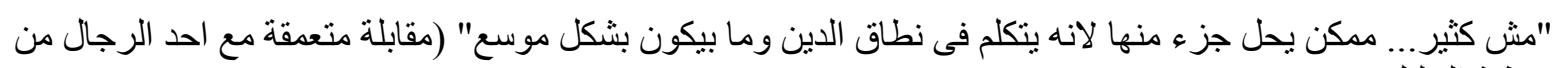

منطقة الخليل)

\section{Community health educators}

Male participants were divided on their acceptance of receiving a health educator at home to talk to them about matters related to their wives' health. While some of them believed that this would be convenient and useful, others believed that it would be embarrassing to discuss such issues with a stranger, especially with the wife and children around the house.

"I do not prefer to receive a health educator at home; I would rather go to lectures at the health center, you can not discuss such issues with the children around... " (In-depth interview with a male respondent from Hebron)

$$
\text { "لا افضل ـ لكن افضل انظل يكون ندوات فى مر اكز ـ ما بتقدر تتكلم فى هذا الكلام امام الأو لاد" (مقابلة متعمقة مع أحد }
$$

"Receiving a health educator at home would be very helpful, because he would be talking to you personally and not to ten other people so I can understand everything ... " (Indepth interview with a male respondent from Jenin)

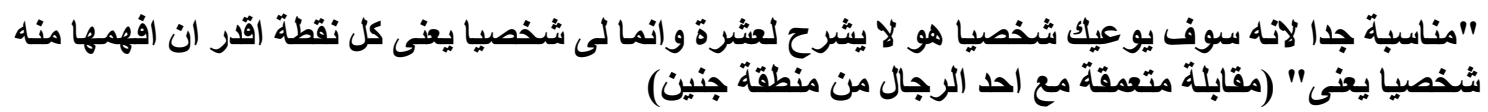

Most of the women and health providers were opposed to the idea of sending male health educators to the men at home. Several women suggested that their husbands might find this procedure insulting. Moreover, some health providers were concerned that sending this educator to particular homes could raise the curiosity of other people in the community with possible negative consequences for the couple. The majority of women and health providers preferred that education take place in a lecture form at the clinic or at a public place so the men would not feel intimidated.

"Receiving a health educator at home would be unacceptable ... it is good to have the men together in a lecture so that a man won't feel stupid if someone visits him at home and explains things to him ..." (In-depth interview with a female physician) 
"We are in an Arab society. A man would not accept that another man talk with him about such things ... you probably notice that a man would not call his wife by her first name before strangers, ...for example my husband would call me Ahmed's mother or Hajja ..." (Focus group discussion with women from Jenin)

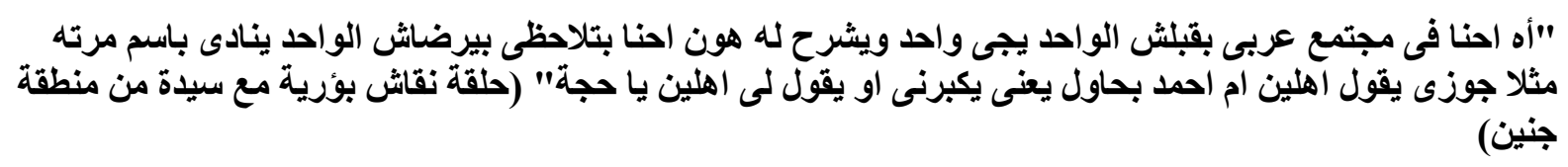

For those participants who approved of the idea of a community health educator, the characteristics of the ideal educator according to them were that he be a male, since he will be dealing mostly with husbands, that he is socially acceptable, convincing, and that he be knowledgeable about medical as well as religious matters. Some respondents required a university degree, while one mentioned that he prefers him to be a doctor. The age of the educator was not an issue to most respondents, although most of them preferred him to be between 20 and 40 years of age.

\section{Television}

The last venue that participants were asked to assess was the suitability of television as a medium for reaching men with reproductive health information. According to the great majority of respondents from the three study groups, broadcasting television messages that promote awareness about reproductive health would be an attractive idea. There was a general belief that television is a powerful medium for raising public awareness.

"Me personally, I attended T.V. programs and benefited from them a lot. I had never thought about those issues before; even if I had asked my parents they would not answer perhaps out of ignorance or shyness because they regard these as taboos ..." (In-depth interview with a male respondent from Hebron)

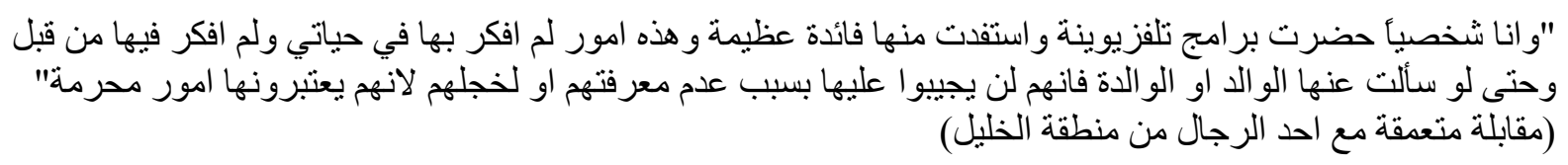

Very few participants opposed the idea because broadcasting such sensitive information on television would not be appropriate, especially when children are watching. But there was a general agreement among participants that any material on reproductive health be presented in decent manner and late at night so the husband and wife can watch it 
together while the children would be asleep. Preferred formats for presenting reproductive health information on television were panel discussions that include experts from different fields, plays or soap operas. The vast majority favored airing such programs on local Palestinian channels, while only a few suggested other Arab channels or satellite channels.

"It could be helpful and not helpful; if the husband and wife are watching alone it could be helpful, but if it is a family gathering it would not be helpful and would be embarrassing..." (In-depth interview with a male respondent from Hebron)

"يعني مفيد ومش مفيد اذا كان الزوجين مع بعض ولوحدهم يفيد لكن اذا بيكون جو عائلة لا يفيد ويكون مخجل" (مقابلة

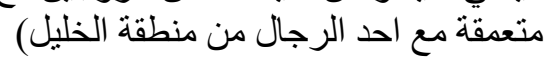




\section{CONCLUSIONS AND PROGRAMMATIC}

IMPLICATIONS

The ultimate objective of this operations research is to reduce maternal and infant mortality in the West Bank and Gaza through increased involvement and participation of men in reproductive health care. An additional objective is to improve the health giving practices of providers and health-seeking behavior of families by involving husbands in their wives' postpartum care in Palestine. The short-term objectives of the present study were to identify culturally sensitive mechanisms for approaching husbands to increase their involvement in the reproductive health of their spouses, as well as practical programmatic interventions that would encourage husbands' involvement and would increase male knowledge about STIs and HIV/AIDS.

The present study showed promising results with regard to increasing the involvement of Palestinian men in matters related to the reproductive health of their spouses. First, husbands already participate in several aspects of their wives' health so there are behaviors that can be reinforced, and expanded upon. Second, although existing social norms do not encourage men to get involved in what is considered to be women's issues, many husbands do not abide by those rules and continue to provide support to their wives. In this instance, religious interpretations support male involvement. Third, there is a trend of increased involvement in matters related to reproductive health, especially among the younger and better educated generation of Palestinian men, many of whom are interested in learning more about reproductive health and are willing to provide more

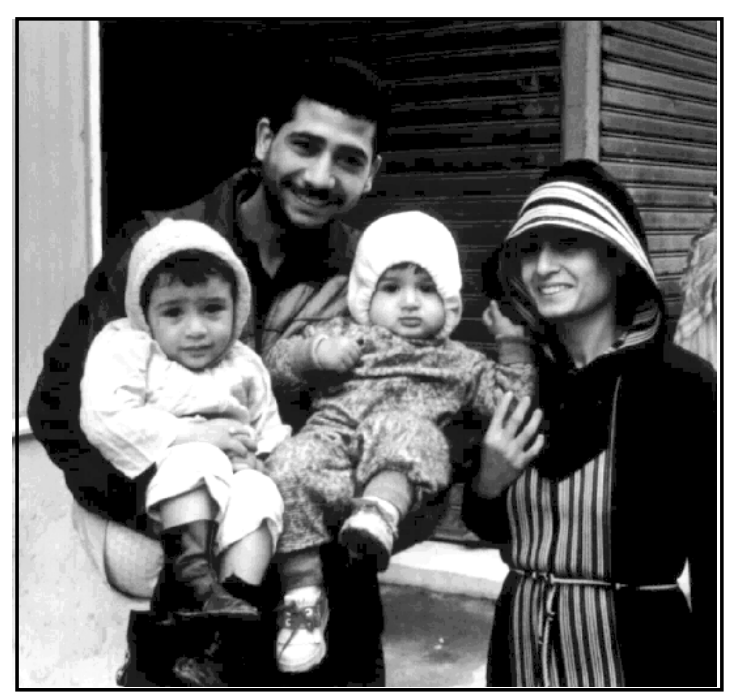
support to their wives.

There is room for greater husband involvement, however. Husbands need to become more understanding of their wives' physical and emotional needs, especially during pregnancy and after delivery and to participate more actively in addressing those needs. Also, husbands need to appreciate the advantages of birth spacing for the mother, the child and the 
entire family and to learn more about different family planning methods, including condoms. Husbands need to understand that STIs do exist in Moslem societies and that both men and women can contract those diseases through a variety of means, including sexual intercourse. More information needs to be given regarding primary prevention, and treatment of infected partners.

The health clinic has a pivotal role to play for increasing husbands' involvement in the health of their spouses. If clinics establish evening shifts, e.g. 6:00 - 8:00 p.m., many husbands would be encouraged to accompany their wives for antenatal or postpartum visits. Moreover, health providers should be more accepting of husbands' presence at the clinic, and should even encourage women to bring in their husbands in subsequent visits. A male doctor or nurse should be present during the evening hours to answer any sensitive questions that husbands might have, while the current staff of female health providers should receive training on providing joint counseling for couples. More space is needed in some of the clinics to accommodate the presence of husbands without causing undue embarrassment to other women or to the husbands themselves.

The clinic can also increase husbands' knowledge of reproductive health matters through providing brochures and through organizing lectures for men. The brochures should address commonly asked questions in relation to different topics, e.g. pregnancy, postpartum period, family planning, others, and the information should be presented in a simple and attractive manner. These brochures could be handed out to women who come to the clinics for prenatal or postpartum care so they can pass on to their husbands. The lectures should be organized for men and women separately. For men the speaker should be a male health educator or preferably a doctor who is well versed on medical as well as religious aspects of reproductive health. To ensure a high attendance, the men in the community should be notified about the lecture two to three days in advance either through direct contact or through the mosque.

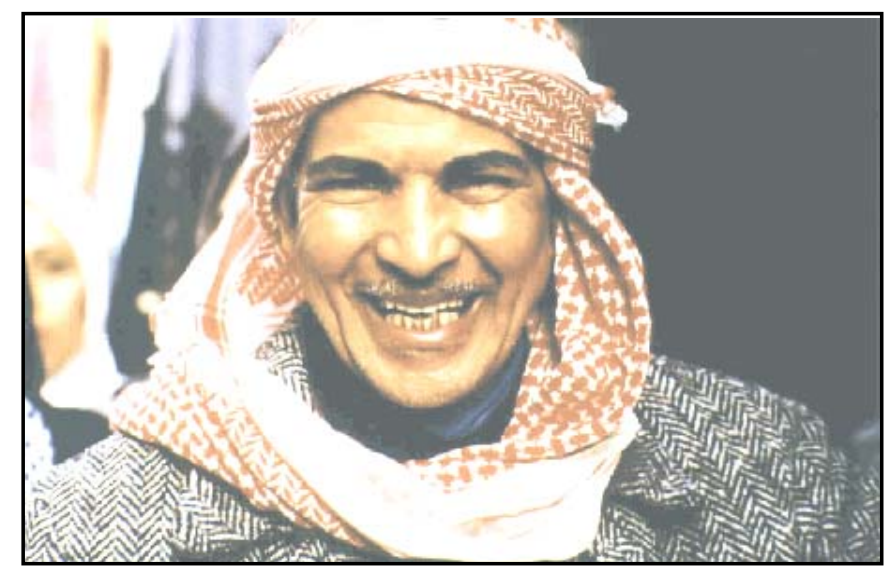

Other institutions like the mosque or church, mass media and school can also play a role in promoting husband's involvement. The mosque or church can motivate men to share responsibility and can address religious concerns as they 
relate to reproductive health. Television can further reinforce concepts of male participation as well as provide information on salient reproductive health problems. This information should be broadcast in a culturally sensitive manner and preferably late at night so as not to be watched by the children. It should also be presented in an attractive format such as a soap opera or a play to maintain people's attention.

A more lasting change in public attitudes and practices would be achieved if reproductive health messages were incorporated into the school curricula of students at the intermediate and secondary levels. By inculcating the concepts of male responsibility and sharing among students at such a young age, we can insure a future generation of well-informed and responsible husbands and fathers. A word of caution needs to be made about the desirability and effectiveness of spousal involvement. Greater husband's involvement is not a universal demand for all women, nor is it a panacea for all the health problems of Palestinian women. Some women may not prefer to involve their husbands in certain aspects of their health care. Others may not benefit, but may even lose, when their husbands get too involved in matters related to their health. Procedures for protecting women's autonomy and privacy should be therefore established so that women have complete and voluntary choice as to when and how to involve their husbands. Under no circumstances should women be pressured to bring their husbands to the clinic, nor should giving information to men become a substitute for giving information or counseling to women.

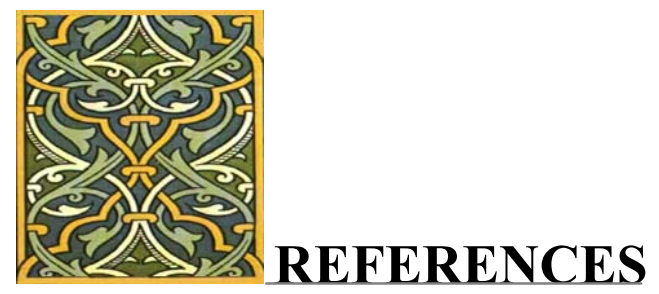

Isamil, N. \& Shahin, M. 1996. Family Planning and Women's Reproductive Health Survey in the West Bank. Ramallah, Palestine: Planning and Research Center.

PCBS (Palestinean Central Bureau of Statistics). 2000. Health Survey 2000- Main Findings. Ramallah, Palestine: PCBS. 


\title{
Outreach Linkages with Public Hospitals to Promote Postpartum Care
}

\author{
Laila Nawar, Ph.D., Dale Huntington, Sc.D., \\ Mawaheb El-Mowelhy, MPH, Ahmed Ragab, Ph.D. \\ Nancy Ali, MPH
}

October 2002

This study was funded by the U.S. AGENCY FOR INTERNATIONAL DEVELOPMENT (USAID) under the terms of Cooperative Agreement number HRN-A-00-98-00012-00 and Project number AI00.16A. The opinions expressed herein are those of the authors and do not necessarily reflect the views of USAID. 


\section{CONTENTS}

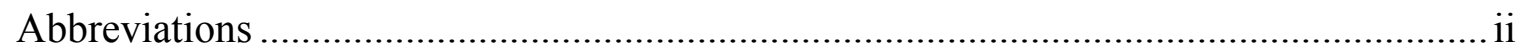

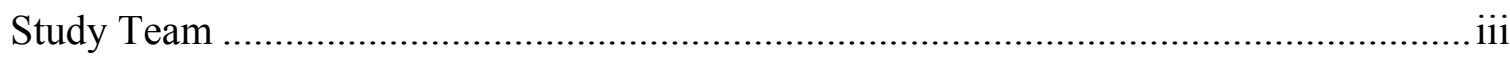

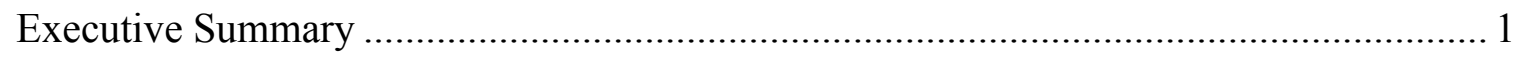

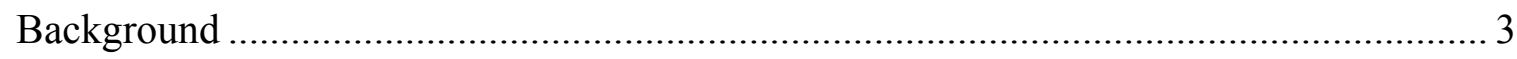

Study Objective

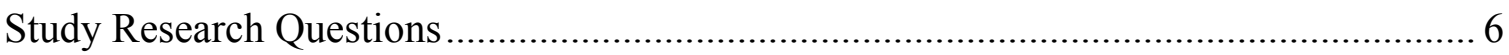

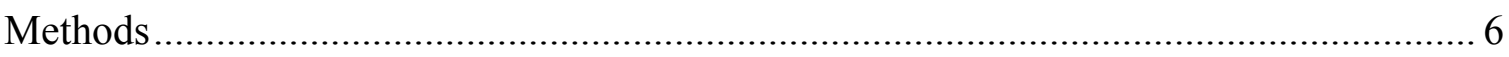

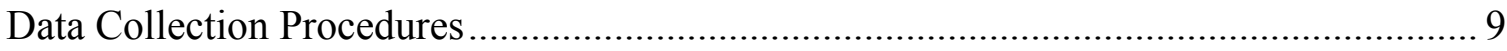

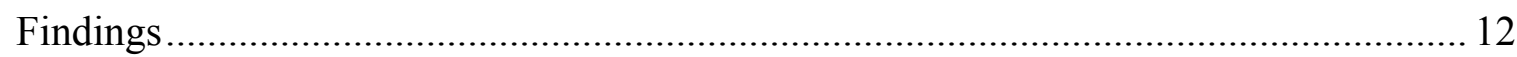

Section 1: Managerial/Administrative Staff Perspectives

Section 2: Health Providers' Perspective

Section 3: Women's Perspective

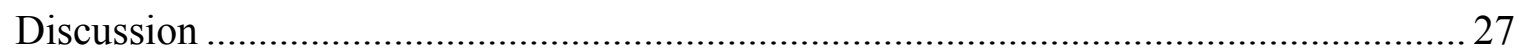

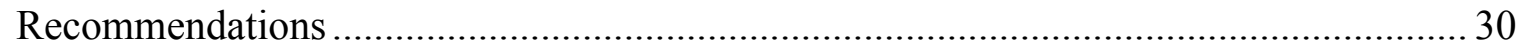

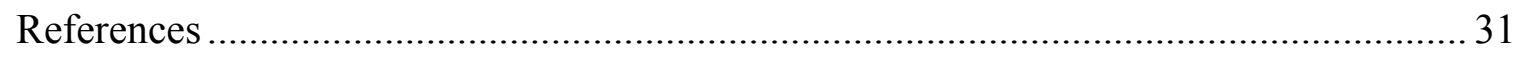

\section{LIST OF TABLES}

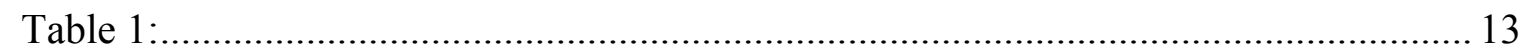

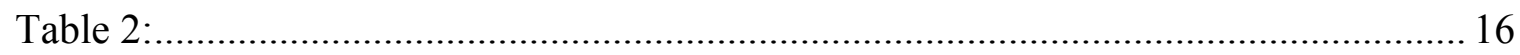

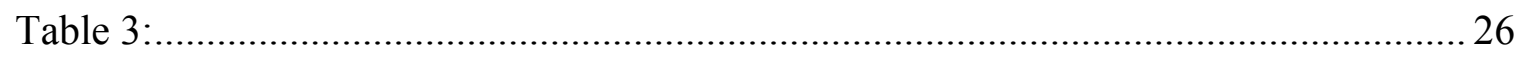

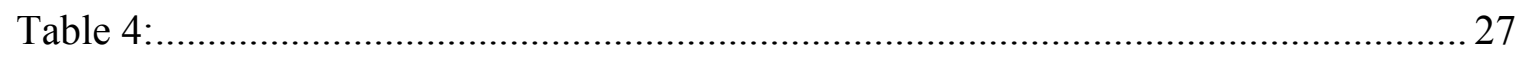




\section{ABBREVIATIONS}

PCBS Palestinian Central Bureau of Statistics

PHP Pilot Health Project

USAID United States Agency for International Development

NGO Non-governmental Organization

CHW Community Health Worker

HDIP Health, Development, Information and Policy Institute

UPMRC The Union of Palestinian Medical Relief Committees

UHWC The Union of Health Work Committees

PFS The Patients Friends Society

$\mathrm{MOH} \quad$ Ministry of Health

UNRWA United Nations Relief and Works Agency for Palestine Refugees in the Near East

IEC Information, Education, and Communication 


\section{STUDY TEAM}

\section{Health, Development, Informational and Policy Institute (HDIP)}

Team Leader:

Field Researchers:

\section{Population Council's Frontiers Team}

Dr. Laila Nawar

Dr. Dale Huntington

Dr. Mawaheb El-Mowelhy

Dr. Ahmed Ragab

Dr. Nancy Ali

Ms. Gihan Hosny

Ms. Magda Fayek
Dr. Mohammad Yassin

Mr. Salam Abu Baker

Ms. Samah Sadqa

Ms. Khitam Abu Hamdeh

Ms. Susan Abu Daqqa

Ms. Fatmeh El-Ajrami

WANA, Regional Advisor

Regional Director, ANE

FRONTIERS' Consultant

FRONTIERS' Consultant

Program Associate

Administrator Assistant

Program Administrator 


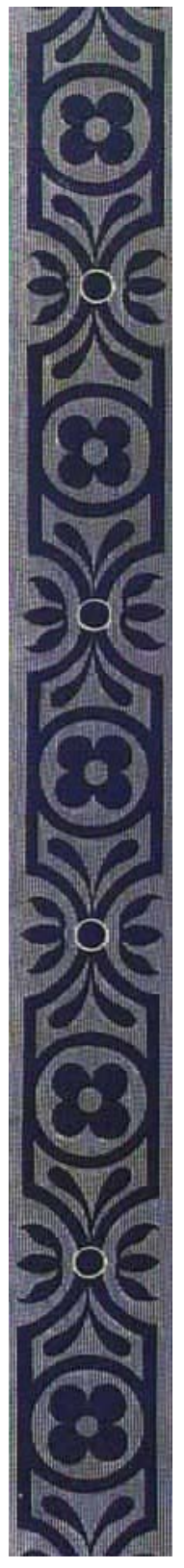

\section{EXECUTIVE SUMMARY}

Fertility rates in the West Bank and Gaza are higher in comparison to other countries in the region of similar development status. Although most Palestinian women receive some prenatal care and deliver in health settings, less than $20 \%$ of them return for postpartum check-ups. In addition, public hospitals in Palestine provide poor quality maternal care, are crowded and suffer from severe shortages in equipment and facilities. Delivering women are usually discharged from the hospital a few hours after delivery without having the opportunity to be properly counseled about postpartum health care issues including family planning, nutrition, breastfeeding and other important issues.

As part of an effort to improve the health status of Palestinian women and their children in the West Bank and Gaza, the United States Agency for International Development (USAID), in collaboration with the Palestinian Ministry of Health $(\mathrm{MOH})$ and seven partners ${ }^{*}$, designed and funded a 28-month long pilot activity that is expected to have significant impact on the health of women and children. The goal of this Pilot Health Project (PHP) is to upgrade antenatal and postpartum services in 27 primary health care clinics in three areas of the West Bank and Gaza.

This operations research study was conducted within the research activities of the PHP. It was conducted with the following objectives:

1. To test the feasibility of outreach linkages to a hospital in order to reach mothers who have not received proper health assessment and/or adequate counseling in postpartum health care and practices.

2. To test the effectiveness of the study intervention on mothers' knowledge and postpartum health care practices, including the use of family planning methods.

\footnotetext{
*Partners include CARE International, The Population Council, the Patients Friends Society (PFS), the Union of Palestinian Medical Relief Committees (UPMRC), the Union of Health Work Committees (UHWC), the Health, Development, Information and Policy Institute (HDIP), and the Center for Development in Primary Health Care (CDPHC)
} 
A purposive sample of 30 recently delivered women in two public hospitals that were not PHP sites (equally divided between Jenin and Gaza cities) were interviewed using qualitative methods at home 40 days post delivery. Each of these women received the PHP standard home visit by a community health worker (CHW) 2-3 days after delivery, which constituted the study intervention. A second purposive sample of the same size was drawn in Jenin and Gaza cities for the comparison group that also contained recently delivered women in the same public hospitals with similar background characteristics. This comparison group did not receive the PHP standard home visit by a CHW. The interviews probed women's perceptions about issues such as the care received in the hospital, knowledge about reproductive health issues, family planning attitudes and use of a contraceptive method.

The study also included in-depth interviews with eight managerial/administrative staff and 54 service providers at the two public hospitals in the two cities. These interviews assessed the readiness of the hospitals to provide care to delivering women, problems and obstacles providers encounter, and their views on creating a referral system between hospitals and local clinics for postpartum care.

Managerial staff and service providers confirmed the poor quality of care in hospitals due to the shortage of equipment and supplies. They welcomed the idea of establishing a link between the public hospitals and the local clinics so women can be seen and followed-up in clinics near their homes, instead of having to travel a long distance to the hospitals.

Almost all women in both hospitals and both groups complained about the poor quality of care provided by the two hospitals. Also, they reported that they hadn't received any health education or counseling while at the hospitals. A few women, however, stated that they did receive good quality of care at the hospital. All women in the intervention group received a home visit after delivery. Most of these visits (26 out of 30) took place two to four days after delivery.

All women in the intervention group appreciated the home visit and recommended that it be systematically provided. Also, most of them appreciated the information, counseling and IEC materials received. Additionally, most of participants in the intervention group were able to recall the health information they had been given. 
Thirteen women from the comparison group (those who received no home visit) and 14 women from the intervention group did make the day 40 clinic visit. However, dividing the participants by region, 26 women in Gaza made day 40 clinic visits, while in contrast in Jenin only one woman attended the clinic. Out of the 26 women from Gaza who carried out the day 40 clinic visit, 13 were from the intervention group and 13 were from the comparison group. The only woman who visited the day 40 clinic from Jenin was from the intervention group. This finding suggests that there was no impact by the CHW on the day 40 follow-up visit in the study sites.

However, other factors contributed to the inability of women to carry out the day 40 visit. One factor is the geographic distribution of the participants; women in Gaza were able to carry out the visit more easily than women in Jenin. The Israeli occupation of Jenin while the study was going on undoubtedly had a tremendous effect on women's ability to move.

It is recommended that more attention be given to improving the infrastructure of maternity wards in public hospitals and employing more qualified nurses; a referral system be established between public hospitals and local clinics; more than one home visit be paid to recently delivered women during the first 60 days postpartum; and that IEC programs be available which emphasize the fact that breastfeeding alone may not be a reliable method of contraception. 


\section{BACKGROUND}

The lack of care that is provided to mothers and newborns during the perinatal period is one of the most pressing health care problems in the West Bank and Gaza. Although large proportions of mothers receive some prenatal care, only about 17 percent return for postpartum check-ups and few adopt family planning for spacing births during the postpartum period (Ismail and Shahin, 1996). Although current levels of modern contraceptive use are moderate (estimated at $34 \%$ in the West Bank and $25 \%$ in Gaza), wide variations of use exist. For example, in parts of

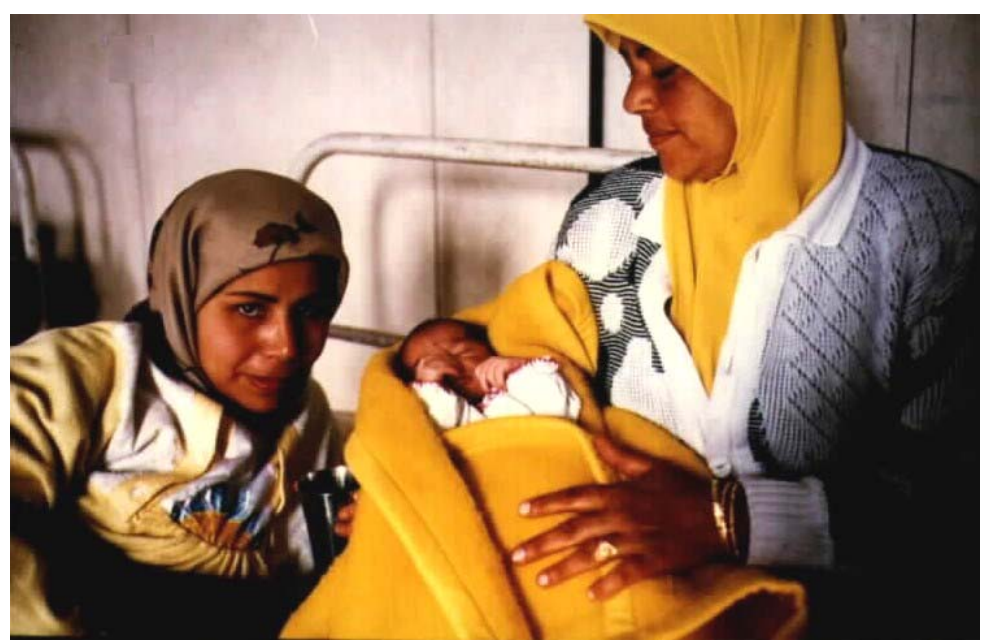
East Jerusalem prevalence is about 50 percent, while it is near zero in isolated areas of the West Bank. The use of family planning varies according to age and parity as well. Contraceptive use is very low among younger, low-parity women and family planning is generally only acceptable after several births for most families (PCBS, 1997).

Although West Bank and Gaza residents have good access to health care services (100 percent of the Gaza population and 90 percent of the West Bank population are within five kilometers of a public or private clinic), there are problems with the costs of services, equity of access to health facilities, quality of care and availability of services (i.e., clinics are often without a doctor). Because of the limited coverage of the Palestinian Authority (PA)'s general health insurance system, about 50 percent of households bear the full costs of health care. The non-refugee poor, in particular, have difficulty accessing health care. Government hospitals also suffer from severe overcrowding. Among the many consequences of this situation is the fact that about $70 \%$ of women deliver at public hospitals and the large majority of them are discharged as early as one to six hours after delivery without receiving a proper assessment of their or their baby's health, or obtaining adequate counseling on postpartum health care. 
Baseline data obtained from a survey conducted at PHP clinics in late 2000 (HDIP, 2001) further corroborates the above. Despite the small number of postpartum cases captured by the baseline $(n=27)$, the majority of postpartum clients interviewed in the survey reported delivering their babies at a hospital (85\%) and most of these women were discharged shortly after delivery (about 30\% were discharged after one to four hours and 35\% after five to 12 hours). In addition, approximately one-half of postpartum women interviewed (56\%) were first seen by a health care provider within 10 days of delivery. Most of these women received their first postpartum service from the same clinic where they had received antenatal care, but about one-fifth (19\%) went to a private physician or hospital and about one-sixth $(15 \%)$ went to UNRWA or MOH health facilities for the first postpartum check-up visit. Only one-third of postpartum clients in the PHP baseline survey reported receiving a home visit by a health provider after their index delivery, usually within three to seven days after the index delivery.

The baseline data also clearly indicated that very few women visited PHP clinics to receive postpartum care (approximately 3\% of the 792 women interviewed visited the clinics for postpartum care or postpartum and family planning services). When probed further about the number of postpartum visits made to the clinic after index delivery, over 70 percent of women reported visiting the clinic only once after delivery. The study final report also confirmed these patterns (Alpha International, 2002). These findings highlight the low rate of postpartum care coverage at PHP clinics and in the West Bank and Gaza in general. 


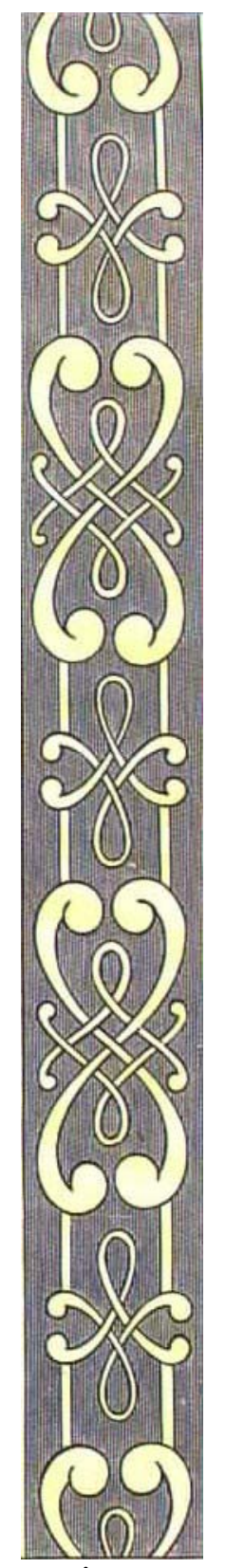

\section{STUDY OBJECTIVES}

The ultimate objective of this study is to reduce maternal and infant mortality in the West Bank and Gaza through improved postpartum health care practices of the mother and child, including family planning use for birth spacing. The study will address the following short-term objectives:

1. To examine the feasibility of outreach linkages from a hospital in order to reach mothers who have not sought out or received prenatal care prior to delivery and/or have not had a sufficient length of stay in the hospital to receive adequate counseling in postpartum health care and practices.

2. To assess the effectiveness of the outreach linkages on mothers' knowledge and postpartum health care practices, including the use of family planning methods.

3. To develop useful guidelines for scaling-up outreach services.

\section{STUDY RESEARCH QUESTIONS}

The study investigates the following research questions:

1. Would it be feasible for hospital staff at maternity hospitals to provide counseling on postpartum care to women before they are discharged? Would it be both possible and acceptable for women to receive such counseling?

2. Will women at maternity hospitals who receive information about the importance of postpartum care and follow-up postpartum clinic visits be willing to receive a home visit by a CHW 2-3 days after delivery?

3. Will a 2-3 day postpartum visit increase women's knowledge of good postpartum practices, including the importance of family planning?

4. What are the factors affecting a woman's decision to attend the day 40 postpartum clinic?

5. Would it be feasible to establish referral systems and services between maternity hospitals and NGO clinics?

6. Will the establishment of referral systems between maternity hospitals and NGO clinics increase postpartum care coverage? 


\section{METHODS}

\section{Study Design}

The study included two phases. The first phase provides a description of the quality of care provided to women delivering at Al-Shifaa Hospital in Gaza city and Jenin Hospital in Jenin city. This description was qualitative in nature, including mostly results from in-depth interviews with key managers and service providers at the two hospitals. The assessment was designed to obtain a quick overview of the services provided to women delivering at the hospital, including postpartum health care services and counseling offered.

The second phase consisted of comparing results from in-depth home interviews with clients who have recently delivered and have received the PHP standard home delivery intervention (i.e. a home visit by a CHW 2-3 days after delivery), with a comparison group of clients who did not receive a home visit. Information on the design and procedures followed in the study are elaborated further in the data collection procedures section below.

\section{Launching Study Intervention: Informed Consent}

The case definition for inclusion in the study was: women who have not received antenatal care at PHP clinics, have stayed at the hospital after delivery for less than 12 hours, and did not plan to change their residence for at least three months after delivery. All women meeting these criteria were approached before discharge to obtain their informed consent for a home visit by a CHW 2-3 days after delivery and for a home interview 40 days after the home visit. These women received a home visit from a CHW from one of the three PHP NGOs (i.e., UHWC, PFS, or UPMRC depending on their residence as a special service for the purposes of this study). They were also encouraged to return to the clinic on/or about day 40 for a postpartum check-up for both mother and baby. Thirty women (15 from Gaza hospital and 15 from Jenin hospital) gave consent to receive the intervention activities and to conduct a home interview.

The same case definition used for women enrolled in the intervention group was applied to identify women eligible for enrollment in the comparison assessment. Thirty 
women were enrolled in the study for the purpose of comparison assessment (15 from Gaza hospital and 15 from Jenin hospital). Informed consent for home interviews six weeks after delivery was obtained from women who agreed to participate in the study before discharge. Women were asked the same questions that were posed to women in the intervention group in order to collect information about the type and quality of postpartum care received, including medical examinations conducted and postpartum information/counseling received, if any. This included information on whether or not women made the day 40 visit to the PHP clinic, as well as the outcome of that visit.

\section{Description of the Intervention}

The intervention consisted of providing a single home visit 2-3 days after delivery to women who had recently delivered at one of the two public hospital included in the study and had: a) not received antenatal care at PHP clinics prior to delivery, and b) stayed at the hospital for less than 12 hours after delivery. Women delivering at the study sites were met by research staff before discharge to get their informed consent for a home visit 2-3 days after delivery. The home visits were conducted by CHWs and included the same services offered under the basic package of services for the PHP. Mothers were also encouraged to visit the nearest PHP clinic on/or about day 40 with their babies for a postpartum check-up (for both mother and baby) and for family planning counseling.

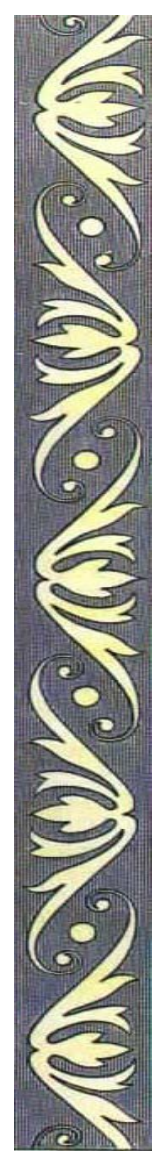

\section{Study Sites}

This study was conducted at two public maternity hospitals purposively selected because of their high caseloads and proximity to a PHP clinic in Gaza and the West Bank. Al-Shifaa Hospital in Gaza has 102 beds in the maternity ward and is close to five clinics run by the Union of Health Workers Committees (UHWC). Each of these clinics is open eight hours a day, six days a week and has general physicians, midwives, and CHWs as part of their staff. It is estimated that approximately 700 clients visit these five clinics per month.

The Jenin Hospital in the West Bank city of Jenin has 21 beds in the maternity ward. The partner NGOs that provide MCH/FP services in Jenin area are the Patients Friend Society (PFS) and the Union of Palestinian Medical Relief Committee (UPMRC). PFS operates 14 clinics in villages and one clinic in the city 
of Jenin. These clinics are open six days a week and eight hours a day, and a CHW is the only health professional present in each clinic at all times. Two general physicians periodically visit all of the 14 clinics. About 1,625 clients visit these 14 clinics per month. Five clinics in the five other villages are operated by UPMRC. Like PFS clinics, they are open full-time and have a health team consisting of a physician, nurses and CHWs. Approximately 800 clients visit these five clinics each month.

In each of the two hospitals selected for the study, 60 women who met the case definition criteria were identified from the available patients, and then were assigned (nonrandomly) to either the intervention or the comparison group. More information on the selection of women is provided in the section "Organization of Field Work".

\section{DATA COLLECTION PROCEDURES}

As mentioned previously, the study relied primarily on in-depth interviews with service providers and women. Eight in-depth interviews were conducted with key managerial/ administrative staff in the two hospitals and 54 in-depth interviews with service providers (21 physicians and 33 nurses, health workers and midwives). Also, 60 in-depth interviews were held with women, 30 from the comparison group and 30 from the intervention group.

\section{Assessment of Health Care Provided at Study Sites}

The study explored the quality of services provided to women delivering at the hospital and the postpartum health care services offered. In-depth interviews were conducted with service providers such as doctors, nurses, midwives, and CHWs and key management staff at the study sites to obtain information about the services provided to women before and during delivery. The type and quality of postpartum care services offered after delivery, including postpartum counseling, were also assessed.

\section{Home Interviews}

Trained interviewers contacted all women who had given consent to be enrolled in the study six weeks after delivery (comparison assessment) and approximately 40 days after the home visit (women who received the intervention at their homes). The interviewer reconfirmed their consent to conduct the interview at that contact. If there were several family 
members present in the household, the interviewer suggested moving to a section/room in the house that was more private. A guide for the in-depth interview was used to conduct the interview with the woman in her home. Information related to postpartum care received after delivery at home and at the PHP clinic (for those women who returned to the clinic) and other relevant information was based on the perceptions and information reported by women during home interviews.

\section{Field Data Collection}

Data collection from key administration and management staff, as well

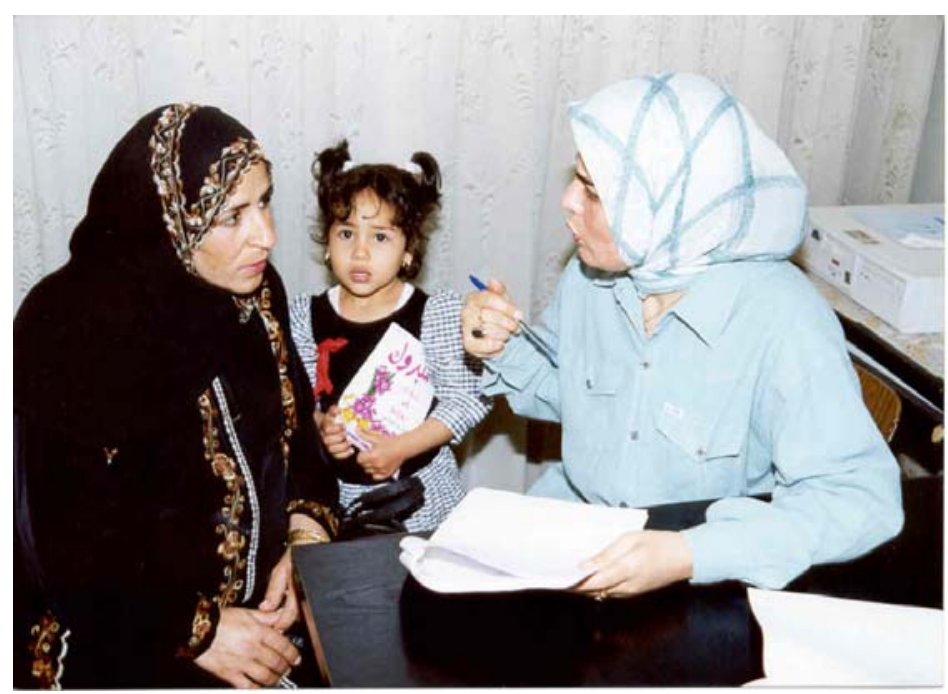
as service providers at the two study sites, took place between late-October to mid-November, 2001. The in-depth interviews with women took place during December 2001.

\section{Research Instruments}

Three guides were developed for data collection: two were designed for interviews with the health team and key management staff, and the third was designed for interviews with women. The following is a brief description of these three guides' key indicators.

\section{Hospital management}

- Personal characteristics including age, qualifications, specialty, year of graduation, number of years at hospital, and job at the hospital.

- Deliveries at the hospital, including the number, type and complications during last 12 months, average length of stay in the hospital and average cost of deliveries.

- Staff and equipment at the hospital, including shortage in the number of health providers, necessary equipment and supporting services such as ambulances.

- Reproductive health programs at the hospital including breast and cervical cancer surveillance programs.

- Follow-up after delivery and the existence of coordination between the hospital and local clinics. 


\section{Health Care Providers}

- Personal characteristics including age, qualifications, specialty, year of graduation, number of years at the hospital, job at the hospital, and special training in reproductive health.

- Procedures done on women and newborns while in the hospital and the standard of care provided to them.

- Family planning methods including information provided to women regarding family planning and most popular contraceptive methods used.

- Most common complications during/ after delivery.

- Readiness of the hospital with regards to the adequacy of the available health team, beds, incubators, examination rooms, and equipment.

\section{Women}

- Demographic and socio-economic status including age, education, job, family size, consanguineous marriage; husband's age, education, and job.

- Reproductive history including age at first marriage, age at first pregnancy, parity, abortions, stillbirths, alive and dead children, desire of the last pregnancy, preferred spacing period until next pregnancy, total desired number of children, and who makes decision about family size.

- Care received while at the hospital including length of stay and health education received; perception of the quality and satisfaction.

- Care received while at home including questions related to home visit 2-3 days after delivery, knowledge received and benefits gained.

- Health care seeking behavior during the postpartum period including any visits to a health care facility.

- Family planning methods use including ever and current contraceptive use, how long women intend to use them, reasons for stopping and intention for future use.

Research guides developed were pre-tested with: a) four service providers at hospitals not included in the study, and b) four women at their homes who recently delivered at a hospital where the informed consent and confidentiality measures were applied when conducting the pre-test of the home interviews. 


\section{Organization of Field Work}

\section{Comparison Group}

Arrangements were made with hospital management for research staff to identify and enroll women in the study during a two-week period. Hospital staff provided information to the research team on the expected discharge dates of clients. Research staff was stationed at the study sites and enrolled the first 15 available women who consented from each hospital into the study for the comparison group.

Women were approached at a convenient time around their discharge and were asked to participate in the study and in a home interview. Informed consent for home interviews was obtained from all women who agreed to participate in the study before they were discharged. At this time, basic information was collected from those women, including their names, addresses, delivery dates, the duration of hospital stay after delivery, as well as other relevant information. Efforts were made to ensure that ethically acceptable procedures were used to enroll women in the study. During their encounter with women, research staff ensured that the women were not in any stress or pain and freely agreed to provide information and their informed consent (i.e., there was absolutely no coercion of the women by research staff). If a woman was approached who did not want to participate in the study, research staff left the vicinity immediately and proceeded with arrangements to identify and enroll another woman in the study. In-depth home interviews were conducted with all of 30 women (15 from Gaza hospital and 15 from Jenin hospital) who consented to be enrolled in the study six weeks after discharge from the hospital.

\section{Intervention Group}

Women who participated in this part of the study were identified in the same manner as those selected for the comparison group. Before their discharge, each identified woman was asked to give their informed consent for a home visit 2-3 days after delivery and a follow-up interview at home. The majority of the women who were approached were amenable to receiving a home visit by a CHW 2-3 days after delivery. Out of all the women approached, only two women in Gaza and one woman in Jenin refused to give consent for the home visit. The home visit was conducted by a CHW from one of the PHP NGO clinics, depending on location of the public hospital (see above section for more information on study sites and partner NGO). Home interviews took place 40 days after the home visit. 


\section{Training of Data Collectors and Pre-testing of Instruments}

Data collectors and field supervisors from Jenin and Gaza city who were involved in the study received six days of training by HDIP staff. Training highlighted the importance and objectives of the study. It also included careful review of all study instruments, role-playing exercises and pre-test interviews with women and health team members. Informed consent and confidentiality issues were covered comprehensively during the training workshop.

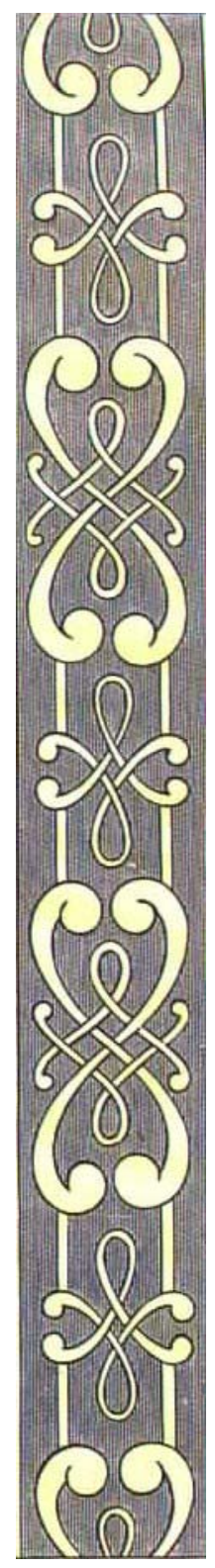

\section{FINDINGS}

\section{Section 1: Managerial/Administrative Staff Perspectives}

The following managerial/administrative staff in each of the two hospitals was interviewed using qualitative, in-depth interview techniques: two director general assistants, two assistant supervisors of the building, one hospital nursing supervisor, one nursing supervisor at the maternity ward and the head nurse of the hemorrhage department and the maternity ward.

\section{Hospital load and staffing}

The two hospitals selected for the study are busy: Jenin Hospital had 4,500 deliveries in 2000 and Al-Shifaa Hospital had 13,248. While normal deliveries in the two hospitals constitute around 50 percent of the received cases, rates of stillbirths constitute about 10 percent, miscarriages 30 percent and premature deliveries around another 10 percent of those cases. On average, women stay in the hospital between one and three days. Normal delivery costs 150-400 and a Cesarean section costs 300-1200 New Israeli Shekels.

Table 1 shows the delivery events at the two hospitals. While some of the managers' views regarding the number of physicians in relation to the obstetric workload varied, they all agreed that the number of nurses was not enough for the workload in obstetric wards. 
Table 1: Description of delivery events at Al Shifaa and Jenin hospitals.

\begin{tabular}{|l|l|l|}
\hline Characteristic & $\begin{array}{l}\text { Al Shifaa } \\
\text { Hospital/ } \\
\text { Gaza } \\
\text { Strip }\end{array}$ & $\begin{array}{l}\text { Jenin } \\
\text { Hospital/ } \\
\text { Jenin } \\
\text { area }\end{array}$ \\
\hline Deliveries at hospital & 13,248 & 4,500 \\
\hline $\begin{array}{l}\text { Total number of deliveries in the last 12 } \\
\text { months }\end{array}$ & 10 & 10 \\
\hline$\%$ stillbirths & 29 & 30 \\
\hline \% miscarriages & 20 & 20 \\
\hline \% premature births & & \\
\hline $\begin{array}{l}\text { Average stay (days) in hospitals after } \\
\text { delivery in the last 12 months }\end{array}$ & 2.5 & 1.5 \\
\hline All deliveries & 3.5 & 3.5 \\
\hline Cesarean section deliveries & 1 & 0.25 \\
\hline Normal deliveries & 2 & 1.5 \\
\hline Complicated deliveries & & \\
\hline Costs in New Israeli Shekel & $300-500$ & $400-1,200$ \\
\hline Cesarean section delivery & 150 & $200-400$ \\
\hline Normal delivery & 150 & $150-400$ \\
\hline One day stay at hospital & & \\
\hline Source: Hospital data provided by key & mag & \\
\hline
\end{tabular}

Source: Hospital data provided by key management staff of the two hospitals; *\$1USD = NIS $4.02 /$ year 2000

"Yes the number of physicians is OK and not bad at all." (Nurse Supervisor/Al-Shifaa Hospital)

$$
\text { "نعم عدد الأطباء يتناسب و لا بأس به." مشرفة تمريض/مسنشفى الثفاء }
$$

"Number of physicians is not sufficient." (Assistant Head of Obstetric Department /Jenin Hospital)

$$
\text { "عدد الأطباء غير كافى." نائب رئيس قسم التوليد/مستشفى جنين }
$$

"Number of nurses is not sufficient." (Nurse Supervisors/Al-Shifaa and Assistant Head of Obstetric Department/Jenin Hospitals)

$$
\text { التوليد/مستشفى الممرضنين لا يكفى." مشرفة تمريض/مستشفى الثفاء و نائب رئيس قسم }
$$

Women reportedly stay in the hospital on average one to three days after normal delivery, one to five days after difficult labor and three to five days after a Cesarean section. The length of stay depends on the woman's condition and is the physician's decision, but it 
may also depend on bed availability. The shortage of bed space (particularly in Jenin) and incubators can result in an early discharge.

"The physician in charge is the one who decides how long the woman is to stay. It should be three days for a normal delivery or longer, depending on her condition. But sometimes it could depend on availability of beds in the hospital. Some people sign and discharge themselves out of hospital at their own responsibility." (Nurse Supervisor/Al-Shifaa Hospital)

$$
\begin{aligned}
& \text { "الدكتور المختص هو الذى يقرر فترة المكوث, هو المفروض أنها } 3 \text { أيام للو لادة الطبيعيه أو أو الهو }
\end{aligned}
$$

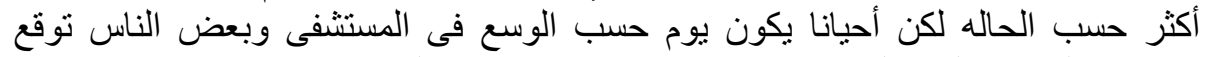

$$
\begin{aligned}
& \text { وتخرج على مسئوليتها الخاصه." مشرفة تمريض/مستشفى الثفاء الثياء }
\end{aligned}
$$

"Number of beds is not enough. Sometimes two women have to share one bed." (Nurse Supervisor/Jenin Hospital)

$$
\text { "عدد الأسرة لا يكفى, فى معظم الأحيان تجتمع } 2 \text { على سرير." مشرفة تمريض/مستشفى }
$$

"Number of incubators is not enough. Sometimes three newly born infants share one incubator." (Nurse Supervisor/Jenin Hospital)

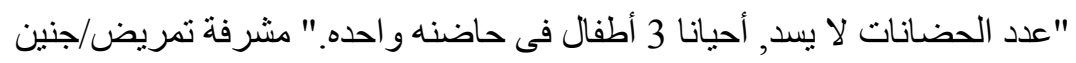

\section{Equipment and IEC Material}

Management staff reported that the number of examination rooms and obstetric equipment for difficult labor is sufficient in some sites, and insufficient in other settings. There was no shortage of ideas on how to improve the current situation, and managers are keen for assistance as well as support.

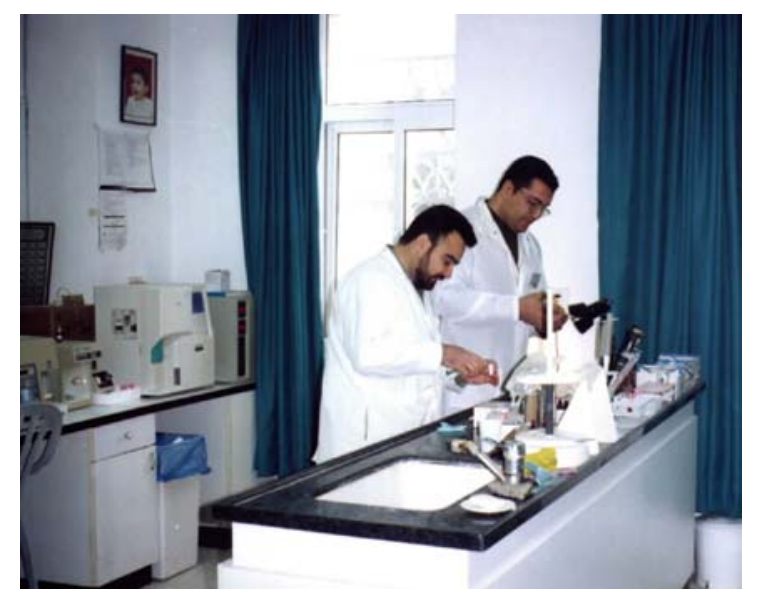

"Increase number of nurses, make use of the period the women stay in hospital to provide them with health education, conduct lectures through the nurses and the health workers, show video films on reproductive health issues and disseminate health awareness to people in general through the specialized establishments and the different media channels." (Nurse Supervisor/Al-Shifaa Hospital)

$$
\begin{aligned}
& \text { "زيادة طاقم التمريض, استغلال فترة مكوث المر أه في المستشفى لاعطائها ارشادات صحيه }
\end{aligned}
$$

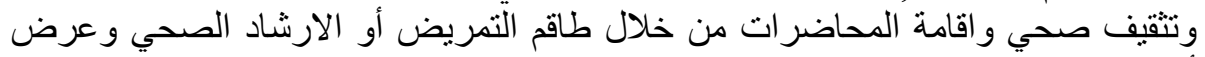

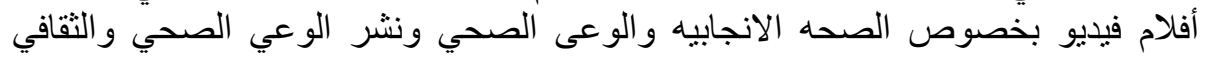




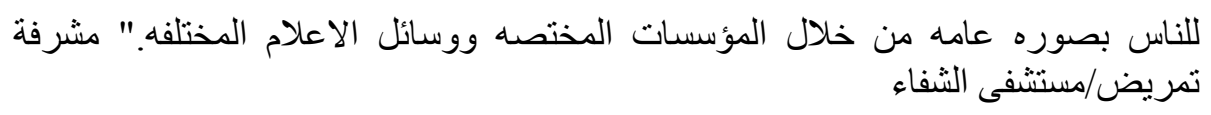

\section{Women's Health Programs}

Jenin Hospital does not have comprehensive women's health programs, but does offer Pap smear tests in the outpatient clinic. By comparison, Al-Shifaa Hospital provides health instructions, investigations for breast cancer and Pap smear tests.

"We had three programs for health education, breastfeeding and health workers, but now these programs have been transferred to the Primary Health Care. Health instructions and counseling are provided in the outpatient clinic. There are no programs for investigations, nor community campaigns or seminars." (Nurse Supervisor/Al-Shifaa Hospital)

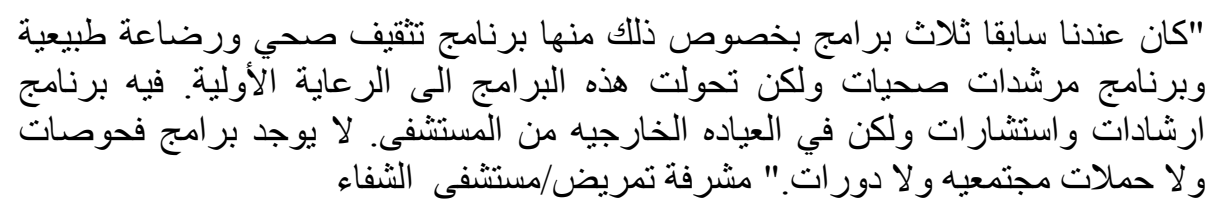

Answering the question on how to improve the standard of care for women, managerial staff suggested increasing the number of staff, improving coordination between hospitals and Primary Health Care (PHC) facilities, providing health education to mothers and reaching youth with reproductive health information.

"Expanding the medical cadre, establishing centers in each town, employing health workers in these centers to provide health education for women, holding seminars for women and giving them health education leaflets." (Assistant Head of Obstetric Department/Jenin Hospital)

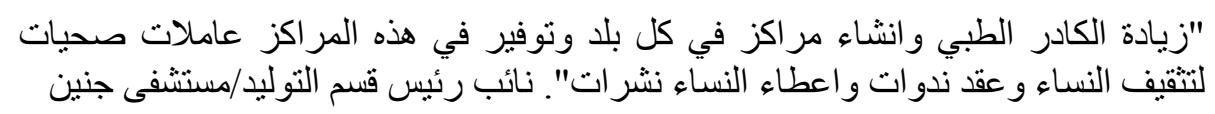

"Establishing special programs through the Ministry of Health or other settings to visit women at home (especially for difficult cases like Cesarean or diabetic or hypertensive women), increasing the number of nurses, providing health education seminars and lectures to pregnant women through health workers, establishing follow-up programs through distributing booklets and video tapes in the departments, conducting seminars for pregnant women and their relatives and demolishing the old building (labor hospital) because it 
is old and is not suitable for proper health conditions." (Nurse Supervisor/Al-Shifaa Hospital)

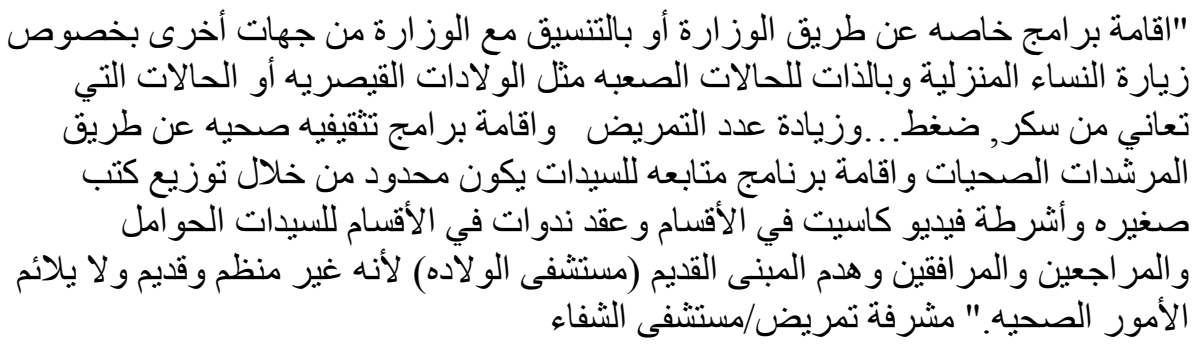

\section{Section 2: Health Providers Perspectives}

Table 2 shows the health staff interviewed at the Al-Shifaa and Jenin hospitals by category.

Data collected (not shown) indicate that about one-third of the health providers were male.

About one-half of these staff members have been

Table 2: Job title of health staff interviewed

working in the study sites for about seven years

and about one-fourth have worked in health

facilities other than the study sites. Overall, less

than one-third has received special training in

reproductive health.

\section{Hospitals' Workload and Staffing}

\begin{tabular}{|l|c|c|c|}
\hline Job & $\begin{array}{c}\text { Al Shifaa } \\
\text { Hospital }\end{array}$ & $\begin{array}{c}\text { Jenin } \\
\text { Hospital }\end{array}$ & Total \\
\hline Obstetrician & 6 & 3 & 9 \\
\hline General Practitioner & 4 & 4 & 8 \\
\hline Nurse & 5 & 4 & 9 \\
\hline Midwife & 5 & 8 & 13 \\
\hline Health worker & 7 & 4 & 11 \\
\hline Resident physician & 2 & 2 & 4 \\
\hline Key management staff & 4 & 4 & 8 \\
\hline Total & $\mathbf{3 3}$ & $\mathbf{2 9}$ & $\mathbf{6 2}$ \\
\hline
\end{tabular}

Almost all of the health providers stated that the hospitals/obstetric departments are busy and that the number of beds is not sufficient to cope with the number of deliveries. They all agree that there is a shortage in the number of nurses and, sometimes, physicians. There is also a shortage in the number of available incubators.

"Number of nurses is not sufficient and we need to have 45 nurses more." (Physician/Al-Shifaa Hospital)

$$
\text { "عدد الممرضات غير كافي ويوجد نقص حو الي } 45 \text { تمريض." طبيب|مستشفى الثفاء }
$$

"Never. Number of nurses is never enough." (Midwife/Jenin Hospital)

$$
\text { "لا, نهائيا. عدد المرضات لا يكفي." قابلة|مستشفى جنين }
$$

"The number of beds does not meet even one-quarter of our needs." (Physician/Jenin Hospital) 
"The number of incubators is not enough." (Physician/Al-Shifaa and midwife/Jenin Hospitals)

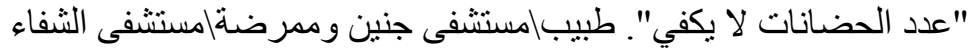

Women usually stay in the hospital for a short time after delivery because of a shortage in beds or incubators, or sometimes because they live far from the hospital and they prefer to go home as soon as possible to avoid being stuck in the area for security measures.

"The woman who delivers is supposed to stay in hospital for three days after normal delivery and for five days after a Cesarean, but in fact the average time the woman stays is two to 24 hours after normal delivery and around three days after a Cesarean." (Physician/AlShifaa Hospital)

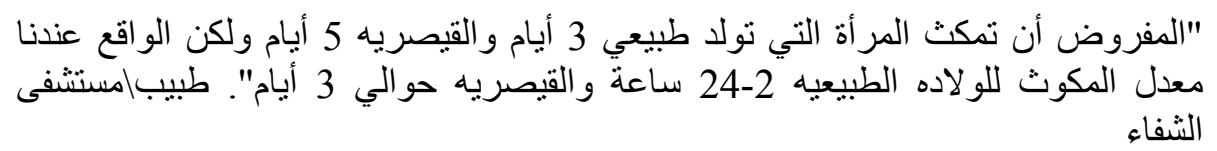

"Conditions in the department are not appropriate in terms of the large number of delivering women [due to] the small number of available beds, as well as the difficult economic situation." (Physician (head of high risk pregnancy department)/Al-Shifaa Hospital)

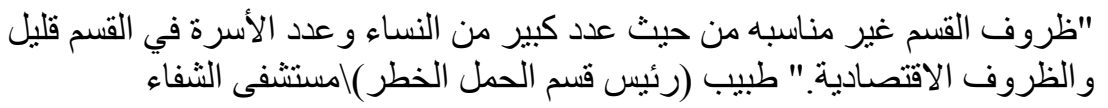

Responding to the question of providing health education to women after delivery and before discharge from the hospital, the health providers' answers varied. Many providers reported that they do talk to women about different topics such as family planning, nutrition, breastfeeding and risky symptoms during the postpartum period.

"We focus on the necessity of breastfeeding, spacing between pregnancies and nutrition." (Physician/Jenin Hospital)

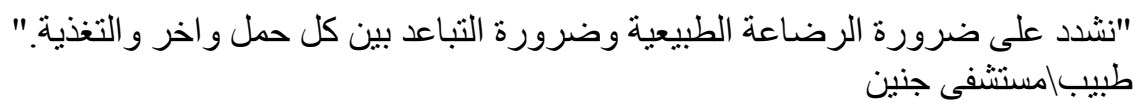

"We advise the woman to look for any abnormal signs such as vaginal bleeding, discharge with bad odor and any other complaints. We also advise her to breastfeed her baby, have good nutrition and we discuss 
family planning if she wants contraception." (Physician/Al-Shifaa Hospital)

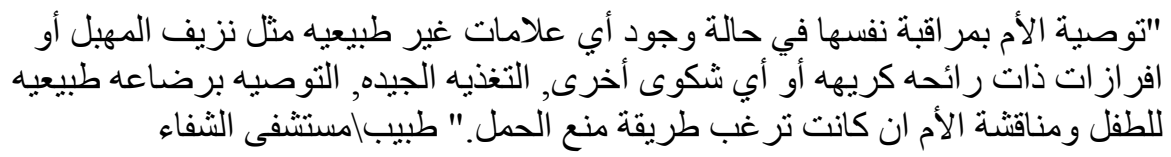

\section{Hospital Equipment}

Health providers did not agree among themselves on whether the available examination rooms, equipment for difficult labor and hospital facilities meet women's needs.

"Number of examination rooms is sufficient." (Physician/Al-Shifaa Hospital)

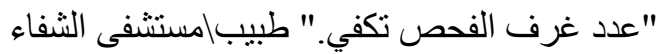

"No. We are having a severe shortage (of equipment and supplies).," (Nurse/Al-Shifaa Hospital)

$$
\text { "لا, نعاني من نقص شديد في المعدات." ممرضة|مستشفى الثنفاء }
$$

"The number [of examination rooms] is not enough." (Midwife/Jenin Hospital)

$$
\text { "عدد الغرف غير كافي." قابلة|مستشفى جنين }
$$

"There is no equipment." (Physician/Jenin Hospital)

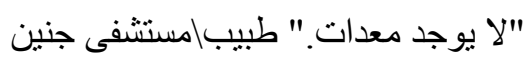

Responding to the question on how health providers would evaluate the hospital's readiness to meet the large number and different types of deliveries, some thought it was below standard, while others considered it acceptable to a certain extent.

"The readiness standard for the hospital team is weak, for the equipment it is almost okay, but for the ambulances is limited." (Midwife/Al-Shifaa Hospital_

$$
\text { كافية ولكن جاهزية لجنها طحدوده. المستشفى قابلة|مستشفه أما المعدات تقريبا كافية نوعا ما, سيارات الاسعاف }
$$

\section{Improving Women's Health}

Regarding health providers' views on how to improve women's care while staying in the hospital, providers suggested the following: 
"Build a larger obstetric department to accommodate this large number of women. I do not think that the available 17 beds are enough." Physician/Jenin Hospital

$$
\text { "العمل على بناء قسم للو لاده يتسع لهذا العدد الكبير من النساء والتي لا أعتقد أن } 17 \text { سريرا }
$$

"Increase the number of beds and cleaning workers and improve the type of food." Physician/Al-Shifaa Hospital

$$
\text { "زيبادمستشفى الثنفاءة وزيادة عدد التمريض وعمال النظافة وتحسين نوعية الطعام." }
$$

"Improve the scientific and practical standard for physicians, have enough midwives and nurses for supervision and to work in the departments and labor rooms, make places available for women before, during and after delivery and help newly married women understand health and sexual messages which they need for a happy and healthy family free from health problems and hereditary diseases." (Physician/Al-Shifaa Hospital)

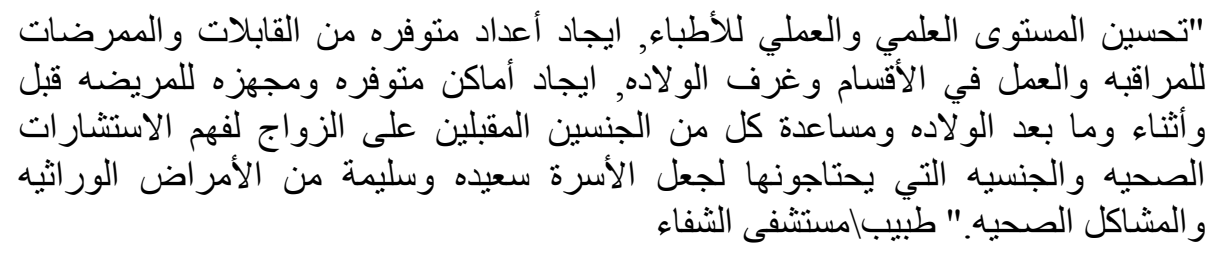

\section{Women's Health Programs}

Health providers gave different answers to the question of availability and types of women's health programs provided by the hospitals to improve women and children's health. While a few of them stated that such programs exist and are basically addressing family planning and breastfeeding issues, others responded negatively and a few did not know or had not even heard about these programs.

"Educational seminars in collaboration with Palestine's health centers, the television and through posters and talking to patients about the postpartum period." (Physician/Al-Shifaa Hospital)

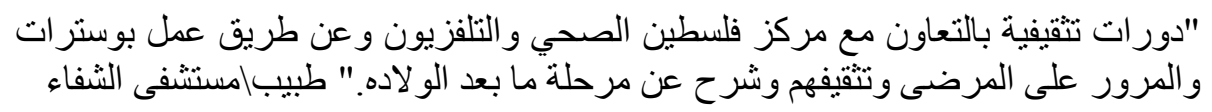

"Nothing, there are not any programs." (Physician /Jenin Hospital)

$$
\text { " ل الشئ, لاتوجد بر امج." طبيب|مستشفى جنين }
$$




\section{Follow-up for Women}

Most of the health providers stated that there is no effort made to follow-up women after delivery. Among the few who said some efforts do exist, it was clear that these efforts were limited to merely asking the women to come back to hospital later.

"We ask the woman to come back to hospital later." (Physician/Jenin Hospital)

$$
\text { "نطلب من المر أه المر اجعه بعد الخروج من المستشفى." طبيب|مستشفى جنين }
$$

"Our relation with the woman is finished after she gets out of hospital. However, if some emergency happens, she goes to the outpatient department to receive the necessary aid." (Physician/Al-Shifaa Hospital)

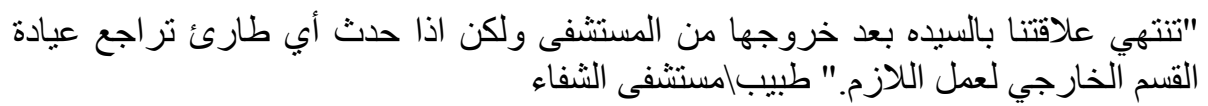

When asked about the existence of any coordination between the hospital and the local clinics, some health providers answered yes, others answered no and some stated that they know nothing about it.

"I do not think so." Physician/Jenin Hospital

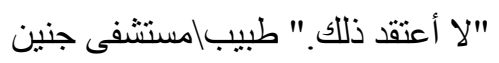

"There is coordination when a problem arises with a woman in the local clinic. She will be transferred to the hospital." (Physician/AlShifaa Hospital)

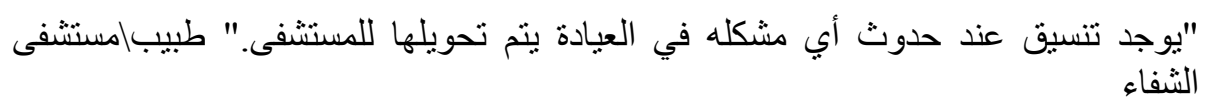

"I do not know; all I know is the mother goes to the Agency (UNRWA) for the child's vaccination and for her to be followed-up after delivery." (Nurse/Al-Shifaa Hospital)

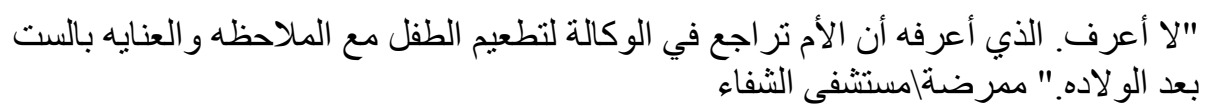

Almost all the health providers interviewed approved of the idea of establishing a referral system through which women can be referred to local clinics for postpartum care after being discharged from the hospital. They agreed that such a system would take the burden off the busy hospitals. 
"Good, it takes the burden off the hospital. Besides not every woman can come back to hospital for follow-up because of the long distance." (Physician/Jenin Hospital)

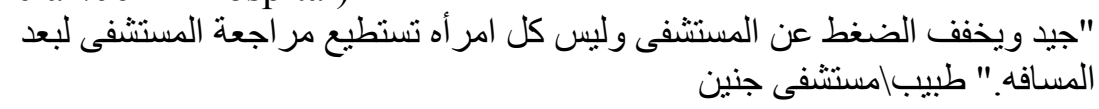

"Good step because we lack such a service. This will make it easy for us and will take the burden off the hospital. There in the health clinic, women can be health educated and children's health can be followedup. " (Midwife/Al-Shifaa Hospital)

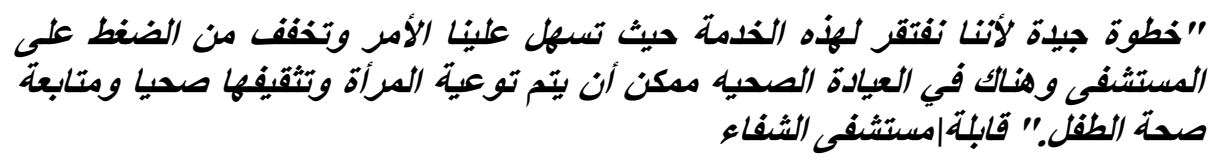

\section{Section 3: Women's Perspective}

Thirty women participated in in-depth interviews in Gaza (15 in comparison and 15 in intervention group), and 30 (15 in comparison and 15 in intervention group) participated in Jenin. The age at first marriage for women in Gaza (median 17 and ranging between 14 and 23 ) is lower compared to women in Jenin (median 22 and ranging between 15 and 34). Also, marriage between relatives was more prevalent among the women from Gaza than among women from the Jenin area. Women in Gaza had a higher number of pregnancies, higher number of living children and desired number of children compared to women in Jenin. The educational level was more or less the same between the two groups of women (median 10 years schooling). Women in Gaza preferred longer birth spacing (median of two-and-a-half years) compared to women in Jenin and men in Gaza and Jenin (median of two years). These socio-demographic characteristics were similar between the two study groups, since each group was composed of women from Gaza and Jenin.

\section{Family Planning Use}

Contraceptive behavior of the respondents in the current study was examined. About one-third of the cases used a family planning method before the index child. However, fear of side effects was the main reason of discontinuing the method use. The majority of those who are currently using family planning rely on traditional methods, safe period, withdrawal, and breastfeeding (not explicitly LAM). Breastfeeding and withdrawal were the main methods used by postpartum women for spacing purposes. Close to one-third of the participants intend 
to use a method in the near future. The belief that breastfeeding can protect women from getting pregnant for some time after delivery was widely expressed by women.

"I am breastfeeding my baby. When my menstrual cycle resumes, I am going to have an IUD." (A 32-year-old woman with 12 years of education, Intervention Group, Gaza)

$$
\text { "النا بأرضع حاليا واول ما تيجى الدورة هاركب لولب." سيدة عمر ها } 32 \text { سنة ، } 12 \text { سنة }
$$

\section{Unmet Need}

Most of the respondents who do not want more children were not currently using a method or relying on breastfeeding and other traditional methods. About a quarter of the respondents think that they have enough children, yet they were not using a reliable method for family planning.

"I am 38 years old and I have seven children. My last pregnancy was undesired; my husband and I do not want any more children. I am breastfeeding my child, once I wean him, I will use the Pill." (A 38year-old woman with six years of education from the Jenin intervention group)

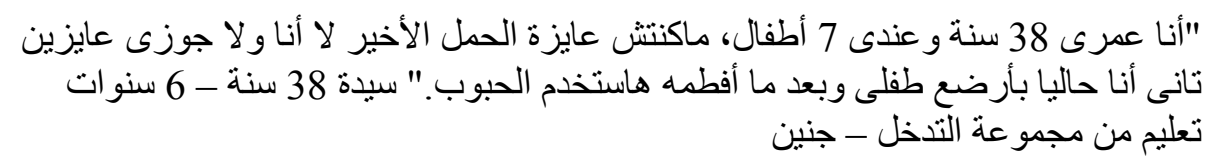

\section{Care Provided at Hospitals}

The in-depth interviews included questions about the type and quality of care received by women while in the hospital. In general, both study groups agreed that the quality of care received while in the delivery room was good. Most reported that they were given step-bystep instructions during the delivery process (particularly during second and third stages). However, after delivery many women reported receiving bad quality of care. Almost all women in both hospitals and both groups reported that they hadn't received any health education or counseling while at the hospital. Women in Gaza were more knowledgeable about breast and cervical cancer compared to women in Jenin. However, some of the women in both study groups reported having bad experiences at these hospitals. The following quotations are a sample of what women said during the interviews. 
"Care at Jenin Hospital is restricted to routine investigations and giving medications, but health education and guidance is not given." (A 24- year-old woman with 11 years of education from Jenin)

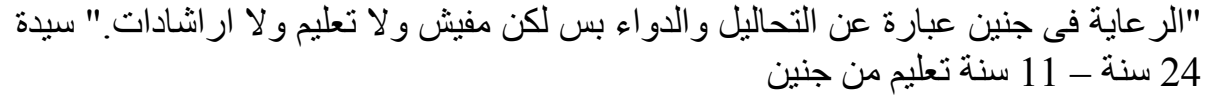

"They say nothing to us, I understand that they have no time for counseling, it is enough for them to help women in emergency situations. The hospital staff is too busy to talk about anything, may Allah help them." (A 26-year-old woman with nine years of education, intervention group Al-Shifaa Hospital)

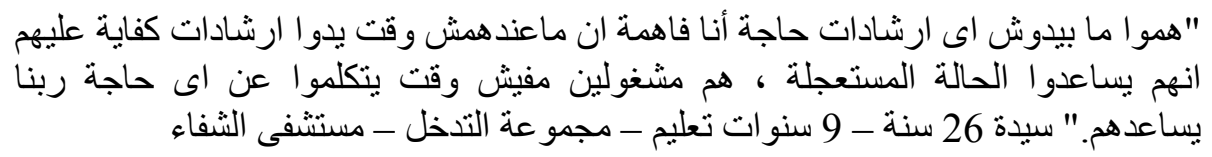

"I haven't received any good care but I received shouting and bad treatment." (A 31- year-old woman with four years of education from Gaza)

$$
\text { "انا كل اللى خدته زعيق ومعاملة سيئة ماخدتش اى رعاية كويسة." سيدة } 31 \text { سنة - } 4
$$

"During labor, I had step-by-step instructions until delivery was completed. No one helped me to clean myself and I had to get out from delivery room with dirty clothes. No one gave me my baby and I held it only after five hours. Both the service and cleanliness are very bad and there weren't even any baskets for toilet papers in the bathrooms. The treatment by physicians was good since I have had a previous Cesarean section." (A 27-year-old woman with 10 years of education from Gaza)

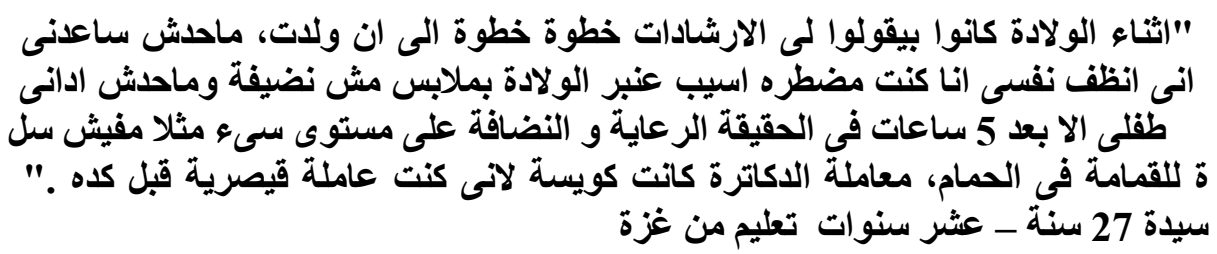

"My last pregnancy was extremely difficult. When I arrived at AlShifaa Hospital, physicians understood my situation and they gave their attention to me. They started IV fluids and there were so many machines beside me that I did not know. My delivery was complicated. They did not allow my mother to enter delivery room with me and they shouted at her. There were neither instructions nor reassurance for me. A female physician said to me in a sarcastic way "why this pregnancy if you can't tolerate pain?' Toward the end of my labor, 
another male physician told me that I am in an advanced stage and after delivery, he congratulated me. He requested one of the cleaners to help me clean myself. I held my baby while I was sitting in the wheelchair. I waited in the wheelchair more than a half hour before someone came and pushed the wheelchair to the ward." (A 26-yearold woman with 12 years of education from Gaza)

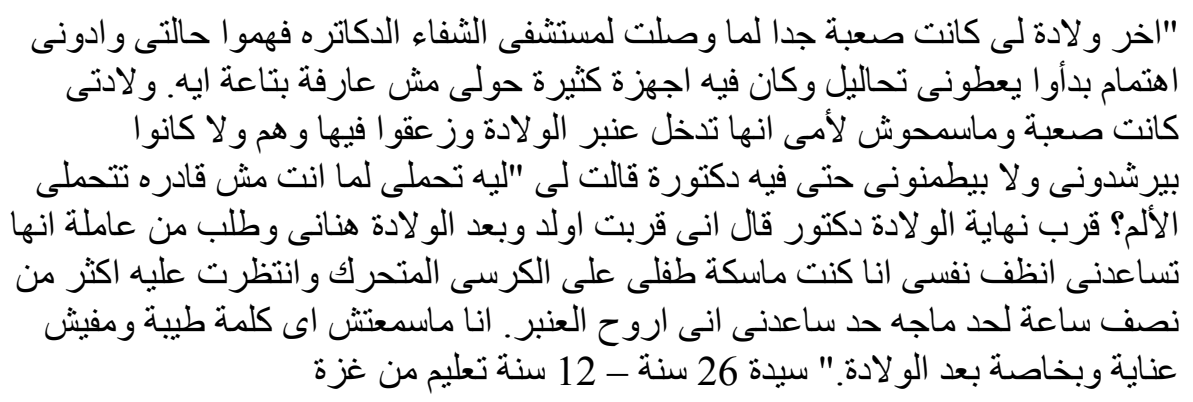

On the other hand, a minority of women affirmed that they received a good quality of care at the hospital:

"When I arrived at Al-Shifaa Hospital, the staff observed the fetal heart rate, took a blood sample from me, measured my blood pressure, did an ultrasound examination, and encouraged me to walk to hasten a normal delivery. The umbilical cord was protruded before the head of the fetus and the physician reassured me and helped me during labor. I had step-by-step instructions until delivery was completed. The physician congratulated me and nurses started to help me to clean myself. The newborn was sent to the incubator. Within one hour of delivery, the baby and I were at home. I felt that the service provided to me was very good." (A 34-year-old woman with 11 years of education from Gaza)

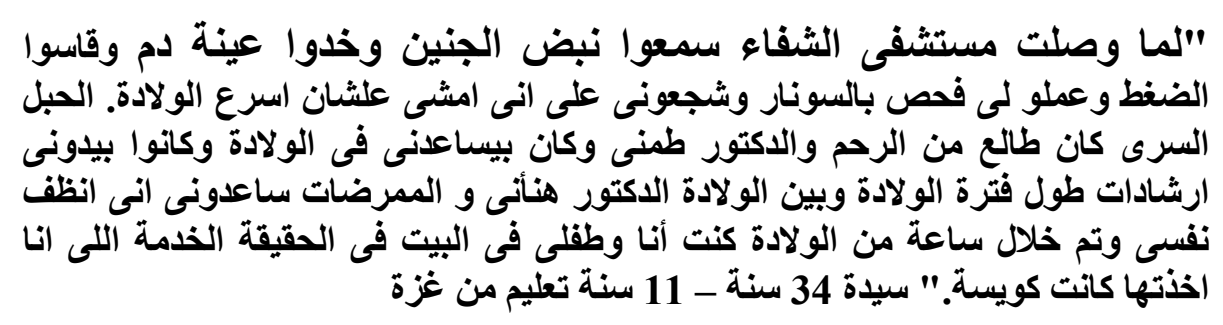

\section{Impact of the Intervention Program}

All women in the intervention group received a home visit after delivery. Twenty-six of the 30 home visits for the intervention group were carried out two to four days after delivery and the remaining four women were visited five to seven days after delivery. The majority of the CHWs provided them with information about postpartum care and health education, examined the mother and her baby, and encouraged women to visit clinics at day 
40 after delivery. Four women were identified as having health-related problems and therefore were referred to the appropriate physician to diagnose and treat the problem.

In the following section, the impact of the intervention will be examined with regard to the following themes: satisfaction with the visit, satisfaction with the information given, the ability to recall the information and the impact on contraception use.

\section{Satisfaction with the Home Visit}

All the participants in the intervention group appreciated the visit and recommended that it be systematically provided.

"In fact, this visit was very useful and needed, you know, the health staff is very busy, they do not have time to give counseling." ( A 27year-old woman with nine years education from the intervention group)

$$
\text { "الزيارات دي مهية جدا انت عارفة ان الدكاترة مشغولين قوى وما بيقولوش الى ارشادات." }
$$

"This is my seventh child and this was the first time someone visited me in that way; it is really very useful." (A 34-year-old woman with seven children, from the intervention group)

$$
7 \text { "دى و لادنى السابعة و لأول مرة حد يزورنى فى الحقيقة كانت مفيدة جدا." سيدة } 34 \text { سنة - }
$$

\section{Satisfaction with the Information Received}

It seems that the appreciation of the program was positive. Many of the participants appreciated the content of information received.

"I learned how to perform breast self examination, it is really good thing, I know now all about the nutrition needs of the lactating mother." (A 24-year-old woman with three children from the intervention group)

$$
\begin{aligned}
& \text { "انا اتعلمت إزاى افحص صدرى، فى الحقيقة دى حاجة كويسة جدا ودلوقت انا عان عارفة كل } \\
& \text { الاحتياجات الغذائية للست اللى بترضع." سيدة } 24 \text { سنة - } 3 \text { أطفال من مجمو عة التنخل }
\end{aligned}
$$

"I am reading all the materials they had given me, they are great. I am even sharing the information with my friends." ( A 27-year-old woman with nine years of education from the intervention group) 


$$
\begin{aligned}
& \text { "أنا بأقر أ كل الكتيبات اللى اعطو هالى ، دى عظيمة جدا وبأقول لأصحابى على المعلومات } \\
& \text { اللى موجودة فيها." سيدة - } 27 \text { سنة - } 9 \text { سنو ات تعليم - مجمو عة التدخل }
\end{aligned}
$$

\section{The Ability to Recall the Health Information}

Most of the participants in the intervention group were able to recall the health information they had been taught. They also correctly explained the content of the health information received.

\section{The Impact of the Intervention on the Day 40 Clinic Visit}

The impact of the intervention on the day 40 clinic visit was not clear. Thirteen women from the comparison group and 14 women from the intervention group made the day 40 clinic visit. Two of the women of the intervention group reported that a health problem was diagnosed and they received the proper treatment. Another two women of the same group reported that the health team at the clinic was absent on the day of the visit.

It seems that there are other factors that contributed to the ability of women to make the day 40 visit. One factor is the geographic location of the participants as well as closures imposed on Jenin residents. More women in Gaza were able to make the day 40 visit compared to women in Jenin.

Table 3: Distribution of women by number of visits to clinics, Gaza and Jenin

\begin{tabular}{|l|c|c|c|c|}
\hline Region & None & $\begin{array}{c}\text { One } \\
\text { visit }\end{array}$ & $\begin{array}{c}\text { Two } \\
\text { visits }\end{array}$ & Total \\
\hline Gaza & 4 & 23 & 3 & 30 \\
\hline Jenin & 2 & 11 & 17 & 30 \\
\hline
\end{tabular}

However, the majority of women in both regions visited the clinic at least once in the first 30 days after delivery (Tables 3 and 4). Fifty-four women out of the 60 reported that they have visited a health care facility at least once during the first month after delivery. The majority of these women (49 out of the 54 women) visited an MCH center. Reasons for these visits were to seek baby health care and immunizations. Only six women reported that the reason was for a postpartum health-related problem. 
Table 4: Distribution of women by number of visits to clinics, by group

\begin{tabular}{|l|c|c|c|c|}
\hline $\begin{array}{l}\text { Study } \\
\text { Groups }\end{array}$ & None & $\begin{array}{c}\text { One } \\
\text { visit }\end{array}$ & $\begin{array}{l}\text { Two } \\
\text { visits }\end{array}$ & Total \\
\hline Comparison & 2 & 14 & 14 & 30 \\
\hline Intervention & 4 & 20 & 6 & 30 \\
\hline
\end{tabular}

\section{The Need for the Intervention Program: Participants Perspective}

The intervention program had a positive influence on women's knowledge. Many of the participants appreciated and were able to recall the health information regarding early detection of cancer, nutrition of the lactating mother and proper breastfeeding practices. Sixteen women out of the 30 of the intervention group were able to explain how to conduct self-breast examination correctly. Only nine women in the comparison group indicated that they knew about self-breast examination and only five among them were able to explain it correctly.

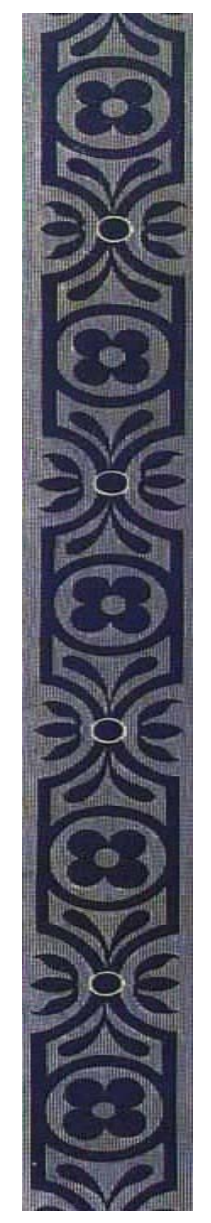

\section{DISCUSSION}

The findings of this study indicate that Jenin and Al-Shifaa hospitals are busy and the quality of care provided to the women is seen by many of the informants as poor. The health team, management staff and women interviewed confirmed the poor infrastructure of the maternity wards at both hospitals, which have severe shortages in the number of beds and staff, particularly nurses and midwives. Thus overcrowding in maternity wards is a characteristic feature. In addition, problems such as the lack of heating systems, necessary equipment and cleaning at both hospitals were identified. Overall, the quality of care provided to women at these public hospitals included in the study is below standard.

Furthermore, it seems that the activities of maternity staff in these two public hospitals are limited to helping women deliver during the labor period only. This is reflected by the lack of reproductive health programs including health education, lack of follow-up activities of women after discharge from hospitals and the lack of coordination between public hospitals and local clinics. 
Additionally, women stay in the hospital for a relatively short time, sometimes only a few hours. Under these circumstances, health providers do not have the time to provide health education to women. Furthermore, women themselves do not have the chance to be exposed to any educational or awareness-raising activities before discharge from the hospital. Therefore, the 2-3 day home visit is the only opportunity for women to receive a health assessment for themselves and their babies and health education on postpartum care and other reproductive health issues. In addition, women in the intervention group were satisfied with the visit and the information and the counseling they received. Also, they were able to recall the health information received during the intervention visit regarding postpartum care, family planning and other reproductive health issues.

Staff, providers and women perceived establishing a referral system between the hospital and the local clinics as a good idea. This system would take the burden off the busy hospitals and their overloaded staff. It would also be much easier for the women living far from the hospital to access local services while caring for a demanding newborn as well as other family members. The referral system can be very simple. A card can be given to a woman before discharge from the hospital that includes her name and the name of the nearest local clinic/s in her area. The card may also include a brief report on how she delivered and any complications that might have happened to her while in the hospital. In addition, it could have clear instructions for the woman to go to one of those clinics around day 40. The name of each woman who delivered and the area she comes from can be registered in a special register for the CHWs to get to know which women they will be visiting and when. Each worker would visit the women in her are 2-3 days after delivery and again once or twice between day 30 and day 60 .

Findings of this study also demonstrate that the intervention adopted (consisting of a single home visit by the CHW to the women 2-3 days after delivery) had a positive effect on the women's knowledge regarding postpartum health care and other reproductive health issues. However, it did not show much effect on the day 40 visit to the clinic. Extenuating factors prohibited women from making a day 40 visit to the clinic, including closures imposed on Jenin residents. 
Although the 2-3 day home visit is very important as it is the only opportunity for women to receive information on reproductive health issues, a single home visit might not be enough to mobilize women and encourage them to attend the day 40 visit to the clinic. Therefore, a second visit between 30 and 40 days after delivery should be paid to the women by the CHW to repeat the same message and another visit at or around 60 days should be performed to ensure the women have been to the clinic and received a family planning method. Almost all women breastfeed their infants and this gives them some feeling of security during the postpartum period. However, efforts should be made to ensure that women do understand that breastfeeding by itself is not sufficient to protect them from getting pregnant unless certain conditions for the lactational amenorrhea method are fulfilled, e.g. nearly exclusive breastfeeding, frequent feeds, absence of menses, among others.

Although women in this study did not go to clinics to seek health care and advice for themselves, the majority of them went to clinics for newborn immunization and to seek advice about their children's health problems. Therefore, it is advisable to integrate both reproductive health services and children's services in local clinics so that women can get counseling on reproductive health issues, including family planning at the same time their children receive their vaccinations.

In conclusion, the findings show that the shortage of care provided to women during the perinatal period could be partially overcome by conducting home visits to provide information on many reproductive health issues, to help women and their families make decisions regarding their future fertility, and to provide proper assessment of the woman and the newborn's health conditions. This would help promote spacing between births and reduce the high level of unmet need that was demonstrated in the current study. It would also reduce cases of unplanned pregnancy. The need for such an intervention is clear. 


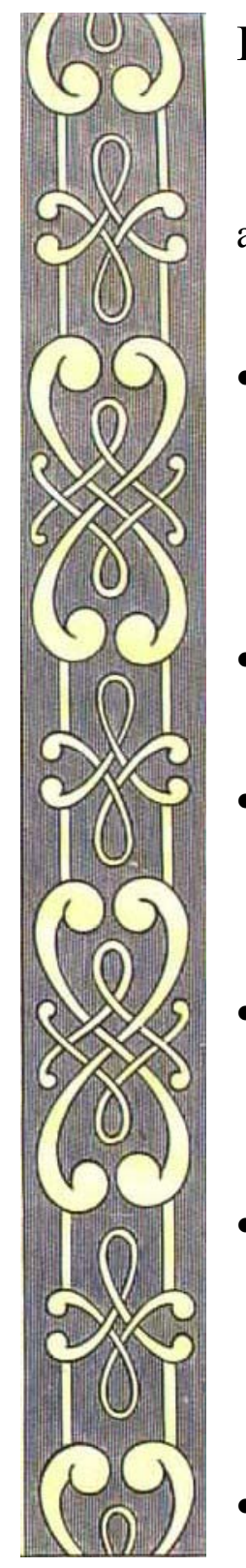

\section{RECOMMENDATIONS}

Based on the findings of this study, the following programmatic actions are proposed to improve the reproductive health of Palestinian women.

- Efforts should be made to improve the infrastructure of maternity wards in public hospitals. Whenever possible, proper equipment should be provided to hospitals and the hospitals' capacity should be increased to meet women's needs.

- Increase the number of qualified nurses and midwives in order to meet the increasing need and the workload in hospitals.

- Ensure proper training of health providers on quality reproductive health care, especially counseling and client-provider interaction. The respect and dignity of women delivering in the hospital should be ensured.

- Adopt a comprehensive approach to reproductive health and build trust between the health team and women if women are required to comply with instructions and directions provided to them by the health team.

- Establish a referral system to ensure proper and efficient communication and coordination between the hospitals and the local clinics. Such a system would have a dual role: it would take the burden off the overloaded hospitals and provide an easy and comfortable way for women to reach nearby clinics.

- Expand the intervention program and widen its scope to include other key decision makers, like husbands and mother-in-laws, in diffusing relevant aspects of counseling.

- Provide more than a single home visit to women during the first two months postpartum. When feasible, it is advisable to visit the woman at home three times: the first visit at 2-3 days after delivery, a second visit around day 40 and a third around day 60. Those visits would mobilize and encourage women to seek reproductive health counseling and services including family planning. If, however, this proves to be a burden on the health workers, a second home visit may be paid between day 40 and day 60 to ensure the first visit's message has been properly received.

- Make IEC programs available for women to encourage them to adopt family planning for birth spacing and to avoid the incidence of unmet need. These IEC programs should also 
educate women about their reproductive health needs, especially early detection of cancer, breastfeeding promotion and healthy nutritional practices.

- Emphasize the fact that breastfeeding alone may not provide reliable protection from pregnancy unless certain conditions are fulfilled. Women must be amenorrheaic and exclusively breastfeeding during the first six months postpartum.

- Integrate children and women's health services to better educate women on reproductive health issues and provide the range of services needed.

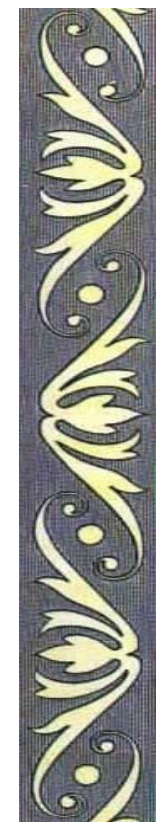

\section{REFERENCES}

1. Health Development Information and Policy Institute (HDIP). 2001. Pilot Health Project Baseline Survey Report: West Bank and Gaza. Ramallah, Palestine.

2. Ismail, N. and M. Shahin. 1996. Family Planning and Women's Reproductive Health Survey in the West Bank. Planning and Research Center: Ramallah, Palestine.

3. Palestinian Central Bureau of Statistics. 1997. The Demographic Survey in the West Bank and Gaza Strip: Final Report. Ramallah, Palestine.

4. Alpha International. 2002. Assessment of Pilot Health Project Outcome Indicators: West Bank/Gaza. Ramallah, Palestine. 